Cochrane Database of Systematic Reviews

\title{
Chlorpromazine dose for people with schizophrenia (Review)
}

Dudley K, Liu X, De Haan S

Dudley K, Liu X, De Haan S.

Chlorpromazine dose for people with schizophrenia.

Cochrane Database of Systematic Reviews 2017, Issue 4. Art. No.: CD007778.

DOI: 10.1002/14651858.CD007778.pub2.

www.cochranelibrary.com 
TABLE OF CONTENTS

HEADER

ABSTRACT

PLAIN LANGUAGE SUMMARY

SUMMARY OF FINDINGS

BACKGROUND

Figure 1.

OBJECTIVES

METHODS

RESULTS

Figure 2.

Figure 3.

Figure 4.

DISCUSSION

AUTHORS' CONCLUSIONS

ACKNOWLEDGEMENTS

REFERENCES

CHARACTERISTICS OF STUDIES

DATA AND ANALYSES

Analysis 1.1. Comparison 1 CHLORPROMAZINE LOW DOSE ( $\leq 400 \mathrm{mg} /$ day) vs MEDIUM DOSE (401-800 mg/day), Outcome 1 Global state: 1. Not improved - short term (CGI-SI).

Analysis 1.2. Comparison 1 CHLORPROMAZINE LOW DOSE ( $\leq 400 \mathrm{mg} /$ day) vs MEDIUM DOSE (401-800 mg/day), Outcome 2 Global state: 2. Requiring additional medication (sedation with chloral hydrate or a barbiturate $>5$ times) - medium term.

Analysis 1.3. Comparison 1 CHLORPROMAZINE LOW DOSE ( $\leq 400 \mathrm{mg} /$ day) vs MEDIUM DOSE (401-800 mg/day), Outcome 3 Leaving the study early.

Analysis 1.4. Comparison 1 CHLORPROMAZINE LOW DOSE ( $\leq 400 \mathrm{mg} /$ day) vs MEDIUM DOSE (401-800 mg/day), Outcome 4 Mental state: 1a. Average endpoint score (BPRS total, high $=$ poor).

Analysis 1.5. Comparison 1 CHLORPROMAZINE LOW DOSE ( $\leq 400 \mathrm{mg} /$ day) vs MEDIUM DOSE (401-800 mg/day), Outcome 5 Mental state: 1 b. Average endpoint score (PANSS total and subscores, high = poor).

Analysis 1.6. Comparison 1 CHLORPROMAZINE LOW DOSE ( $\leq 400 \mathrm{mg} /$ day) vs MEDIUM DOSE (401-800 mg/day), Outcome 6 Adverse effects: 1 . Central nervous system - extrapyramidal symptoms.

Analysis 1.7. Comparison 1 CHLORPROMAZINE LOW DOSE ( $\leq 400 \mathrm{mg} /$ day) vs MEDIUM DOSE (401-800 mg/day), Outcome 7 Adverse effects: 2 . Anticholinergic.

Analysis 1.8. Comparison 1 CHLORPROMAZINE LOW DOSE ( $\leq 400 \mathrm{mg} /$ day) vs MEDIUM DOSE (401-800 mg/day), Outcome 8 Adverse effects: 3 . Cardiovascular.

Analysis 1.9. Comparison 1 CHLORPROMAZINE LOW DOSE ( $\leq 400 \mathrm{mg} /$ day) vs MEDIUM DOSE (401-800 mg/day), Outcome 9 Adverse effects: 4. Central nervous system - other than extrapyramidal symptoms.

Analysis 1.10. Comparison 1 CHLORPROMAZINE LOW DOSE ( $\leq 400 \mathrm{mg} /$ day) vs MEDIUM DOSE (401-800 mg/day), Outcome 10 Adverse effects: 5. Dermatological.

Analysis 1.11. Comparison 1 CHLORPROMAZINE LOW DOSE ( $\leq 400 \mathrm{mg} /$ day) vs MEDIUM DOSE (401-800 mg/day), Outcome 11 Adverse effects: 6 . Endocrine and metabolic.

Analysis 1.12. Comparison 1 CHLORPROMAZINE LOW DOSE ( $\leq 400 \mathrm{mg} /$ day) vs MEDIUM DOSE (401-800 mg/day), Outcome 12 Adverse effects: 7. Gastrointestinal.

Analysis 1.13. Comparison 1 CHLORPROMAZINE LOW DOSE ( $\leq 400 \mathrm{mg} /$ day) vs MEDIUM DOSE (401-800 mg/day), Outcome 13 Adverse effects: 8. Genitourinary.

Analysis 1.14. Comparison 1 CHLORPROMAZINE LOW DOSE ( $\leq 400 \mathrm{mg} /$ day) vs MEDIUM DOSE (401-800 mg/day), Outcome 14 Adverse effects: 9. Haematological.

Analysis 1.15. Comparison 1 CHLORPROMAZINE LOW DOSE ( $\leq 400 \mathrm{mg} /$ day) vs MEDIUM DOSE (401-800 mg/day), Outcome 15 Adverse effects: 10. Hepatological.

Analysis 1.16. Comparison 1 CHLORPROMAZINE LOW DOSE ( $\leq 400 \mathrm{mg} /$ day) vs MEDIUM DOSE (401-800 mg/day), Outcome 16 Adverse effects: 11 . Others.

Analysis 2.1. Comparison 2 CHLORPROMAZINE LOW DOSE ( $\leq 400 \mathrm{mg} /$ day) vs HIGH DOSE (>800 mg/day - all medium term), Outcome 1 Global state: Not improved, severely ill, relapse (GAS).

Analysis 2.2. Comparison 2 CHLORPROMAZINE LOW DOSE ( $\leq 400 \mathrm{mg} /$ day) vs HIGH DOSE ( $>800 \mathrm{mg} /$ day - all medium term), Outcome 2 Leaving the study early. 
Analysis 2.3. Comparison 2 CHLORPROMAZINE LOW DOSE ( $\leq 400 \mathrm{mg} /$ day) vs HIGH DOSE (>800 mg/day - all medium term), Outcome 3 Adverse effects: 1 . Central nervous system - extrapyramidal symptoms.

Analysis 2.4. Comparison 2 CHLORPROMAZINE LOW DOSE ( $\leq 400 \mathrm{mg} /$ day) vs HIGH DOSE (>800 mg/day - all medium term), Outcome 4 Adverse effects: 2. Anticholinergic symptoms.

Analysis 2.5. Comparison 2 CHLORPROMAZINE LOW DOSE ( $\leq 400 \mathrm{mg} /$ day) vs HIGH DOSE (>800 mg/day - all medium term), Outcome 5 Adverse effects: 3 . Central nervous system - other than extrapyramidal symptoms.

Analysis 2.6. Comparison 2 CHLORPROMAZINE LOW DOSE ( $\leq 400 \mathrm{mg} /$ day) vs HIGH DOSE (>800 mg/day - all medium term), Outcome 6 Adverse effects: 4. Cardiovascular.

Analysis 2.7. Comparison 2 CHLORPROMAZINE LOW DOSE ( $\leq 400 \mathrm{mg} /$ day) vs HIGH DOSE (>800 mg/day - all medium term), Outcome 7 Adverse effects: 5. Dermatological.

Analysis 2.8. Comparison 2 CHLORPROMAZINE LOW DOSE ( $\leq 400 \mathrm{mg} /$ day) vs HIGH DOSE (>800 mg/day - all medium term), Outcome 8 Adverse effects: 6 . Gastrointestinal.

Analysis 2.9. Comparison 2 CHLORPROMAZINE LOW DOSE ( $\leq 400 \mathrm{mg} /$ day) vs HIGH DOSE ( $>800 \mathrm{mg} /$ day - all medium term), Outcome 9 Adverse effects: 7. Genitourinary.

Analysis 2.10. Comparison 2 CHLORPROMAZINE LOW DOSE $(\leq 400 \mathrm{mg} /$ day) vs HIGH DOSE ( $>800 \mathrm{mg} /$ day - all medium term), Outcome 10 Adverse effects: 8. Others.

ADDITIONAL TABLES

APPENDICES

WHAT'S NEW

HISTORY

CONTRIBUTIONS OF AUTHORS 
[Intervention Review]

\section{Chlorpromazine dose for people with schizophrenia}

Katharine Dudley¹, Xiaomeng Liu², Saskia De Haan³

1Institute of Mental Health, University of Nottingham, Nottingham, UK. 2Utrecht University, Utrecht, Netherlands. ${ }^{3 G G Z ~ N o o r d ~ H o l l a n d ~}$ Noord, Alkmaar, Netherlands

Contact address: Katharine Dudley, Institute of Mental Health, University of Nottingham, Nottingham, UK. mzykd4@nottingham.ac.uk.

Editorial group: Cochrane Schizophrenia Group.

Publication status and date: New search for studies and content updated (no change to conclusions), published in Issue 4, 2017.

Citation: Dudley K, Liu X, De Haan S. Chlorpromazine dose for people with schizophrenia. Cochrane Database of Systematic Reviews 2017, Issue 4. Art. No.: CD007778. DOI: 10.1002/14651858.CD007778.pub2.

Copyright @ 2017 The Cochrane Collaboration. Published by John Wiley \& Sons, Ltd.

\section{A B S T R A C T}

\section{Background}

The World Health Organization (WHO) Model Lists of Essential Medicines lists chlorpromazine as one of its five medicines used in psychotic disorders.

\section{Objectives}

To determine chlorpromazine dose response and dose side-effect relationships for schizophrenia and schizophrenia-like psychoses.

\section{Search methods}

We searched the Cochrane Schizophrenia Group's Study-Based Register of Trials (December 2008; 2 October 2014; 19 December 2016).

\section{Selection criteria}

All relevant randomised controlled trials (RCTs) comparing low doses of chlorpromazine ( $\leq 400 \mathrm{mg} /$ day), medium dose (401 mg/day to 800 $\mathrm{mg} /$ day) or higher doses (> $800 \mathrm{mg} /$ day) for people with schizophrenia, and which reported clinical outcomes.

\section{Data collection and analysis}

We included studies meeting review criteria and providing useable data. Review authors extracted data independently. For dichotomous data, we calculated fixed-effect risk ratios (RR) and their 95\% confidence intervals (Cls). For continuous data, we calculated mean differences (MD) and their $95 \% \mathrm{Cls}$ based on a fixed-effect model. We assessed risk of bias for included studies and graded trial quality using GRADE (Grading of Recommendations Assessment, Development and Evaluation).

\section{Main results}

As a result of searches undertaken in 2014, we found one new study and in 2016 more data for already included studies. Five relevant studies with 1132 participants (585 are relevant to this review) are now included. All are hospital-based trials and, despite over 60 years of chlorpromazine use, have durations of less than six months and all are at least at moderate risk of bias. We found only data on lowdose ( $\leq 400 \mathrm{mg} /$ day) versus medium-dose chlorpromazine (401 mg/day to $800 \mathrm{mg} /$ day) and low-dose versus high-dose chlorpromazine (>800 mg/day).

When low-dose chlorpromazine ( $\leq 400 \mathrm{mg} /$ day) was compared to medium-dose chlorpromazine ( $401 \mathrm{mg} /$ day to $800 \mathrm{mg} /$ day), there was no clear benefit of one dose over the other for both global and mental state outcomes (low-quality and very low-quality evidence). There was also no clear evidence for people in one dosage group being more likely to leave the study early, over the other dosage group (moderatequality evidence). Similar numbers of participants from each group experienced agitation and restlessness (very low-quality evidence). However, significantly more people in the medium-dose group ( $401 \mathrm{mg} /$ day to $800 \mathrm{mg} /$ day) experienced extrapyramidal symptoms in the short term ( $2 \mathrm{RCTS}, \mathrm{n}=108$, RR $0.47,95 \% \mathrm{Cl} 0.30$ to 0.74 , moderate-quality evidence). No data for death were available. 
When low-dose chlorpromazine ( $\leq 400 \mathrm{mg} /$ day) was compared to high-dose chlorpromazine (> $800 \mathrm{mg} /$ day), data from one study with 416 patients were available. Clear evidence of a benefit of the high dose was found with regards to global state. The low-dose group had significantly fewer people improving (RR 1.13, 95\% Cl 1.01 to 1.25, moderate-quality evidence). There was also a marked difference between the number of people leaving the study from each group for any reason, with significantly more people leaving from the highdose group (RR $0.60,95 \% \mathrm{Cl} 0.40$ to 0.89 , moderate-quality evidence). More people in the low-dose group had to leave the study due to deterioration in behaviour (RR $2.70,95 \% \mathrm{Cl} 1.34$ to 5.44 , low-quality evidence). There was clear evidence of a greater risk of people experiencing extrapyramidal symptoms in general in the high-dose group (RR $0.43,95 \% \mathrm{Cl} 0.32$ to 0.59 , moderate-quality evidence). One death was reported in the high-dose group yet no effect was shown between the two dosage groups (RR $0.33,95 \% \mathrm{Cl} 0.01$ to 8.14 , moderatequality evidence). No data for mental state were available.

\section{Authors' conclusions}

The dosage of chlorpromazine has changed drastically over the past 50 years with lower doses now being the preferred of choice. However, this change was gradual and arose not due to trial-based evidence, but due to clinical experience and consensus. Chlorpromazine is one of the most widely used antipsychotic drugs yet appropriate use of lower levels has come about after many years of trial and error with much higher doses. In the absence of high-grade evaluative studies, clinicians have had no alternative but to learn from experience. However, such an approach can lack scientific rigor and does not allow for proper dissemination of information that would assist clinicians find the optimum treatment dosage for their patients. In the future, data for recently released medication should be available from high-quality trials and studies to provide optimum treatment to patients in the shortest amount of time.

\section{PLAIN LANGUAGE SUMMARY}

\section{Chlorpromazine dose for people with schizophrenia}

\section{Review question}

This review looks at the best dose of chlorpromazine for treating people with schizophrenia.

\section{Background}

Schizophrenia is a serious mental illness affecting around $1 \%$ of the adult population worldwide. People with schizophrenia often hear voices or see things (hallucinations) and have strange beliefs (delusions). The main treatment for these symptoms of schizophrenia are antipsychotic drugs. Chlorpromazine was one of the first antipsychotic drugs discovered to be effective in the treatment of schizophrenia during the 1950s. It still remains one of the most commonly used and inexpensive treatments even today. However, it also has serious side effects, such as blurred vision, a dry mouth, tremors or uncontrollable shaking, depression, muscle stiffness and restlessness.

\section{Study characteristics}

An updated search for relevant randomised controlled trials was run in October 2014, and again, in December 2016 and found one new study. Five studies have now been found that meet the review inclusion criteria. The included studies are all randomised, and investigate the effects of giving different doses of chlorpromazine to people with schizophrenia. The total number of participants was 585.

\section{Key results}

Chlorpromazine showed different effects at varying doses. Based on weak evidence, the effects on people's mental health at low dosage and medium dosage are much the same. However, there are more side effects at medium dose. There is more improvement in people's mental health at high dose compared to low dose. However, side effects are much more numerous and debilitating at high dose. In the past fifty years, low dose has been the favoured amount to use with patients. This change has come about gradually and is based on everyday experience and consensus rather than hard scientific evidence. Chlorpromazine is low-cost and widely available. Despite its many side effects, chlorpromazine is likely to remain a benchmark or 'gold standard' drug and one of the most widely used treatments for schizophrenia worldwide.

\section{Quality of the evidence}

All trials in the review are hospital- based and all but one date from 20 years ago. There are a limited number of studies of limited quality and these are poorly reported and short term. Further research and trials on chlorpromazine dose are justified.

Ben Gray, Senior Peer Researcher, McPin Foundation. http://mcpin.org/ 


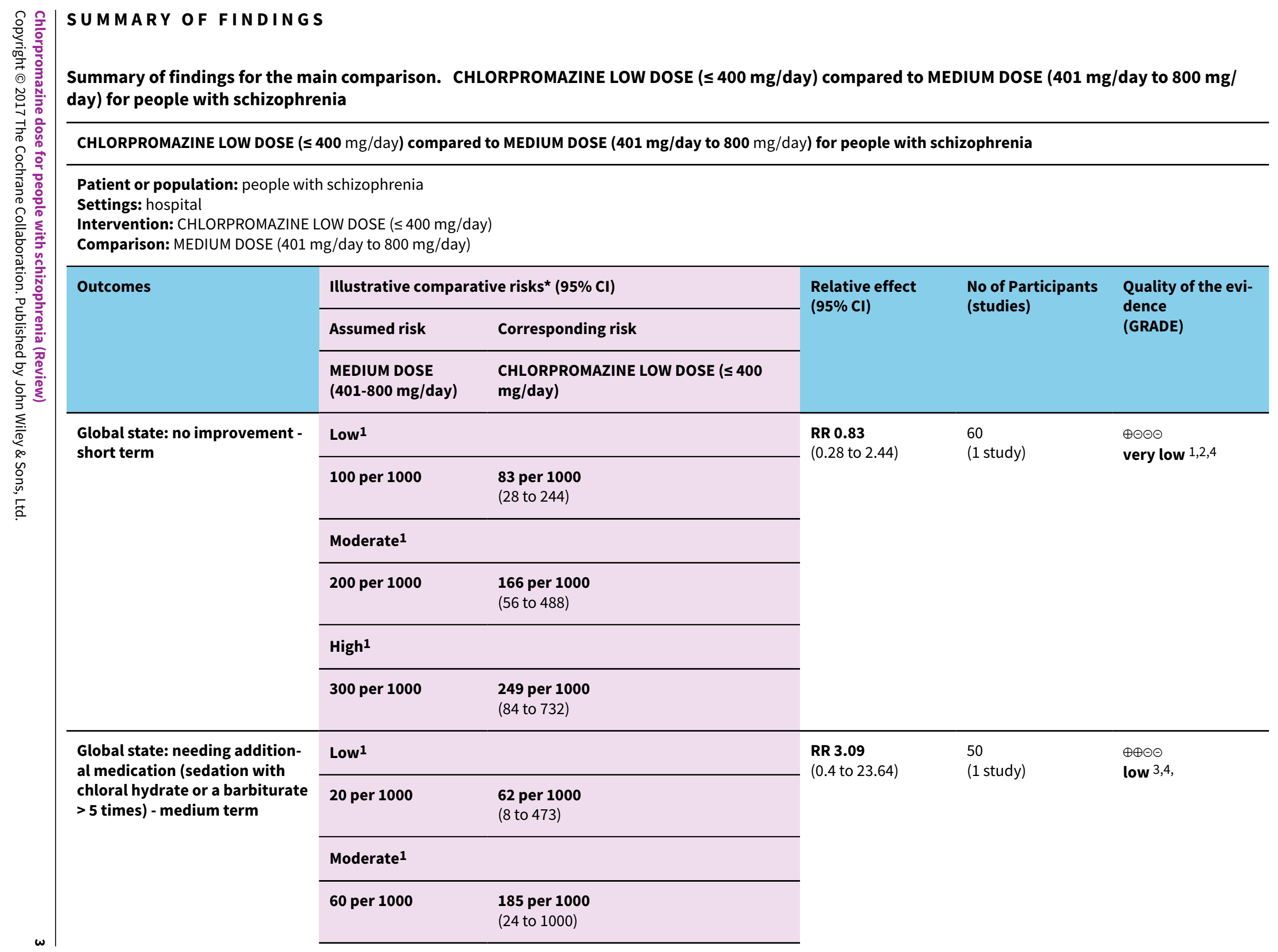




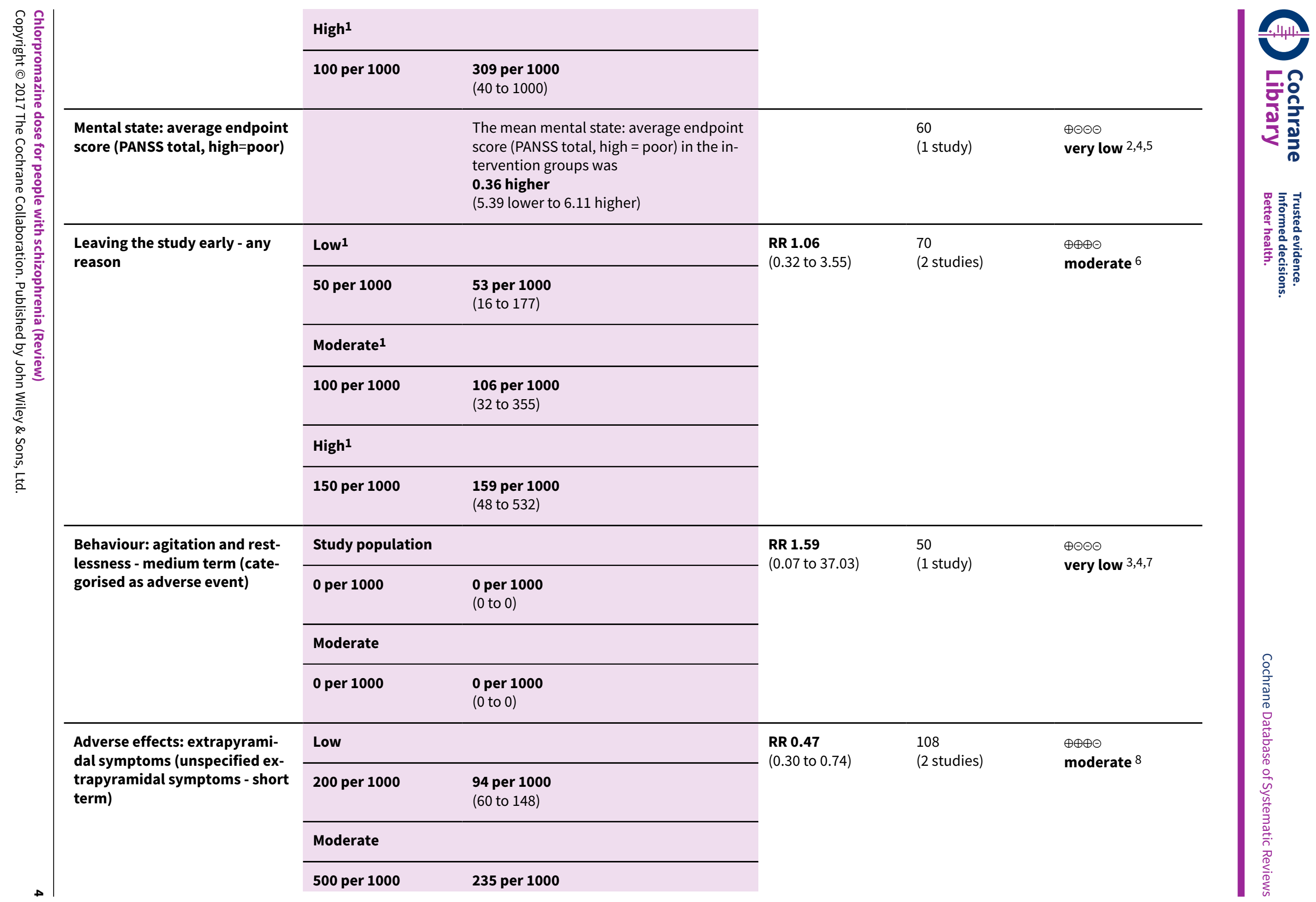


High

800 per $1000 \quad 376$ per 1000

(240 to 592)

Adverse event: death

No trial reported this outcome

*The basis for the assumed risk (e.g. the median control group risk across studies) is provided in footnotes. The corresponding risk (and its $95 \%$ confidence interval) is based on the assumed risk in the comparison group and the relative effect of the intervention (and its $95 \% \mathrm{Cl}$ ).

Cl: Confidence interval; RR: Risk ratio;

GRADE Working Group grades of evidence

High quality: Further research is very unlikely to change our confidence in the estimate of effect.

Moderate quality: Further research is likely to have an important impact on our confidence in the estimate of effect and may change the estimate.

Low quality: Further research is very likely to have an important impact on our confidence in the estimate of effect and is likely to change the estimate.

Very low quality: We are very uncertain about the estimate.

1 Indirectness: rated serious: downgraded by 1 - unclear if clinically important improvement, no prespecified medium-term data available.

2 Risk of bias: rated 'serious': downgraded by 1 - randomisation not described well, no mention of allocation concealment or blinding.

3 Risk of bias: rated 'serious': downgraded by 1 - randomisation not described well, no mention of allocation concealment, unclear regarding selection bias or management of lost data, industry partnering of author.

4 Imprecision: rated 'serious': downgraded by 1 - only one study providing data, there are very few participants, number of events small.

5 Indirectness: rated 'serious': downgraded by 1 - no data available for prespecified outcome of 'no clinically important change in general mental state' - only scale scores reported.

6 Risk of bias: rated 'serious' : downgraded by 1 - randomisation not described well, no mention of allocation concealment, unclear if loss to follow-up data for Chouinard 1976

accurate as we have made assumptions it is zero in these groups.

7 Indirectness: rated 'serious' : downgraded by 1 - no data available for prespecified outcome of no clinically important change in general behaviour - behaviour of agitation/ restlessness rated within trial as adverse event.

8 Risk of bias: rated 'serious' : downgraded by 1 - randomisation not described well, no mention of allocation concealment, Xu 2009 not blinded, concern regarding selective reporting (Wode-Helgodt 1978).

Summary of findings 2. CHLORPROMAZINE LOW DOSE ( $\leq 400 \mathrm{mg} / \mathrm{day}$ ) compared to HIGH DOSE (> $800 \mathrm{mg} / \mathrm{day}$ - all medium term) for people with schizophrenia

CHLORPROMAZINE LOW DOSE ( $\leq 400 \mathrm{mg} /$ day) compared to HIGH DOSE (> $800 \mathrm{mg} /$ day-all medium term) for people with schizophrenia

Patient or population: patients with people with schizophrenia

Settings:

Intervention: CHLORPROMAZINE LOW DOSE ( $\leq 400 \mathrm{mg} /$ day)

Comparison: $\mathrm{HIGH}$ DOSE (> $800 \mathrm{mg} /$ day - all medium term) 


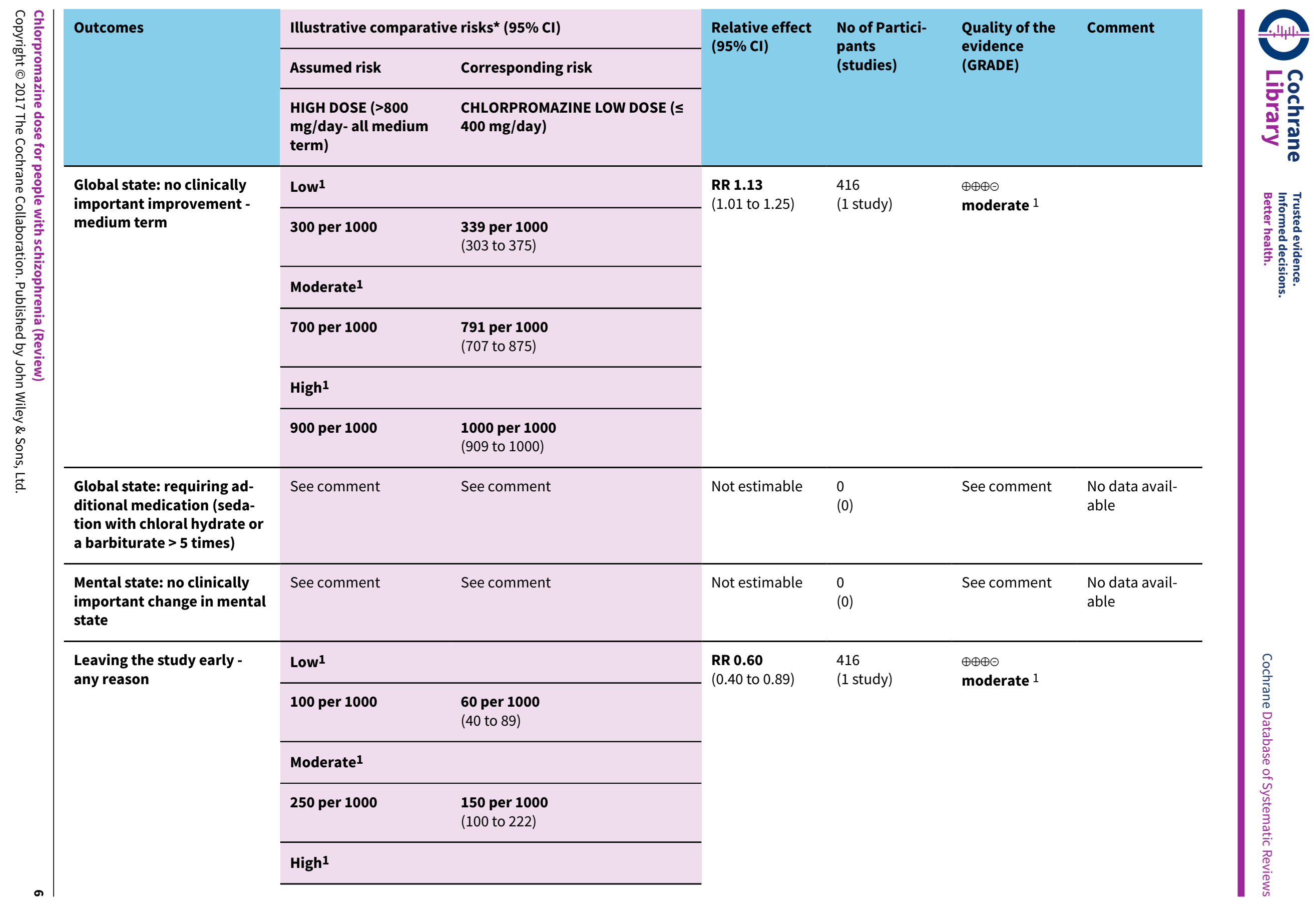




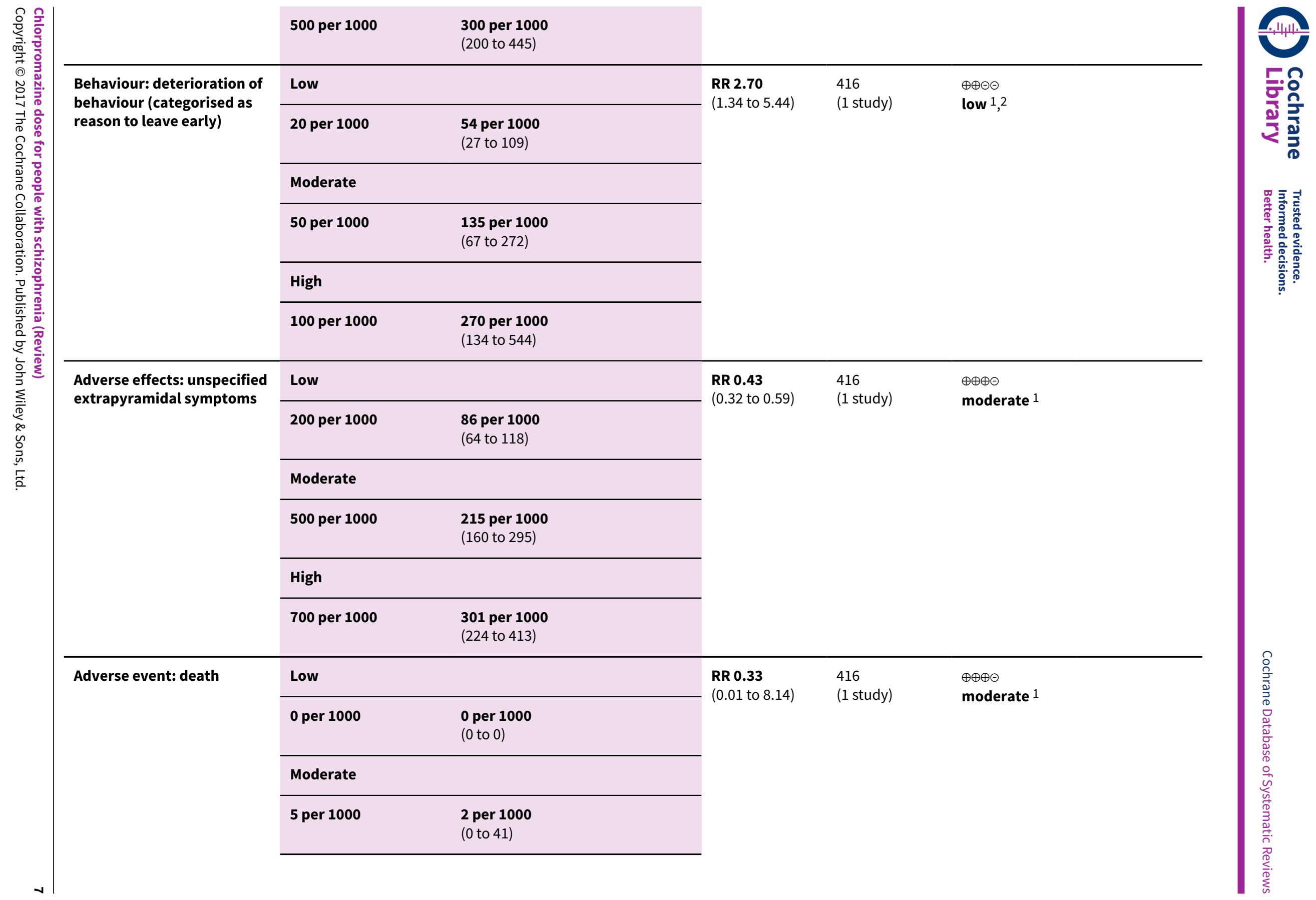




$\begin{array}{ll}\mathbf{5 0} \text { per } 1000 & \mathbf{1 7} \text { per } 1000 \\ \text { (0 to } 407)\end{array}$

*The basis for the assumed risk (e.g. the median control group risk across studies) is provided in footnotes. The corresponding risk (and its $95 \%$ confidence interval) is based on the assumed risk in the comparison group and the relative effect of the intervention (and its 95\% Cl).

Cl: Confidence interval; RR: Risk ratio;

GRADE Working Group grades of evidence

High quality: Further research is very unlikely to change our confidence in the estimate of effect.

Moderate quality: Further research is likely to have an important impact on our confidence in the estimate of effect and may change the estimate.

Low quality: Further research is very likely to have an important impact on our confidence in the estimate of effect and is likely to change the estimate. Very low quality: We are very uncertain about the estimate.

1 Risk of bias: rated serious: downgraded by 1 - randomisation not described well, no mention of allocation concealment, concern regarding selective reporting.

2Indirectness: rated serious: downgraded by 1 - unclear if clinically important change in behaviour, rated within trial as leaving the study early outcome. 


\section{B A C K G R O U N D}

\section{Description of the condition}

Schizophrenia is a severe mental illness comprising a range of different symptoms that vary greatly between individuals (Weinberger 2011). Typical symptoms include hallucinations (perceptions without external stimuli), delusions (fixed false beliefs and ideas), disorders of thinking, as well as changes in emotion and behaviour (Barbato 1998). People with schizophrenia may recover fully $(20 \%)$, have recurrences $(60 \%)$ or have a longer-term illness (20\%), (WHO 2001). About one per cent of people will experience at least one schizophrenic episode with two thirds of them going on to suffer later episodes. Twenty-six million people in the world are affected by schizophrenia with over $50 \%$ not receiving appropriate treatment (MHF 2014).

\section{Figure 1. Chlorpromazine structure}

\section{Description of the intervention}

Chlorpromazine is a drug from the phenothiazine group originally developed in the 1950 s as an antihistamine to be used in anaesthesia (chemical name: 3-(2-chloro-10H-phenothiazin-10yl)- $N, N$-dimethyl-propan-1-amine; formula $\mathrm{C}_{17} \mathrm{H}_{19} \mathrm{ClN}_{2} \mathrm{~S}$ - Figure 1). Calming effects were noted and later tested. Being the first effective antipsychotic drug, referred to as 'psychic penicillin', it greatly reduced the number of people admitted to asylums. It also transformed the way people with schizophrenia were cared for after 1956 (Turner 2007). At present, the World Health Organization (WHO) Model Lists of Essential Medicines lists chlorpromazine as one of five medicines used in psychotic disorders (WHO 2013).

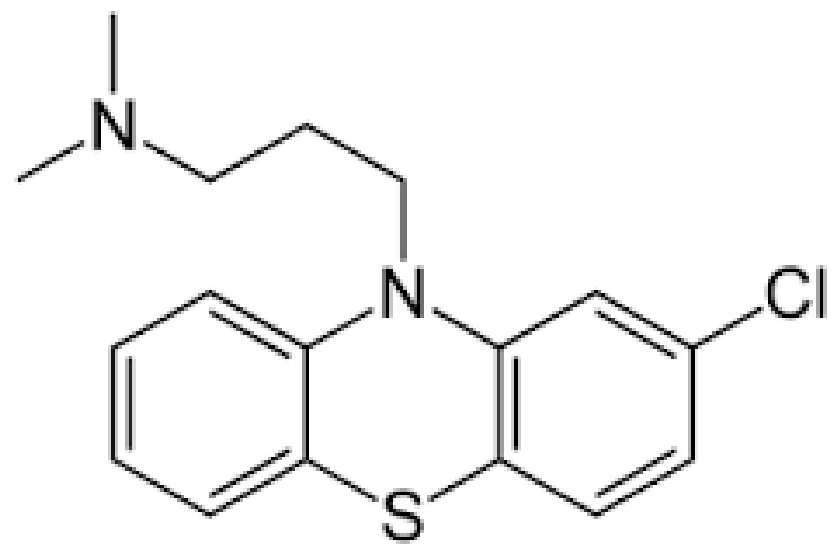

\section{How the intervention might work}

There are many theories about the causes of schizophrenia involving neurotransmitters and neuronal pathways. However, the most fixed theory would be the dopamine hypothesis: excess dopamine activity in the mesolimbic pathway (Bazire 2014). Hyperactivity of dopaminergic pathways would result in positive symptoms such as hallucinations and delusions while hypo-activity would cause negative symptoms like cognitive dysfunctions and altered mood (Weinberger 2001).

All antipsychotic drugs act as a dopamine D2 receptor antagonist. However, as chlorpromazine is a first-generation antipsychotic, these D2 receptors are blocked far more permanently than the newer, atypical antipsychotics. This leads to extrapyramidal side effects such as tardive dyskinesia, tremor, akinesia, etc. (Seeman 2002). Chlorpromazine is not selective and so will block the four alternative dopamine pathways as well as ones involving other neurotransmitters (BNF 2014). Many of the side effects can be attributed to chlorpromazine blocking these neurotransmitter receptors.

\section{Why it is important to do this review}

Chlorpromazine is a well-established antipsychotic treatment. This old drug remains a 'benchmark' for the treatment of schizophrenia (Bazire 2014).
Newer antipsychotics are more expensive than drugs such as chlorpromazine and are less accessible. There is no definite evidence that the newer antipsychotics are a more effective treatment yet they are believed to cause fewer extrapyramidal symptoms (Geddes 2000). However, these findings may be biased because they are compared to doses of traditional antipsychotics that are far higher than recommended (Leucht 2003).

Little research is being done regarding optimum doses of traditional antipsychotics. These drugs do not provide the opportunity of patenting and hence are not studies for which large pharmaceutical industries would consider funding or encourage further investigations. The benefits of antipsychotic must plateau above a certain dose, yet the adverse effects will continue to accrue as doses increase. This exact ranges for many antipsychotic drugs are still debated (Bollini 1994), and so, reviewing the best evidence on comparisons for these drugs is important.

\section{O B JECT IVES}

To determine chlorpromazine dose response and dose side-effect relationships for schizophrenia and schizophrenia-like psychoses. 


\section{METHODS}

\section{Criteria for considering studies for this review}

\section{Types of studies}

All relevant randomised control trials. We excluded quasirandomised trials, such as those where allocation is undertaken on alphabetical order. If a trial had been described as double-blinded, but it was implied it had been randomised, we would have included these trials in a Sensitivity analysis. Randomised cross-over studies were eligible for inclusion, but if identified, we would only have included data up to the point of first cross-over because of the likely carry-over effects of treatments.

\section{Types of participants}

People with schizophrenia and other types of schizophrenia-like psychoses (schizophreniform and schizoaffective disorders). There is no clear evidence that the schizophrenia-like psychoses are caused by fundamentally different pathophysiologic processes or require different treatments (Carpenter 1994).

\section{Types of interventions}

Chlorpromazine alone; given in any dose irrespective of the administration method. We predefined the dosage categories as follows.

1. Chlorpromazine: $0 \mathrm{mg}$ to $400 \mathrm{mg} /$ day (low dose)

2. Chlorpromazine: $401 \mathrm{mg}$ to $800 \mathrm{mg} /$ day (medium dose)

3. Chlorpromazine: higher than $800 \mathrm{mg} /$ day (high dose)

\section{Types of outcome measures}

Where possible, we divided outcomes into three groups: short term (up to 12 weeks), medium term (13 to 26 weeks) and long term (over 26 weeks).

\section{Primary outcomes}

1. Global state: No clinically important improvement in global state (as defined by individual studies) at medium term

2. Adverse effects: Extrapyramidal side effects (specifically pseudoparkinsonism, tardive dyskinesia and neuroleptic malignant syndrome) at long term.

\section{Secondary outcomes}

\section{Global state}

1.1 Relapse (as defined by the individual studies)

1.2 No clinically important improvement in global state (as defined by individual studies) at short and long term

1.3 Average endpoint global state score

1.4 Average change in global state scores

1.5 Needing additional medication

1.6 Healthy days

2. Mental state (with particular reference to the positive and negative symptoms of schizophrenia)

2.1 No clinically important change in general mental state

2.2 Average endpoint general mental state score

2.3 Average change in general mental state scores

2.4 No clinically important change in specific symptoms (positive and negative symptoms of schizophrenia)
2.5 Average endpoint specific symptom score

2.6 Average change in specific symptom scores

\section{Leaving the studies early}

3.1 Inefficacy of treatment

3.2 Disabling adverse effects

3.3 Any reason provided

3.4 Others

\section{General functioning}

4.1 No clinically important change in general functioning

4.2 Average endpoint general functioning score

4.3 Average change in general functioning scores

4.4 No clinically important change in specific aspects of functioning, such as social or life skills

4.5 Average endpoint specific aspects of functioning, such as social or life skills

4.6 Average change in specific aspects of functioning, such as social or life skills

\section{Behaviour}

5.1 No clinically important change in general behaviour

5.2 Average endpoint general behaviour score

5.3 Average change in general behaviour scores

5.4 No clinically important change in specific aspects of behaviour

5.5 Average endpoint specific aspects of behaviour

5.6 Average change in specific aspects of behaviour

\section{Quality of life/satisfaction with treatment}

6.1 No clinically important change in general quality of life

6.2 Average endpoint general quality of life score

6.3 Average change in general quality of life scores

\section{Cognitive functioning}

7.1 No clinically important change in overall cognitive functioning 7.2 Average endpoint of overall cognitive functioning score

7.3 Average change of overall cognitive functioning scores

\section{Service use}

8.1 Number of participants hospitalised

8.2 Time to hospitalisation

\section{Adverse effects}

9.1 Number of participants with at least one adverse effect

9.2 Clinically important specific adverse effects (cardiovascular, ocular, haematological, hepatic, gastrointestinal, genitourinary, endocrine and metabolic, dermatologic, and central nervous system disorders)

9.3 Average endpoint in specific adverse effects

9.4 Average change in specific adverse effects

9.5 Use of any drugs for adverse effects

\subsection{Death}

\section{Economic (cost of care)}

\section{1. 'Summary of findings' table}

We used the GRADE approach to interpret findings (Schünemann 2008; Schünemann 2011) and used the GRADE profiler to import data from Review Manager 5 (RevMan) to create 'Summary of findings' tables. These tables provide outcome-specific information concerning the overall quality of evidence from each 
included study in the comparison, the magnitude of effect of the interventions examined, and the sum of available data on all outcomes we rated as important to patient-care and decision making. We selected the following main outcomes for inclusion in the summary of findings table.

1. Global state: no clinically important improvement in global state (as defined by individual studies) at medium term.

2. Global state: needing additional medication.

3. Mental state: no clinically important change in general mental state (as defined by individual studies).

4. Leaving the study early.

5. Behaviour: no clinically important change in general behaviour (as defined by individual studies) at long term.

6. Adverse effects: important movement disorder (as defined by individual studies).

7. Adverse effects: death.

\section{Search methods for identification of studies}

For previous searches, please see also Appendix 1.

\section{Electronic searches}

\section{Cochrane Schizophrenia Group's Study-Based Register of Trials}

On December 19, 2016, the Information Specialist searched the register using the following search strategy.

\section{Dosage - Chlorpromazine in Intervention Field of STUDY}

In such study-based register, searching the major concept retrieves all the synonyms and relevant studies because all the studies have already been organised based on their interventions and linked to the relevant topics.

This register is compiled by systematic searches of major resources (including AMED, BIOSIS, CINAHL, Embase, MEDLINE, PsycINFO, PubMed, and registries of clinical trials) and their monthly updates, handsearches, grey literature, and conference proceedings (see Group's Module). There is no language, date, document type, or publication status limitations for inclusion of records into the register.

\section{Searching other resources}

1. Reference lists

We searched all references of articles selected for inclusion for further relevant trials.

\section{Personal contact}

If required, we contacted the first author of each included study for information regarding unpublished trials and noted response or non-response in Characteristics of included studies

\section{Data collection and analysis}

For previous data collection and analysis methods please see Appendix 2.

\section{Selection of studies}

For the 2016 and 2014 searches, review author KD independently inspected citations from the new electronic search and identified relevant abstracts. KD also inspected full articles of the abstracts meeting inclusion criteria.

\section{Data extraction and management}

\section{Extraction}

For the 2016 and 2014 searches, review author KD extracted data from new included studies. KD extracted data presented only in graphs and figures whenever it was possible. When further information was necessary, KD contacted authors of studies in order to obtain missing data or for clarification. If studies were multi-centre, where possible, KD extracted data relevant to each component centre separately.

\section{Management}

\subsection{Forms}

We extracted data onto standard, simple forms.

\subsection{Scale-derived data}

We included continuous data from rating scales only if: a. the psychometric properties of the measuring instrument had been described in a peer-reviewed journal (Marshall 2000); and b. the measuring instrument had not been written or modified by one of the trialists for that particular trial; or

c) the instrument should be a global assessment of an area of functioning and not subscores which are not, in themselves, validated or shown to be reliable.

However there are exceptions, we included subscores from mental state scales measuring positive and negative symptoms of schizophrenia.

Ideally, the measuring instrument was either i. a self-report or ii. completed by an independent rater or relative (not the therapist). We realised that this was not often reported clearly; we have noted whether or not this was the case in Description of studies.

\subsection{Endpoint versus change data}

There are advantages of both endpoint and change data. Change data can remove a component of between-person variability from the analysis. On the other hand, calculation of change needs two assessments (baseline and endpoint), which can be difficult in unstable and difficult to measure conditions such as schizophrenia. We decided primarily to use endpoint data, and only use change data if the former were not available. We combined endpoint and change data in the analysis as we used mean differences (MD) rather than standardised mean differences (SMD) throughout (Deeks 2011).

\subsection{Skewed data}

Continuous data on clinical and social outcomes are often not normally distributed. To avoid the pitfall of applying parametric tests to non-parametric data, we applied the following standards.

\section{For change data}

- We entered change data, as when continuous data are presented on a scale that included a possibility of negative values (such as 
change data), it was difficult to tell whether data were skewed or not. We presented and entered change data into statistical analyses.

\section{For endpoint data from studies $<200$ participants}

- When a scale starts from the finite number 0 , we subtracted the lowest possible value from the mean, and divided this by the standard deviation (SD). If this value is lower than 1 , it strongly suggests a skew, and we would exclude such data. If this ratio is higher than 1 but below 2, there is a suggestion of skew. We would enter such data and test whether its inclusion or exclusion changes the results substantially. Finally, if the ratio is larger than 2, we would include such data because skew is less likely (Altman 1996; Higgins 2011).

- If a scale started from a positive value (such as the Positive and Negative Syndrome Scale (PANSS), which could have values from 30 to 210) (Kay 1986), we modified the calculation described above to take into account the scale starting point. In such cases skew is present if $2 \mathrm{SD}>(\mathrm{S}-\mathrm{S} \mathrm{min})$, where $\mathrm{S}$ was the mean score and $\mathrm{S}$ min was the minimum score.

(Please note, irrespective of the above rules, we planned to enter endpoint data from studies of at least 200 participants in the analysis because skewed data pose less of a problem in large studies).

\subsection{Common measure}

To facilitate comparison between trials, we planned to convert variables that can be reported in different metrics, such as days in hospital (mean days per year, per week or per month) to a common metric (e.g. mean days per month).

\subsection{Conversion of continuous to binary}

Where possible, we made efforts to convert outcome measures to dichotomous data. This was done by identifying cut-off points on rating scales and dividing participants accordingly into 'clinically improved' or 'not clinically improved'. It is generally assumed that if there is a $50 \%$ reduction in a scale-derived score such as the Brief Psychiatric Rating Scale (BPRS, Overall 1962) or the Positive and Negative Syndrome Scale (PANSS, Kay 1986), this could be considered as a clinically significant response (Leucht 2005; Leucht 2005a). If data based on these thresholds were not available, we used the primary cut-off presented by the original authors.

\subsection{Direction of graphs}

Where possible, we entered data in such a way that the area to the left of the line of no effect indicated a favourable outcome for chlorpromazine dose. If keeping to this was not possible, we reported data where the left of the line indicates an unfavourable outcome and noted this on the graph.

\section{Assessment of risk of bias in included studies}

For the 2016 and 2014 updates, KD worked independently by using criteria described in the Cochrane Handbook for Systematic Reviews of Interventions (Higgins 2011a) to assess trial quality. This new set of criteria is based on evidence of associations between overestimate of effect and high risk of bias of the article such as sequence generation, allocation concealment, blinding, incomplete outcome data and selective reporting.
Where inadequate details of randomisation and other characteristics of trials were provided, we contacted authors of the studies in order to obtain additional information.

We noted the level of risk of bias in both the text of the review and in the Summary of findings for the main comparison and the Summary of findings 2 .

\section{Measures of treatment effect}

\section{Binary data}

For binary outcomes we calculated a standard estimation of the risk ratio (RR) and its $95 \%$ confidence interval $(\mathrm{Cl})$. It has been shown that RR is more intuitive (Boissel 1999) than odds ratios and that odds ratios tend to be interpreted as RR by clinicians (Deeks 2000). The Number Needed to Treat/Harm (NNT/H) statistic with its confidence intervals is intuitively attractive to clinicians but is problematic both in its accurate calculation in meta-analyses and interpretation (Hutton 2009). For binary data presented in the 'Summary of findings' table/s, where possible, we calculated illustrative comparative risks.

\section{Continuous data}

For continuous outcomes, we estimated mean difference (MD) between groups. We preferred not to calculate effect size measures (standardised mean difference SMD). However, if scales of very considerable similarity had been used, we would have presumed there was a small difference in measurement, and we would have calculated the effect size and transformed the effect back to the units of one or more of the specific instruments.

\section{Unit of analysis issues}

\section{Cluster trials}

Studies increasingly employ 'cluster randomisation' (such as randomisation by clinician or practice), but analysis and pooling of clustered data poses problems. Authors often fail to account for intra-class correlation in clustered studies, leading to a 'unit of analysis' error (Divine 1992) whereby $P$ values are spuriously low, confidence intervals unduly narrow and statistical significance overestimated. This causes type I errors (Bland 1997; Gulliford 1999).

If we had found cluster trials not accounted for in primary studies, we would have presented data in a table, with a $\left(^{*}\right)$ symbol to indicate the presence of a probable unit of analysis error. If such trials are identified in subsequent versions of this review, we will attempt to contact first authors of studies to obtain intra-class correlation coefficients (ICCS) for their clustered data and adjust for this by using accepted methods (Gulliford 1999). Where clustering has been incorporated into the analysis of these primary studies, we will present these data as if from a non-cluster randomised study, but adjust for the clustering effect.

We have sought statistical advice and have been advised that the binary data as presented in a report should be divided by a 'design effect'. This is calculated using the mean number of participants per cluster $(m)$ and the ICC [Design effect $\left.=1+(m-1)^{\star} I C C\right]$ (Donner 2002). If the ICC is not reported it was assumed to be 0.1 (Ukoumunne 1999).

If cluster studies have been appropriately analysed taking into account ICCs and relevant data documented in the report, synthesis 
with other studies will be possible using the generic inverse variance technique.

\section{Cross-over trials}

A major concern of cross-over trials is the carry-over effect. It occurs if an effect (e.g. pharmacological, physiological or psychological) of the treatment in the first phase is carried over to the second phase. As a consequence, on entry to the second phase the participants can differ systematically from their initial state despite a wash-out phase. For the same reason cross-over trials are not appropriate if the condition of interest is unstable (Elbourne 2002). As both effects are very likely in severe mental illness, if we had included cross-over trials, we would have used only data from the first phase of crossover studies.

\section{Studies with multiple treatment groups}

Where a study involved more than two treatment arms, if relevant, we presented the additional treatment arms in comparisons. If data were binary we simply added these and combined within the two-by-two table. If data were continuous, we combined data following the formula in chapter 7 of the Cochrane Handbook for Systematic Reviews of Interventions (Higgins 2011). Where the additional treatment arms were not relevant, we did not reproduce these data.

\section{Dealing with missing data}

\section{Overall loss of credibility}

At some degree of loss of follow-up, data must lose credibility (Xia 2009). We chose that, for any particular outcome, should more than $50 \%$ of data be unaccounted for, we would not reproduce these data or use them within analyses. If, however, more than $50 \%$ of those in one arm of a study was lost, but the total loss was less than $50 \%$, we would have addressed this within the 'Summary of findings' table/s by down-rating quality. Finally, we would have also downgraded quality within the 'Summary of findings' table/s had loss been $25 \%$ to $50 \%$ in total.

\section{Binary}

In the case where attrition for a binary outcome was between $0 \%$ and $50 \%$ and where these data were not clearly described, we presented data on a 'once-randomised-always-analyse' basis (an intention-to-treat (ITT) analysis). Those leaving the study early were all assumed to have the same rates of negative outcome as those who completed, with the exception of the outcome of death and adverse effects. For these outcomes, we used the rate of those who stayed in the study - in that particular arm of the trial - for those who did not. We undertook a sensitivity analysis to test how prone the primary outcomes were to change when 'completer' data only were compared to the ITT analysis using the above assumptions.

\section{Continuous}

\subsection{Attrition}

Had we found data where attrition for a continuous outcome was between $0 \%$ and $50 \%$, and data only from people who completed the study to that point were reported, we would have reproduced and presented these data.

\subsection{Standard deviations}

If we had found data where standard deviations (SDs) were not reported, we would have first tried to obtain the missing values from the authors. If not available, where there were missing measures of variance for continuous data, but an exact standard error (SE) and confidence intervals available for group means, and either ' $P$ ' value or ' $t$ ' value available for differences in mean, we would have calculated them according to the rules described in the Cochrane Handbook for Systematic reviews of Interventions (Higgins 2011): When only the SE was reported, SDs would have been calculated by the formula SD $=S E{ }^{*}$ square root $(n)$. The Cochrane Handbook for Systematic reviews of Interventions (Higgins 2011) presents detailed formulae for estimating SDs from P values, $\mathrm{t}$ or $\mathrm{F}$ values, confidence intervals, ranges or other statistics. If these formulae did not apply, we would have calculated the SDs according to a validated imputation method which is based on the SDs of the other included studies (Furukawa 2006). Although some of these imputation strategies can introduce error, the alternative would have been to exclude a given study's outcome and thus to lose information. We nevertheless would have examined the validity of the imputations in a sensitivity analysis excluding imputed values.

\subsection{Assumptions about participants who left the trials early or were lost to follow-up}

Various methods are available to account for participants who left the trials early or were lost to follow-up. Some trials just present the results of study completers, others use the method of last observation carried forward (LOCF), while more recently methods such as multiple imputation or mixed-effects models for repeated measurements (MMRM) have become more of a standard. While the latter methods seem to be somewhat better than LOCF (Leon 2006), we feel that the high percentage of participants leaving the studies early and differences in the reasons for leaving the studies early between groups is often the core problem in randomised schizophrenia trials. We would therefore have not excluded studies based on the statistical approach used. However, we would have preferably used the more sophisticated approaches. For example, we prefer MMRM or multiple-imputation to LOCF and we would only present completer analyses if some kind of ITT data were not available at all. Moreover, we would have addressed this issue in the item "incomplete outcome data" of the 'Risk of bias' tool.

\section{Assessment of heterogeneity}

\section{Clinical heterogeneity}

We considered all included studies initially, without seeing comparison data, to judge clinical heterogeneity. We simply inspected all studies for clearly outlying people or situations which we had not predicted would arise. If we had such situations or participant groups, we would have discussed these.

\section{Methodological heterogeneity}

We considered all included studies initially, without seeing comparison data, to judge methodological heterogeneity. We simply inspected all studies for clearly outlying methods which we had not predicted would arise. When such methodological outliers arose, we fully discussed these. 


\section{Statistical heterogeneity}

\subsection{Visual inspection}

We visually inspected graphs to investigate the possibility of statistical heterogeneity.

\subsection{Employing the $\mathrm{I}^{2}$ statistic}

We investigated heterogeneity between studies by considering the $\mathrm{I}^{2}$ method alongside the $\mathrm{Chi}^{2} \mathrm{P}$ value. The $\mathrm{I}^{2}$ provides an estimate of the percentage of inconsistency thought to be due to chance (Higgins 2003). The importance of the observed value of $\mathrm{I}^{2}$ depends on i. magnitude and direction of effects and ii. strength of evidence for heterogeneity (e.g. $\mathrm{P}$ value from $\mathrm{Chi}^{2}$ test, or a confidence interval for $1^{2}$ ). An $1^{2}$ estimate greater than or equal to around $50 \%$ accompanied by a statistically significant $\mathrm{Chi}^{2}$ statistic was interpreted as evidence of substantial levels of heterogeneity (Deeks 2011). When substantial levels of heterogeneity were found in the primary outcome, we explored reasons for heterogeneity (Subgroup analysis and investigation of heterogeneity).

\section{Assessment of reporting biases}

Reporting biases arise when the dissemination of research findings is influenced by the nature and direction of results (Egger 1997). These are described in Section 10 of the Handbook (Sterne 2011). We are aware that funnel plots may be useful in investigating reporting biases, but are of limited power to detect small-study effects. We proposed to not use funnel plots for outcomes where there were 10 or fewer studies, or where all studies were of similar size so we did not produce a funnel plot as all outcomes were measured in fewer than 10 studies. In future versions of this review, if funnel plots are possible, we will seek statistical advice in their interpretation.

\section{Data synthesis}

We understand that there is no closed argument for preference for use of fixed-effect or random-effects models. The random-effects method incorporates an assumption that the different studies are estimating different, yet related, intervention effects. This often seems to be true to us and the random-effects model takes into account differences between studies even if there is no statistically significant heterogeneity. There is, however, a disadvantage to the random-effects model: it puts added weight onto small studies, which often are the most biased ones. Depending on the direction of effect, these studies can either inflate or deflate the effect size. We chose the fixed-effect model for all analyses.

\section{Subgroup analysis and investigation of heterogeneity}

\section{Subgroup analyses - only primary outcomes}

\subsection{Clinical state, stage or problem}

We proposed to undertake this review and provide an overview of the effects of different chlorpromazine doses for people with schizophrenia in general. In addition, we also proposed to report, if possible, data on subgroups of people in the same clinical state, stage and with similar problems. Such data were not available.

\section{Investigation of heterogeneity}

If inconsistency was high, we have reported this. First, we investigated whether data had been entered correctly. Second, if data were correct, we visually inspected the graph and successively removed outlying studies to see if homogeneity was restored. For this review, we decided that should this occur with data contributing to the summary finding of no more than around $10 \%$ of the total weighting, we would present the data. If not, then we did not pool data and discussed issues. We know of no supporting research for this $10 \%$ cut-off, but we use prediction intervals as an alternative to this unsatisfactory state.

When unanticipated clinical or methodological heterogeneity was obvious, we simply stated hypotheses regarding these for future reviews or versions of this review. We do not anticipate undertaking analyses relating to these.

\section{Sensitivity analysis}

\section{Implication of randomisation}

If trials had been described in some way so as to imply randomisation, for the primary outcomes we would have included these studies, and if there was no substantive difference when the implied randomised studies were added to those with better description of randomisation, then we entered all data from these studies.

\section{Assumptions for lost binary data}

Where assumptions had to be made regarding people lost to follow-up and missing SD data (see Dealing with missing data), we compared the findings on primary outcomes when we used our assumption compared with complete data only. We undertook a sensitivity analysis to test how prone results were to change when we compared 'completer' data only to the imputed data using the above assumption. If there was a substantial difference, we reported results and discussed them, but continued to employ our assumption.

\section{Risk of bias}

We analysed the effects of excluding trials that were judged to be at high risk of bias across one or more of the domains of randomisation (see also Assessment of risk of bias in included studies) reporting data for the meta-analysis of the primary outcome. If the exclusion of trials at high risk of bias did not substantially alter the direction of effect or the precision of the effect estimates, then we included data from these trials in the analysis.

\section{Imputed values}

We planned to undertake a sensitivity analysis to assess the effects of including data from trials where we used imputed values for ICC in calculating the design effect in cluster-randomised trials.

If we noted substantial differences in the direction or precision of effect estimates in any of the sensitivity analyses listed above, we did not pool data from the excluded trials with the other trials contributing to the outcome, but presented them separately.

\section{Fixed-effect and random-effects}

We synthesised data using a random-effects model to compare results from primary outcomes when using our preferred fixedeffect model. Had we found substantial differences, we would have noted this. 


\section{RESULTS}

\section{Description of studies}

\section{Results of the search}

\section{Cochrane Schizophrenia Trials Register}

We carried out searches of the Cochrane Schizophrenia Trials Register in 2008, 2014 and 2016. For full details please see Search methods for identification of studies.

\section{2008 search}

The December 2008 search identified 449 references from 169 studies. We also inspected the reference sections of selected studies for additional trials. We identified 25 additional citations of studies possibly relevant to this review. Out of these 449 articles
434 were easily excluded, mostly because they compared one fixeddose chlorpromazine with another antipsychotic drug. From the 13 remaining articles, seven were excluded, mostly for inappropriate data presentation or insufficient data specification. Another two were unusable due to differing classification of dosage than in our review. We inspected references of all identified studies for further trials. This left four studies to include.

\section{2014 search}

In October 2014, 22 records were identified through database searching and these trials were added to 'Classification pending references' section of the review. Five additional records were identified through further consideration of two records. Twentyseven articles were assessed for eligibility. Three full-text articles (one new study) were included in qualitative synthesis but two references related to studies already identified for the 2009 version of this review (see Figure 2).

Figure 2. Study flow diagram

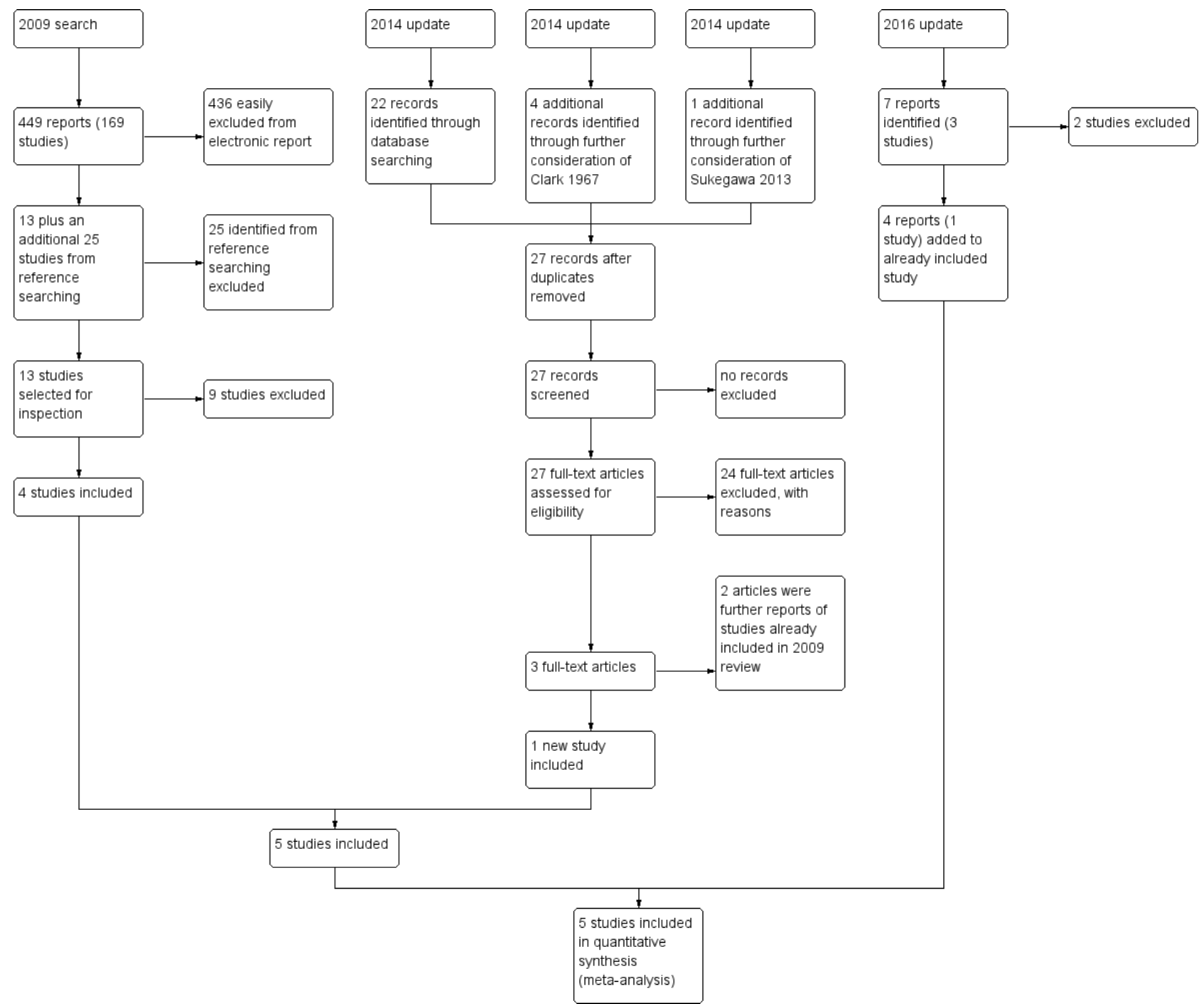

\section{2016 search}

In December 2016, we found seven more reports. Four of these related to the included study Prien 1968 and have been added.
Two were reports of Gibbs 1956, which unfortunately had to be excluded. Finally, Lehmann 1983 was also excluded. 


\section{Included studies}

The review includes 18 papers describing five studies. All were described as being randomised.

\section{Study length}

Prien 1968 and Clark 1972 were longer than 13 weeks (medium term). The other three studies fall into the short-term category with a maximum length of 12 weeks (Chouinard 1976; Wode-Helgodt 1978; Xu 2009).

\section{Design}

All studies were randomised controlled trials. We were not able to include cross-over trials. For further details, please see below.

\section{Participants}

A total of 1132 participants are included in the five trials, 585 of whom are relevant this review. All participants had been diagnosed with schizophrenia, but only Xu 2009 mentioned which tools were used for this assessment, CCMD-3 (Chinese Classification of Mental Disorders Version 3) for this particular study. Only one trial reports that diagnoses were confirmed by a research psychiatrist (Chouinard 1976). The core symptoms of schizophrenia, however, are fairly easy to observe and recognise. This diminishes, but will not eliminate the risk of error because of the normal diagnostic heterogeneity.The included trials were performed between 1968 and 2009. Age of participants ranged from 18 to 69 years over all the trials with the mean age of the trials being between 30 and 44 years. Four studies reported the sex of participants ( 81 men, 82 women). One trial included only women (Clark 1972) and Prien 1968 stated a distribution of approximately 50-50 (838 participants). Of the five studies, two focused specifically on people with chronic schizophrenia (Clark 1972; Prien 1968).

\section{Settings}

All trials were based in hospital.

\section{Interventions}

Four of the five studies compared low-dose chlorpromazine (ranging between $150 \mathrm{mg} /$ day and $400 \mathrm{mg} /$ day) with a medium dose (always $600 \mathrm{mg} /$ day, apart from Xu 2009 with doses ranging between $425 \mathrm{mg} /$ day and $600 \mathrm{mg}$ /day). Only Prien 1968 compared a high dose ( $2 \mathrm{gm} /$ day) with a low dose ( $300 \mathrm{mg} /$ day).

Studies had also included an additional control treatment (chlorpromazine in combination with alpha-methyldopa, Chouinard 1976), conventional treatment (Prien 1968), alternative treatment (clozapine instead of chlorpromazine, Xu 2009), and placebo (Clark 1972; Prien 1968).

\section{Outcomes}

\subsection{Outcome scales}

Only details of the scales that provided usable data are shown below. Some data from rating scales were unusable. This was mainly due to missing data, especially the standard deviations. In one instance, there was a lack of numeric data. Reasons for exclusions of data are given under 'Outcomes' in the 'Characteristics of included studies' tables. Several of the scales were used to produce a binary outcome. For example, the global scales listed below were used by Prien 1968 to categorise people into 'severely ill' or not and into 'improved' or not.

\subsubsection{Global state}

6.1.1.1 Clinical Global Improvement - Severity of Illness - CGI-SI (Guy 1976)

The CGI-SI is used to assess the degree of mental illness within the clinical experience of the therapist. Scores range from one (normal, not ill at all) to seven (extremely ill).

\subsubsection{Global Assessment Scale - GAS (Endicott 1976)}

The GAS is a scale used for scoring the severity of mental disorders in a patient. It has a range from zero to 100 , with higher scores indicating better psychosocial adjustment. A score of above 70 is usually considered a full remission. It is increasingly used in studies of schizophrenia, borderline patients, depression, dysthymia and mania.

\subsubsection{Mental state}

\subsubsection{Brief Psychiatric Rating Scale BPRS (Overall 1962)}

The BPRS measures positive symptoms, general psychopathology and affective symptoms. The original scale has 16 items, but a revised 18 -item scale is commonly used. Scores can range from zero to 126 . Each item is rated on a seven-point scale varying from 'not present' to 'extremely severe', with high scores indicating more severe symptoms. Chouinard 1976 used this scale.

6.1.2.2 Positive and Negative Syndrome Scale - PANSS (Kay 1986) This schizophrenia scale has 30 items, each of which can be defined on a seven-point scoring system varying from one - absent to seven - extreme. It can be divided into three subscales for measuring the severity of general psychopathology, positive symptoms (PANSS$\mathrm{P})$, and negative symptoms (PANSS-N). A low score indicates lesser severity.

\subsubsection{Adverse effects}

\subsubsection{Chouinard 1976's approach}

Emergent symptoms were tabulated by a psychiatrist on special forms at weeks zero, two, five and eight of treatment.

\subsubsection{Clark 1972's approach}

Clark 1972 does not give a description of the methodology used to record adverse effects.

\subsubsection{Prien 1968's approach}

Side effects were recorded on a 40 -item side effect checklist by the research physician and the research nurse.

\subsubsection{Wode-Helgodt 1978's approach}

Two psychiatrists used a modified version of a previously published scale for extrapyramidal symptoms (Simpson 1970). Within this scale each adverse effect item was rated through a seven-point scale (range zero to three). Reported adverse effects were rated by asking the patients if they had experienced side effects of the medication. If a symptom was present before treatment, its score at $\mathrm{RO}$ was subtracted from the figures in later ratings.

\subsubsection{Xu 2009's approach}

Adverse effects were reported using treatment-emergent symptom side effect (TESS) scale (Guy 1976). 


\subsection{Missing outcomes}

We did find some data for our primary outcomes (Types of outcome measures) and some additional data. There were, however, very few data overall and no useful information on general functioning, behaviour, quality of life/satisfaction with treatment, cognitive functioning, service use or cost of care.

\section{Excluded studies}

\section{2008 search}

The original review authors excluded 165 studies at initial screening. One hundred and fifty-six of these studies were easily seen not to be relevant, most frequently because in these chlorpromazine was compared with another antipsychotic such as clozapine or haloperidol. Five of the remaining nine studies had investigated the interventions in question for people with schizophrenia (Andrews 1976; Bartko 1988; Clark 1978; Crane 1968; Janakiramaiah 1982). Clark 1961 and Schiele 1959 had used sliding doses of chlorpromazine and not the fixed doses we were looking for. Finally, Curry 1976 was not randomised and Green 1996 included only healthy people.

\section{2014 search}

We excluded 24 studies from the review. Initially, these studies were not clearly irrelevant and so we assessed the full text of these articles for eligibility. Overall, many studies were rejected as chlorpromazine was being compared with another antipsychotic or placebo (Borison 1991; Caffey 1975; Chen 2002; Clark 1970a; Clark 1970b) or were being compared in conjunction with a varying dose of antipsychotic/medication (Casey 1961; Joshi 1982 ). Additionally, some studies were rejected because the different doses of chlorpromazine fell under the same category (Altman 1973; Yuan-Guang 1994), only useful if reviewing differences in ultra-low doses of chlorpromazine. Clark 1960, Cooper 1973 and Pigache 1993 were not randomised by dose. Clark 1967 used increasing doses of chlorpromazine to make comparisons against a placebo. Danion 1992 and Hartley 1978 only included healthy people. Jeste 1977 and Kalyanasundaram 1981 compared different schedules rather than dose. Ota 1974 compared different brands rather than dose. Sukegawa 2008, Sukegawa 2012 and Sukegawa 2014 compared dose reduction methods of multiple antipsychotics against a control group.

\section{2016 search}

In 2016, we identified Gibbs 1956. This clearly reported randomised study compared outcomes for two levels of dosage (expressed in ranges), which we really could not justify including in our mediumdose range - both fell into the lower-dose range which we had pre-stated in our protocol. Finally, Lehmann 1983 also had to be excluded. This was a randomised study but randomisation had not been entirely successful and that alone may have been reason to exclude it. However, this trial compared unspecified antipsychotics given in doses at levels that were expressed in chlorpromazine equivalents - so we are unclear if this even included the drug chlorpromazine at all.

\section{Risk of bias in included studies}

For graphical display please see Figure 3 and Figure 4. Please also see the tables of Characteristics of included studies. 
Figure 3. Methodological quality summary: review authors' judgements about each methodological quality item for each included study.

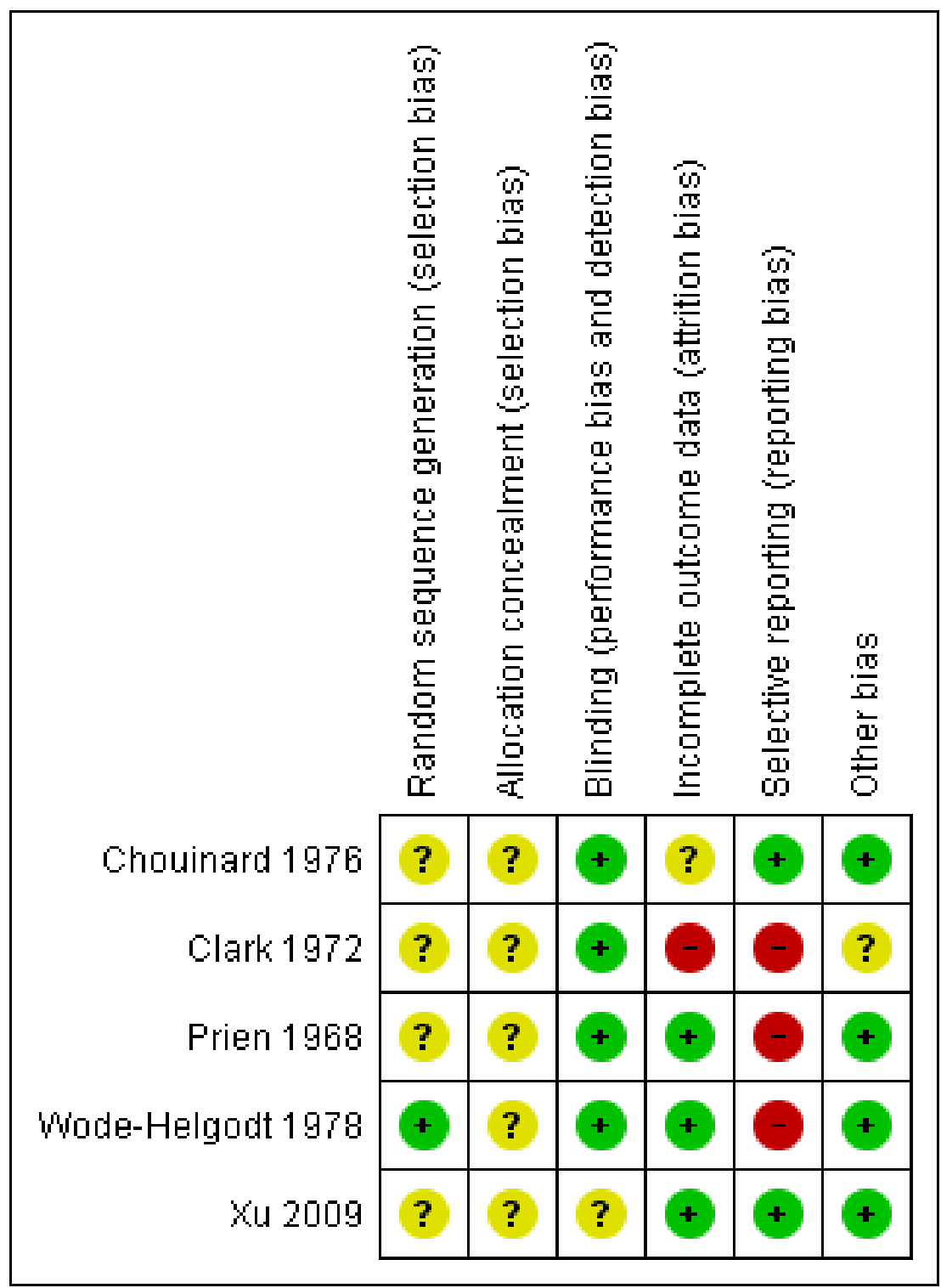


Figure 4. 'Risk of bias' graph: review authors' judgements about each risk of bias item presented as percentages across all included studies.

\section{Random sequence generation (selection bias)}

Allocation concealment (selection bias)

Blinding (performance bias and detection bias)

Incomplete outcome data (attrition bias)

Selective reporting (reporting bias)

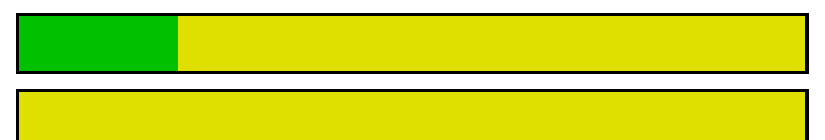

\section{즐}

Other bias

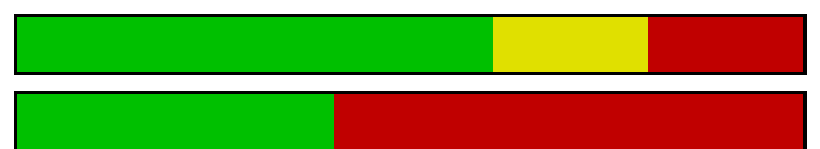

Other bias

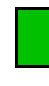

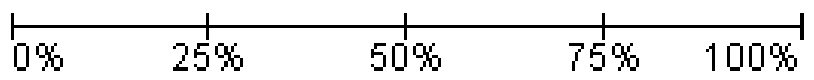

\section{Allocation}

All studies were randomised, but the description of allocation was poor in all but Wode-Helgodt 1978, where the trialists seemed to have given considerable consideration to the process. Although the method used was referenced (Armitage 1971), the technique used was 'restricted'. Hence this method was poor and could have easily introduced selection bias with an overestimation of positive effect (Jüni 2001). Therefore, all studies, apart from WodeHelgodt 1978, were labelled as having an 'unclear risk' with regards to selection bias. Furthermore, none of the studies mentioned allocation concealment.

\section{Blinding}

We rated Chouinard 1976, Clark 1972, Prien 1968 and Wode-Helgodt 1978 low risk for this domain as they were stated to be doubleblinded and briefly described the methods used. However, none of the studies tested the success of this blinding. Xu 2009 presents an unclear risk as blinding was not mentioned or described.

\section{Incomplete outcome data}

Overall, the number, treatment group and reasons for people who left the studies early was reported adequately. Prien 1968 did not describe the losses in the text but provided a table of percentage losses and reasons, which could be converted to absolute numbers. However, Chouinard 1976 failed to report from what treatment group the person who left the study was from. Clark 1972 provided the number of people as well as their individual reasons for leaving the study early, without revealing which treatment group they belonged to. In both studies the missing information could not be calculated from any tables of results.

\section{Selective reporting}

Overall, data reporting was poor. All but two studies (Chouinard 1976 and Xu 2009) had a high risk of reporting bias. We were unable to use a lot of data from the five included trials. Continuous data and data about general state were especially problematic. Very often the reason for exclusion was a lack of reporting standard deviations with no additional numerical data from which estimates could be generated. Another common reason for exclusion was the failure to provide any numerical information about specific outcomes at all. For example, Clark 1972 reported people's reasons for leaving the study but provided no information about their distribution among the treatment groups. Wode-Helgodt 1978 presented many findings in graphs, but it was only possible in one graph to extract data. We had to give Prien 1968 a rating of high risk - there were no variances for several continuous outcomes, several outcomes not reported at all, and only data of patients evaluated by same rater at pre-treatment and termination were reported in general state.

\section{Other potential sources of bias}

Only Clark 1972 stated that they had gained the drugs from Smith, Kline and French Laboratories. This is a form of support, but we are unclear if the company had any more influence on the study - and marked the level of bias as 'unclear'. Other potential sources of bias were not found.

\section{Effects of interventions}

See: Summary of findings for the main comparison CHLORPROMAZINE LOW DOSE ( $\leq 400 \mathrm{mg} /$ day) compared to MEDIUM DOSE (401 mg/day to $800 \mathrm{mg} /$ day) for people with schizophrenia; Summary of findings 2 CHLORPROMAZINE LOW DOSE ( $\leq 400 \mathrm{mg} /$ day) compared to HIGH DOSE (> $800 \mathrm{mg} /$ day - all medium term) for people with schizophrenia

\section{COMPARISON 1: CHLORPROMAZINE LOW DOSE ( $\leq 400 \mathrm{mg} /$ day) versus MEDIUM DOSE (401 mg/day to $800 \mathrm{mg} /$ day)}

\subsection{Global state: Not improved - short term}

We identified one relevant trial $(n=60, X u 2009)$ and there was no evidence of a clear difference between chlorpromazine low dose ( $\leq$ $400 \mathrm{mg} /$ day) and medium dose $(401 \mathrm{mg} /$ day to $800 \mathrm{mg} /$ day, risk ratio (RR) $0.83,95 \%$ confidence interval $(\mathrm{Cl}) 0.28$ to 2.44 , Analysis $1.1)$. 
1.2 Global state: Requiring additional medication (sedation with chloral hydrate or a barbiturate > five times) - medium term

We identified one relevant trial $(n=50$, Clark 1972) and there was no evidence of a clear difference between chlorpromazine low dose ( $\leq 400 \mathrm{mg} /$ day) and medium dose $(401 \mathrm{mg} /$ day to $800 \mathrm{mg} /$ day, RR $3.09,95 \% \mathrm{Cl} 0.40$ to 23.64 , Analysis 1.2 ).

\subsection{Leaving the study early}

This outcome was reported by Chouinard 1976 and Wode-Helgodt 1978 with extractable data. Wode-Helgodt 1978 reported this more fully and we were able to divide this outcome into subgroups.

\subsubsection{Any reason}

In this subgroup we found two relevant trials $(n=70)$. There was no significant difference between chlorpromazine low dose $(\leq 400 \mathrm{mg} /$ day) and medium dose ( $401 \mathrm{mg} /$ day to $800 \mathrm{mg} /$ day, RR 1.06, 95\% $\mathrm{Cl} 0.32$ to 3.55 , Analysis 1.3 ).

\subsubsection{Adverse effects}

In this subgroup we identified one relevant trial ( $n=48$, WodeHelgodt 1978) reporting no evidence of a clear difference between chlorpromazine low dose ( $\leq 400 \mathrm{mg} /$ day) and medium dose (401 $\mathrm{mg} /$ day to $800 \mathrm{mg} /$ day, RR $0.23,95 \% \mathrm{Cl} 0.02$ to 2.32 , Analysis 1.3 ).

\subsubsection{Inefficacy of treatment}

In this subgroup we identified one relevant trial ( $n=48$, WodeHelgodt 1978). This single study found no evidence of a clear difference between chlorpromazine low dose ( $\leq 400 \mathrm{mg} /$ day) and medium dose ( $401 \mathrm{mg} /$ day to $800 \mathrm{mg} /$ day, RR $4.24,95 \% \mathrm{Cl} 0.24$ to 74.01, Analysis 1.3).

\subsubsection{Other reason}

In this subgroup we found two relevant trials $(n=70)$. There was no significant difference between chlorpromazine low dose $(\leq 400 \mathrm{mg} /$ day) and medium dose (401 mg/day to $800 \mathrm{mg} /$ day, RR 0.91, 95\% $\mathrm{Cl} 0.09$ to 9.27 , Analysis 1.3).

\subsection{Mental state: 1a. Average endpoint score (BPRS total, high = poor)}

The BPRS score was not expressed as a total so we have presented this outcome in subgroups. One trial with a total of 22 relevant participants reported this outcome.

\subsubsection{Anxious depression}

Within this subgroup we identified one relevant trial $(n=22$, Chouinard 1976) reporting no evidence of a clear difference between chlorpromazine low dose ( $\leq 400 \mathrm{mg} /$ day) and medium dose $(401 \mathrm{mg} /$ day to $800 \mathrm{mg} /$ day, mean difference (MD) $-0.60,95 \%$ $\mathrm{Cl}-1.35$ to 0.15 , Analysis 1.4$)$.

\subsubsection{Thinking disturbance}

In this subgroup we identified one relevant trial $(n=22$, Chouinard 1976) reporting no evidence of a clear difference between chlorpromazine low dose ( $\leq 400 \mathrm{mg} /$ day) and medium dose (401 $\mathrm{mg} /$ day to $800 \mathrm{mg} /$ day, MD, $2.6095 \% \mathrm{Cl}-0.24$ to 5.44 , Analysis 1.4).

\subsubsection{Withdrawal retardation}

Within this subgroup we identified one relevant trial $(n=22$, Chouinard 1976) reporting evidence of a clear difference between chlorpromazine low dose ( $\leq 400 \mathrm{mg} /$ day) and medium dose (401 $\mathrm{mg} /$ day to $800 \mathrm{mg} /$ day, MD $-2.00,95 \% \mathrm{Cl}-3.76$ to -0.24 , Analysis 1.4).

\subsection{Mental state: 1b. Average endpoint score (PANSS total and subscores, high $=$ poor)}

One study with 60 participants relevant to the review recorded PANSS total score as well as subscores.

\subsubsection{Negative}

In this subgroup we identified one relevant trial ( $n=60, X u 2009)$. This single study found no evidence of a clear difference between chlorpromazine low dose ( $\leq 400 \mathrm{mg} /$ day) and medium dose (401 $\mathrm{mg} /$ day to $800 \mathrm{mg} /$ day, MD $-0.17,95 \% \mathrm{Cl}-2.34$ to 2.00 , Analysis 1.5 ).

\subsubsection{Positive}

In this subgroup we identified one relevant trial ( $n=60, \mathrm{Xu} 2009)$. This single study found no evidence of a clear difference between chlorpromazine low dose ( $\leq 400 \mathrm{mg} /$ day) and medium dose (401 $\mathrm{mg} /$ day to $800 \mathrm{mg} /$ day, MD $-0.24,95 \% \mathrm{Cl}-1.98$ to 1.50 , Analysis 1.5 ).

\subsubsection{Total}

In this subgroup we identified one relevant trial ( $\mathrm{n}=60$, Xu 2009) reporting no evidence of a clear difference between chlorpromazine low dose ( $\leq 400 \mathrm{mg} /$ day) and medium dose (401mg/day to $800 \mathrm{mg} /$ day, MD 0.36, $95 \% \mathrm{Cl}-5.39$ to 6.11 , Analysis 1.5).

\subsection{Adverse effects: 1. Central nervous system - extrapyramidal symptoms}

Chouinard 1976 and Wode-Helgodt 1978 reported specific extrapyramidal symptoms in the short term while Clark 1972 reported unspecific extrapyramidal symptoms in the medium term.

\subsubsection{Akathisia - short term}

In this subgroup we found two relevant trials $(n=70)$. There was no significant difference between chlorpromazine low dose $(\leq 400 \mathrm{mg} /$ day) and medium dose (401 mg/day to $800 \mathrm{mg} /$ day, RR 1.37, 95\% $\mathrm{Cl} 0.28$ to 6.68 , Analysis 1.6$)$.

\subsubsection{Akinesia - short term}

In this subgroup we identified one relevant trial $(n=22$, Chouinard 1976). This single study found no evidence of a clear difference between chlorpromazine low dose $(\leq 400 \mathrm{mg} /$ day) and medium dose $(401 \mathrm{mg} /$ day to $800 \mathrm{mg} /$ day, RR $0.50,95 \% \mathrm{Cl} 0.05$ to 4.75 , Analysis 1.6).

\subsubsection{Dystonia - short term}

In this subgroup we identified two relevant trials $(n=70)$. There was no significant difference between chlorpromazine low dose $(\leq 400$ $\mathrm{mg} /$ day) and medium dose $(401 \mathrm{mg} /$ day to $800 \mathrm{mg} /$ day, RR 0.24 , $95 \% \mathrm{Cl} 0.05$ to 1.29 , Analysis 1.6).

\subsubsection{Gait disturbance - short term}

In this subgroup we identified one relevant trial ( $n=48$, WodeHelgodt 1978). This single study found no evidence of a clear difference between chlorpromazine low dose ( $\leq 400 \mathrm{mg} /$ day) and medium dose $(401 \mathrm{mg} /$ day to $800 \mathrm{mg} /$ day, RR $0.36,95 \% \mathrm{Cl} 0.11$ to 1.17, Analysis 1.6). 


\subsubsection{Muscle tension - short term}

In this subgroup we identified one relevant trial ( $n=48$, WodeHelgodt 1978). This single study found evidence of a clear difference between chlorpromazine low dose $(\leq 400 \mathrm{mg} /$ day) and medium dose (401-800 mg/day, RR 0.15, 95\% Cl 0.03 to 0.67 , Analysis 1.6).

\subsubsection{Rigidity - elbow - short term}

In this subgroup we identified one relevant trial $(n=48$, WodeHelgodt 1978) reporting no evidence of a clear difference between chlorpromazine low dose $(\leq 400 \mathrm{mg} /$ day) and medium dose (401 $\mathrm{mg} /$ day to $800 \mathrm{mg} /$ day, RR $0.53,95 \% \mathrm{Cl} 0.21$ to 1.31 , Analysis 1.6).

\subsubsection{Rigidity - unspecified - short term}

In this subgroup we identified one relevant trial $(n=22$, Chouinard 1976) reporting no evidence of a clear difference between chlorpromazine low dose ( $\leq 400 \mathrm{mg} /$ day) and medium dose (401 $\mathrm{mg} /$ day to $800 \mathrm{mg} /$ day, RR $1.00,95 \% \mathrm{Cl} 0.07$ to 14.05 , Analysis 1.6).

\subsubsection{Tremor - short term}

In this subgroup we identified two relevant trials $(n=70)$. There was no significant difference between chlorpromazine low dose $(\leq 400$ $\mathrm{mg} /$ day) and medium dose (401 mg/day to $800 \mathrm{mg} /$ day, RR 0.44 , $95 \% \mathrm{Cl} 0.17$ to 1.10 , Analysis 1.6).

\subsubsection{Unspecified extrapyramidal symptoms - short term}

In this subgroup we identified two relevant trials $(n=108)$ reporting evidence of a clear difference between chlorpromazine low dose ( $\leq 400 \mathrm{mg} /$ day) and medium dose $(401 \mathrm{mg} /$ day to $800 \mathrm{mg} /$ day, RR $0.47,95 \% \mathrm{Cl} 0.30$ to 0.74 , Analysis 1.6$)$.

\subsubsection{Unspecified extrapyramidal symptoms - medium term}

In this subgroup we identified one relevant trial ( $n=50$, Clark 1972). This single study found no evidence of a clear difference between chlorpromazine low dose ( $\leq 400 \mathrm{mg} /$ day) and medium dose (401 $\mathrm{mg} /$ day to $800 \mathrm{mg} /$ day, RR $0.26,95 \% \mathrm{Cl} 0.05$ to 1.27 , Analysis 1.6).

\subsection{Adverse effects: 2. Anticholinergic}

We reported the broad range of adverse effects under subheadings such as anticholinergic, cardiovascular, central nervous system, etc. We found that this method of categorisation allowed the data to be inputted clearly without losing too much detail.

Three trials with a total of 120 participants reported data of one or more anticholinergic side effects of both short and medium term. Some of the reported side effects were particularly specific. However, 'urinary disturbance' and 'trouble starting urination' were reported by two separate trials but not explained. Therefore, we assumed these terms to be referring to the same outcome.

\subsubsection{Blurred vision - short term}

In this subgroup we identified one relevant trial $(n=48$, WodeHelgodt 1978). This single study found no evidence of a clear difference between chlorpromazine low dose ( $\leq 400 \mathrm{mg} /$ day) and medium dose $(401 \mathrm{mg} /$ day to $800 \mathrm{mg} /$ day, RR $0.30,95 \% \mathrm{Cl} 0.06$ to 1.63, Analysis 1.7).

\subsubsection{Constipation - short term}

In this subgroup we identified two relevant trials $(n=70)$. There was no significant difference between chlorpromazine low dose $(\leq 400$ $\mathrm{mg} /$ day) and medium dose (401 mg/day to $800 \mathrm{mg} /$ day, RR 1.82, $95 \% \mathrm{Cl} 0.42$ to 7.99 , Analysis 1.7$)$.

\subsubsection{Constipation - medium term}

In this subgroup we identified one relevant trial ( $n=50$, Clark 1972). This single study found no evidence of a clear difference between chlorpromazine low dose ( $\leq 400 \mathrm{mg} /$ day) and medium dose (401 $\mathrm{mg} /$ day to $800 \mathrm{mg} /$ day, RR $0.11,95 \% \mathrm{Cl} 0.01$ to 2.09 , Analysis 1.7 ).

\subsubsection{Ejaculation disturbance - short term}

In this subgroup we identified one relevant trial $(n=20$, WodeHelgodt 1978). Of the 20 people, no one had this adverse effect in either dosage group (Analysis 1.7).

\subsubsection{Erectile disturbance - short term}

In this subgroup we identified one relevant trial $(n=20$, WodeHelgodt 1978). Of the 20 people, no one had this adverse effect in either dosage group (Analysis 1.7).

\subsubsection{Salivation - dry mouth - short term}

In this subgroup we identified two relevant trials $(n=70)$. There was no significant difference between chlorpromazine low dose $(\leq 400$ $\mathrm{mg} /$ day) and medium dose (401 mg/day to $800 \mathrm{mg} /$ day, RR 1.16 , $95 \% \mathrm{Cl} 0.58$ to 2.34 , Analysis 1.7 ).

\subsubsection{Salivation - too much - short term}

In this subgroup we identified one relevant trial ( $n=48$, WodeHelgodt 1978). This single study found no evidence of a clear difference between chlorpromazine low dose ( $\leq 400 \mathrm{mg} /$ day) and medium dose $(401 \mathrm{mg} /$ day to $800 \mathrm{mg} /$ day, RR $0.09,95 \% \mathrm{Cl} 0.0$ to 1.85, Analysis 1.7).

\subsubsection{Tachycardia - short term}

In this subgroup we identified one relevant trial $(n=22$, Chouinard 1976). This single study found no evidence of a clear difference between chlorpromazine low dose ( $\leq 400 \mathrm{mg} /$ day) and medium dose $(401 \mathrm{mg} /$ day to $800 \mathrm{mg} /$ day, RR $0.50,95 \% \mathrm{Cl} 0.05$ to 4.75 , Analysis 1.7).

\subsubsection{Urinary disturbance/trouble starting urination - short term}

In this subgroup we identified two relevant trials $(n=70)$. There was no significant difference between chlorpromazine low dose $(\leq 400$ $\mathrm{mg} /$ day) and medium dose (401 mg/day to $800 \mathrm{mg} /$ day, RR 3.00, $95 \% \mathrm{Cl} 0.37$ to 24.58 , Analysis 1.7 ).

\subsection{Adverse effects: 3. Cardiovascular}

In total, four trials consisting of 182 participants reported data of one or more cardiovascular adverse effects, of both short and medium term.

\subsubsection{Electrocardiogram abnormal - short term}

Within this subgroup we identified one relevant trial $(\mathrm{n}=$ $60, \mathrm{Xu} 2009$ ) reporting evidence of a clear difference between chlorpromazine low dose ( $\leq 400 \mathrm{mg} /$ day) and medium dose (401 $\mathrm{mg}$ /day to $800 \mathrm{mg} /$ day, RR $0.22,95 \% \mathrm{Cl} 0.05$ to 0.94 , Analysis 1.8 ).

\subsubsection{Orthostatic symptoms (faint, dizzy, weak) - short term}

In this subgroup we identified one relevant trial $(n=22$, Chouinard 1976) reporting no evidence of a clear difference between 
chlorpromazine low dose ( $\leq 400 \mathrm{mg} /$ day) and medium dose (401 $\mathrm{mg} /$ day to $800 \mathrm{mg} /$ day, RR $2.00,95 \% \mathrm{Cl} 0.21$ to 18.98 , Analysis 1.8).

\subsubsection{Orthostatic symptoms - medium term}

In this subgroup we identified one relevant trial ( $n=50$, Clark 1972). This single study found no evidence of a clear difference between chlorpromazine low dose ( $\leq 400 \mathrm{mg} /$ day) and medium dose (401 $\mathrm{mg} /$ day to $800 \mathrm{mg} /$ day, RR $0.11,95 \% \mathrm{Cl} 0.01$ to 2.09, Analysis 1.8).

\subsubsection{Tachycardia - short term}

In this subgroup we identified one relevant trial $(n=22$, Chouinard 1976). This single study found no evidence of a clear difference between chlorpromazine low dose $(\leq 400 \mathrm{mg} /$ day) and medium dose $(401 \mathrm{mg} /$ day to $800 \mathrm{mg} /$ day, RR $0.5,95 \% \mathrm{Cl} 0.05$ to 4.75 , Analysis 1.8).

\subsubsection{Vertigo - short term}

In this subgroup we identified one relevant trial $(n=50$, WodeHelgodt 1978) reporting no evidence of a clear difference between chlorpromazine low dose ( $\leq 400 \mathrm{mg} /$ day) and medium dose (401 $\mathrm{mg} /$ day to $800 \mathrm{mg} /$ day, RR $1.03,95 \% \mathrm{Cl} 0.21$ to 5.07 , Analysis 1.8).

\subsection{Adverse effects: 4. Central nervous system - other than extrapyramidal symptoms}

Four trials with a total of 180 relevant participants reported data on central nervous system adverse effects (other than extrapyramidal) of both short and medium term.

\subsubsection{Depression - medium term}

In this subgroup we identified one relevant trial ( $n=50$, Clark 1972). Of the 50 people, no one reported depression in either dosage group (Analysis 1.9).

\subsubsection{Drowsiness - short term}

In this subgroup we identified one relevant trial $(n=22$, Chouinard 1976). This single study found no evidence of a clear difference between chlorpromazine low dose $(\leq 400 \mathrm{mg} /$ day) and medium dose $(401 \mathrm{mg} /$ day to $800 \mathrm{mg} /$ day, RR $1.00,95 \% \mathrm{Cl} 0.47$ to 2.14 , Analysis 1.9).

\subsubsection{EEG abnormal - short term}

In this subgroup we identified one relevant trial ( $n=60$, Xu 2009) reporting no evidence of a clear difference between chlorpromazine low dose ( $\leq 400 \mathrm{mg} /$ day) and medium dose (401 $\mathrm{mg} /$ day to $800 \mathrm{mg} /$ day, RR $0.78,95 \% \mathrm{Cl} 0.33$ to 1.82 , Analysis 1.9 ).

\subsubsection{Head feels heavy - short term}

In this subgroup we identified one relevant trial $(n=48$, WodeHelgodt 1978) reporting no evidence of a clear difference between chlorpromazine low dose ( $\leq 400 \mathrm{mg} /$ day) and medium dose (401 $\mathrm{mg} /$ day to $800 \mathrm{mg} /$ day, RR $0.15,95 \% \mathrm{Cl} 0.02$ to 1.34 , Analysis 1.9).

\subsubsection{Headache - short term}

In this subgroup we identified one relevant trial ( $n=48$, WodeHelgodt 1978). This single study found no evidence of a clear difference between chlorpromazine low dose ( $\leq 400 \mathrm{mg} /$ day) and medium dose $(401 \mathrm{mg} /$ day to $800 \mathrm{mg} /$ day, RR $2.35,95 \% \mathrm{Cl} 0.12$ to 46.22, Analysis 1.9).

\subsubsection{Sedation - medium term}

Within this subgroup we identified one relevant trial $(n=50$, Clark 1972) reporting evidence of a clear difference between chlorpromazine low dose $(\leq 400 \mathrm{mg} /$ day) and medium dose (401 $\mathrm{mg} /$ day to $800 \mathrm{mg}$ /day, RR $0.17,95 \% \mathrm{Cl} 0.05$ to 0.55 , Analysis 1.9 ).

\subsubsection{Somnolence - short term}

In this subgroup we identified one relevant trial ( $n=48$, WodeHelgodt 1978). This single study found no evidence of a clear difference between chlorpromazine low dose ( $\leq 400 \mathrm{mg} /$ day) and medium dose $(401 \mathrm{mg} /$ day to $800 \mathrm{mg} /$ day, RR $1.1,95 \% \mathrm{Cl} 0.59$ to 2.08, Analysis 1.9).

\subsubsection{Vertigo - short term}

In this subgroup we identified one relevant trial $(n=48$, WodeHelgodt 1978) reporting no evidence of a clear difference between chlorpromazine low dose ( $\leq 400 \mathrm{mg} /$ day) and medium dose (401 $\mathrm{mg}$ /day to $800 \mathrm{mg}$ /day, RR $0.91,95 \% \mathrm{Cl} 0.19$ to 4.43 , Analysis 1.9).

\subsection{Adverse effects: 5. Dermatological}

Clark 1972 reported dermatitis as well as an erythema rash in the medium term while Chouinard 1976 reported data on rashes in the short term.

\subsubsection{Dermatitis - medium term}

In this subgroup we identified one relevant trial $(n=50$, Clark 1972) reporting no evidence of a clear difference between chlorpromazine low dose ( $\leq 400 \mathrm{mg} /$ day) and medium dose (401 $\mathrm{mg} /$ day to $800 \mathrm{mg} /$ day, RR $1.59,95 \% \mathrm{Cl} 0.07$ to 37.03 , Analysis 1.10 ).

\subsubsection{Rash - short term}

In this subgroup we identified one relevant trial $(n=22$, Chouinard 1976). This single study found no evidence of a clear difference between chlorpromazine low dose ( $\leq 400 \mathrm{mg} /$ day) and medium dose $(401 \mathrm{mg} /$ day to $800 \mathrm{mg} /$ day, RR $1.33,95 \% \mathrm{Cl} 0.39$ to 4.62 , Analysis 1.10).

\subsubsection{Rash - 'photosensitivity: erythema' - medium term}

In this subgroup we identified one relevant trial ( $n=50$, Clark 1972). This single study found no evidence of a clear difference between chlorpromazine low dose ( $\leq 400 \mathrm{mg} /$ day) and medium dose (401 $\mathrm{mg} /$ day to $800 \mathrm{mg} /$ day, RR $0.52,95 \% \mathrm{Cl} 0.03$ to 7.74 , Analysis 1.10 ).

\subsection{Adverse effects: 6. Endocrine and metabolic}

Endocrine adverse effects were described specifically. WodeHelgodt 1978 reported amenorrhoea and lactation in the short term while Clark 1972 reported metrorrhagia in the medium term.

\subsubsection{Amenorrhoea - short term}

In this subgroup we identified one relevant trial $(n=28$, WodeHelgodt 1978). This single study found no evidence of a clear difference between chlorpromazine low dose ( $\leq 400 \mathrm{mg} /$ day) and medium dose $(401 \mathrm{mg} /$ day to $800 \mathrm{mg} /$ day, RR $0.47,95 \% \mathrm{Cl} 0.03$ to 6.74, Analysis 1.11).

\subsubsection{Lactation - short term}

In this subgroup we identified one relevant trial $(n=28$, WodeHelgodt 1978). This single study found no evidence of a clear difference between chlorpromazine low dose ( $\leq 400 \mathrm{mg} /$ day) and 
medium dose $(401 \mathrm{mg} /$ day to $800 \mathrm{mg} /$ day, RR $0.17,95 \% \mathrm{Cl} 0.01$ to 3.73, Analysis 1.11).

\subsubsection{Metrorrhagia - medium term}

In this subgroup we identified one relevant trial ( $n=50$, Clark 1972). This single study found no evidence of a clear difference between chlorpromazine low dose ( $\leq 400 \mathrm{mg} /$ day) and medium dose (401 $\mathrm{mg} /$ day to $800 \mathrm{mg} /$ day, RR $0.18,95 \% \mathrm{Cl} 0.01$ to 4.11 , Analysis 1.11).

\subsection{Adverse effects: 7. Gastrointestinal}

Unspecified gastrointestinal adverse effects were reported in the short term. However, further subgroups included constipation at short and medium term.

\subsubsection{Constipation - short term}

In this subgroup we identified two relevant trials $(n=70)$. There was no significant difference between chlorpromazine low dose $(\leq 400$ $\mathrm{mg} /$ day) and medium dose (401 mg/day to $800 \mathrm{mg} /$ day, RR 1.82 , $95 \% \mathrm{Cl} 0.42$ to 7.99 , Analysis 1.12 ).

\subsubsection{Constipation - medium term}

In this subgroup we identified one relevant trial ( $n=50$, Clark 1972) reporting no evidence of a clear difference between chlorpromazine low dose ( $\leq 400 \mathrm{mg} /$ day) and medium dose (401 $\mathrm{mg} /$ day to $800 \mathrm{mg} /$ day, RR $0.11,95 \% \mathrm{Cl} 0.01$ to 2.09 , Analysis 1.12).

\subsubsection{Unspecified - short term}

In this subgroup we identified one relevant trial $(n=22$, Chouinard 1976). This single study found no evidence of a clear difference between chlorpromazine low dose ( $\leq 400 \mathrm{mg} /$ day) and medium dose $(401 \mathrm{mg} /$ day to $800 \mathrm{mg} /$ day, RR $5.00,95 \% \mathrm{Cl} 0.27$ to 93.55 , Analysis 1.12).

\subsection{Adverse effects: 8. Genitourinary}

'Urinary disturbance' and 'trouble starting urination' were assumed these terms to be referring to the same outcome (see above). This outcome was also included under the 'anticholinergic adverse effects' heading as it falls under both categories.

\subsubsection{Urinary disturbance/trouble starting urination - short term}

In this subgroup we identified two relevant trials $(n=70)$. There was no significant difference between chlorpromazine low dose $(\leq 400$ $\mathrm{mg} /$ day) and medium dose (401 mg/day to $800 \mathrm{mg} /$ day, RR 3.00 , $95 \% \mathrm{Cl} 0.37$ to 24.58 , Analysis 1.13 ).

\subsection{Adverse effects: 9. Haematological}

Clark 1972, with 50 participants, was the only trial to report data on haematological adverse effects.

\subsubsection{Agranulocytosis - medium term}

In this subgroup we identified one relevant trial ( $n=50$, Clark 1972). This single study found no evidence of a clear difference between chlorpromazine low dose ( $\leq 400 \mathrm{mg} /$ day) and medium dose (401 $\mathrm{mg} /$ day to $800 \mathrm{mg} /$ day, RR $1.59,95 \% \mathrm{Cl} 0.07$ to 37.03 , Analysis 1.14).

\subsubsection{Anaemia - medium term}

In this subgroup we identified one relevant trial ( $n=50$, Clark 1972). This single study found no evidence of a clear difference between chlorpromazine low dose ( $\leq 400 \mathrm{mg} /$ day) and medium dose (401 $\mathrm{mg}$ /day to $800 \mathrm{mg} /$ day, RR $1.59,95 \% \mathrm{Cl} 0.07$ to 37.03 , Analysis 1.14).

\subsection{Adverse effects: 10. Hepatological}

1.15.1 Abnormal liver function - short term

In this subgroup we identified one relevant trial ( $n=60, X u 2009)$. This single study found no evidence of a clear difference between chlorpromazine low dose ( $\leq 400 \mathrm{mg} /$ day) and medium dose (401 $\mathrm{mg}$ /day to $800 \mathrm{mg}$ /day, RR $1.33,95 \% \mathrm{Cl} 0.33$ to 5.45 , Analysis 1.15 ).

\subsection{Adverse effects: 11. Others}

The following subgroups were difficult to place under the distinct categories above and so were collectively grouped under 'others'.

\subsubsection{Agitation and restlessness - medium term}

In this subgroup we identified one relevant trial ( $\mathrm{n}=50$, Clark 1972) reporting no evidence of a clear difference between chlorpromazine low dose ( $\leq 400 \mathrm{mg} /$ day) and medium dose (401 $\mathrm{mg} /$ day to $800 \mathrm{mg} /$ day, RR $1.59,95 \% \mathrm{Cl} 0.07$ to 37.03 , Analysis 1.16).

\subsubsection{Excitement - short term}

In this subgroup we identified one relevant trial $(n=22$, Chouinard 1976) reporting no evidence of a clear difference between chlorpromazine low dose ( $\leq 400 \mathrm{mg} /$ day) and medium dose (401 $\mathrm{mg} /$ day to $800 \mathrm{mg} /$ day, RR $1.00,95 \% \mathrm{Cl} 0.07$ to 14.05 , Analysis 1.16).

\subsubsection{Restlessness, insomnia - short term}

In this subgroup we identified one relevant trial $(n=22$, Chouinard 1976) reporting no evidence of a clear difference between chlorpromazine low dose ( $\leq 400 \mathrm{mg} /$ day) and medium dose (401 $\mathrm{mg} /$ day to $800 \mathrm{mg}$ /day, RR $0.75,95 \% \mathrm{Cl} 0.22$ to 2.6 , Analysis 1.16 ).

COMPARISON 2: CHLORPROMAZINE LOW DOSE ( $\leq 400 \mathrm{mg} /$ day) versus HIGH DOSE (> $800 \mathrm{mg} /$ day - all medium term)

\subsection{Global state: Not improved or severely ill}

\subsubsection{No clinically important improvement}

In this subgroup we identified one relevant trial $(n=416$, Prien 1968). This single study found evidence of a clear difference between chlorpromazine low dose $(\leq 400 \mathrm{mg} /$ day) and high dose (> $800 \mathrm{mg} /$ day - all medium term, RR $1.13,95 \% \mathrm{Cl} 1.01$ to 1.25 , Analysis 2.1).

\subsubsection{Severely ill}

We identified one relevant trial $(n=416$, Prien 1968). This single study found no evidence of a clear difference between chlorpromazine low dose ( $\leq 400 \mathrm{mg} /$ day) and high dose (>800 mg/ day - all medium term, RR 1.09, 95\% Cl 0.96 to 1.24 , Analysis 2.1 ).

\subsubsection{Relapse}

Again, we identified one relevant trial ( $n=416$, Prien 1968). This study found evidence of a clear difference between chlorpromazine low dose ( $\leq 400 \mathrm{mg} /$ day) and high dose (> $800 \mathrm{mg} /$ day - all medium term, RR $2.25,95 \% \mathrm{Cl} 1.17$ to 4.32 , Analysis 2.1 ).

\subsection{Leaving the study early}

Prien 1968 provided detail as to whether the participants left the study due to 'adverse effects', 'death' or 'deterioration of behaviour'. 


\subsubsection{Any reason}

In this subgroup we identified one relevant trial $(n=416$, Prien 1968). This single study found evidence of a clear difference between chlorpromazine low dose ( $\leq 400 \mathrm{mg} /$ day) and high dose (> $800 \mathrm{mg} /$ day - all medium term, RR 0.6,0 95\% Cl 0.40 to 0.89, Analysis 2.2).

\subsubsection{Adverse effects}

Within this subgroup we identified one relevant trial $(n=416$, Prien 1968) reporting evidence of a clear difference between chlorpromazine low dose ( $\leq 400 \mathrm{mg} /$ day) and high dose (>800 mg/ day - all medium term, RR $0.10,95 \% \mathrm{Cl} 0.03$ to 0.26 , Analysis 2.2).

\subsubsection{Death}

In this subgroup we identified one relevant trial ( $n=416$, Prien 1968) reporting no evidence of a clear difference between chlorpromazine low dose ( $\leq 400 \mathrm{mg} /$ day) and high dose (>800 mg/ day - all medium term, RR $0.33,95 \% \mathrm{Cl} 0.01$ to 8.14 , Analysis 2.2).

\subsubsection{Deterioration of behaviour}

In this subgroup we identified one relevant trial $(n=416$, Prien 1968). This single study found evidence of a clear difference between chlorpromazine low dose ( $\leq 400 \mathrm{mg} /$ day) and high dose (> $800 \mathrm{mg} /$ day - all medium term, RR $2.70,95 \% \mathrm{Cl} 1.34$ to 5.44 , Analysis 2.2).

\subsection{Adverse effects: 1. Central nervous system - extrapyramidal symptoms}

\subsubsection{Akathisia}

In this subgroup we identified one relevant trial $(n=416$, Prien 1968) reporting no evidence of a clear difference between chlorpromazine low dose ( $\leq 400 \mathrm{mg} /$ day) and high dose (>800 mg/ day - all medium term, RR 1.00, (95\% Cl 0.55 to 1.83 , Analysis 2.3 ).

\subsubsection{Dystonia}

Within this subgroup we identified one relevant trial $(n=416$, Prien 1968) reporting evidence of a clear difference between chlorpromazine low dose ( $\leq 400 \mathrm{mg} /$ day) and high dose $(>800 \mathrm{mg} /$ day - all medium term, RR $0.11,95 \% \mathrm{Cl} 0.02$ to 0.45 , Analysis 2.3 ).

\subsubsection{Parkinsonian reaction}

Within this subgroup we identified one relevant trial $(n=416$, Prien 1968) reporting evidence of a clear difference between chlorpromazine low dose ( $\leq 400 \mathrm{mg} /$ day) and high dose $(>800 \mathrm{mg} /$ day - all medium term, RR $0.52,95 \% \mathrm{Cl} 0.30$ to 0.90 , Analysis 2.3 ).

\subsubsection{Required antiparkinsonian medication}

In this subgroup we identified one relevant trial $(n=416$, Prien 1968). This single study found evidence of a clear difference between chlorpromazine low dose ( $\leq 400 \mathrm{mg} /$ day) and high dose (> $800 \mathrm{mg}$ /day - all medium term, RR $0.39,95 \% \mathrm{Cl} 0.26$ to 0.59 , Analysis 2.3).

\subsubsection{Unspecified}

Within this subgroup we identified one relevant trial $(n=416$, Prien 1968) reporting evidence of a clear difference between chlorpromazine low dose ( $\leq 400 \mathrm{mg} /$ day) and high dose (>800 mg/ day - all medium term, RR $0.43,95 \% \mathrm{Cl} 0.32$ to 0.59 , Analysis 2.3 ).

\subsection{Adverse effects: 2. Anticholinergic symptoms}

We reported the broad range of adverse effects under subheadings such as anticholinergic, cardiovascular, central nervous system, etc. We found that this method of categorisation allowed the data to be inputted clearly without losing too much detail.

We used subheading of adverse effects in keeping with those used in 'Comparison 1' above.

\subsubsection{Blurred vision}

In this subgroup we identified one relevant trial ( $n=416$, Prien 1968) reporting no evidence of a clear difference between chlorpromazine low dose ( $\leq 400 \mathrm{mg} /$ day) and high dose (>800 mg/ day - all medium term, RR $0.20,95 \% \mathrm{Cl} 0.01$ to 4.14 , Analysis 2.4 ).

\subsubsection{Constipation}

In this subgroup we identified one relevant trial $(n=416$, Prien 1968). This single study found evidence of a clear difference between chlorpromazine low dose ( $\leq 400 \mathrm{mg} /$ day) and high dose (> $800 \mathrm{mg}$ /day - all medium term, RR $0.27,95 \% \mathrm{Cl} 0.09$ to 0.79 , Analysis 2.4).

\subsubsection{Salivation - too little (dry mouth)}

Within this subgroup we identified one relevant trial $(n=416$, Prien 1968) reporting evidence of a clear difference between chlorpromazine low dose $(\leq 400 \mathrm{mg} /$ day $)$ and high dose $(>800 \mathrm{mg} /$ day - all medium term, RR $0.2195 \% \mathrm{Cl} 0.07$, to 0.61 , Analysis 2.4 ).

\subsubsection{Salivation - too much}

In this subgroup we identified one relevant trial ( $n=416$, Prien 1968). This single study found evidence of a clear difference between chlorpromazine low dose ( $\leq 400 \mathrm{mg} /$ day) and high dose (> $800 \mathrm{mg} /$ day - all medium term, RR $0.20,95 \% \mathrm{Cl} 0.04$ to 0.90 , Analysis 2.4).

\subsubsection{Urinary disturbance}

In this subgroup we identified one relevant trial $(n=416$, Prien 1968). This single study found no evidence of a clear difference between chlorpromazine low dose ( $\leq 400 \mathrm{mg} /$ day) and high dose (> $800 \mathrm{mg}$ /day - all medium term, RR $0.50,95 \% \mathrm{Cl} 0.09$ to 2.70 , Analysis 2.4).

\subsection{Adverse effects: 3. Central nervous system - other than extrapyramidal symptoms}

Prien 1968 provided data on specific central nervous system adverse effects $(n=416)$.

\subsubsection{Drowsiness}

Within this subgroup we identified one relevant trial $(n=416$, Prien 1968) reporting evidence of a clear difference between chlorpromazine low dose ( $\leq 400 \mathrm{mg} /$ day) and high dose $>800 \mathrm{mg} /$ day - all medium term, RR $0.39,95 \% \mathrm{Cl} 0.27$ to 0.57 , Analysis 2.5 ).

\subsubsection{Seizures}

The single study found evidence of a clear difference between chlorpromazine low dose $(\leq 400 \mathrm{mg} /$ day $)$ and high dose $(>800 \mathrm{mg} /$ day - all medium term, RR $0.1795 \% \mathrm{Cl} 0.04$ to 0.74 , Analysis 2.5 ). 


\subsection{Adverse effects: 4. Cardiovascular}

Prien 1968 provided data on specific cardiovascular adverse effects $(n=416)$. These were kept under separate subgroup headings under 'cardiovascular' in order to not lose detail.

\subsubsection{Dizziness, faintness}

The single study found evidence of a clear difference between chlorpromazine low dose ( $\leq 400 \mathrm{mg} /$ day) and high dose $(>800 \mathrm{mg} /$ day - all medium term, RR $0.30,95 \% \mathrm{Cl} 0.16$ to 0.56 , Analysis 2.6).

\subsubsection{Peripheral oedema}

Prien 1968 reported no evidence of a clear difference between chlorpromazine low dose ( $\leq 400 \mathrm{mg} /$ day) and high dose ( $>800 \mathrm{mg} /$ day - all medium term, RR $0.33,95 \% \mathrm{Cl} 0.07$ to 1.63, Analysis 2.6).

\subsubsection{Syncope}

This single study found no evidence of a clear difference between chlorpromazine low dose ( $\leq 400 \mathrm{mg} /$ day) and high dose (> $800 \mathrm{mg}$ / day - all medium term, RR $0.50,95 \% \mathrm{Cl} 0.09$ to 2.70 , Analysis 2.6).

\subsection{Adverse effects: 5. Dermatological}

\subsubsection{Photosensitivity}

Within this subgroup we identified one relevant trial $(n=416$, Prien 1968) reporting evidence of a clear difference between chlorpromazine low dose ( $\leq 400 \mathrm{mg} /$ day) and high dose $(>800 \mathrm{mg} /$ day - all medium term, RR $0.09,95 \% \mathrm{Cl} 0.03$ to 0.24 , Analysis 2.7 ).

\subsubsection{Rashes, itching}

We found one relevant trial $(n=416$, Prien 1968) reporting evidence of a clear difference between chlorpromazine low dose $(\leq 400 \mathrm{mg} /$ day) and high dose (> $800 \mathrm{mg} /$ day - all medium term, RR 0.13, 95\% $\mathrm{Cl} 0.03$ to 0.58 , Analysis 2.7).

\subsection{Adverse effects: 6 . Gastrointestinal}

Prien 1968 provided data on specific gastrointestinal adverse effects. These were kept under separate subgroup headings under 'gastrointestinal' to avoid losing detail.

\subsubsection{Constipation}

There is one relevant trial $(n=416$, Prien 1968). This single study found evidence of a clear difference between chlorpromazine low dose $(\leq 400 \mathrm{mg} /$ day) and high dose $(>800 \mathrm{mg} /$ day - all medium term, RR $0.27,95 \% \mathrm{Cl} 0.09$ to 0.79 , Analysis 2.8 ).

\subsubsection{Diarrhoea}

In this subgroup we identified one relevant trial $(n=416$, Prien 1968) reporting no evidence of a clear difference between chlorpromazine low dose ( $\leq 400 \mathrm{mg} /$ day) and high dose $(>800 \mathrm{mg} /$ day - all medium term, RR $0.50,95 \% \mathrm{Cl} 0.09$ to 2.70 , Analysis 2.8).

\subsubsection{Nausea, vomiting}

We found one relevant trial $(n=416$, Prien 1968). This single study found no evidence of a clear difference between chlorpromazine low dose ( $\leq 400 \mathrm{mg} /$ day) and high dose $(>800 \mathrm{mg} /$ day - all medium term, RR $0.67,95 \% \mathrm{Cl} 0.19$ to 2.33 , Analysis 2.8 ).

\subsection{Adverse effects: 7. Genitourinary}

\subsubsection{Urinary disturbance}

We identified one relevant trial ( $n=416$, Prien 1968). This single study found no evidence of a clear difference between chlorpromazine low dose $(\leq 400 \mathrm{mg} /$ day) and high dose $>800 \mathrm{mg} /$ day - all medium term, RR $0.50,95 \% \mathrm{Cl} 0.09$ to 2.70 , Analysis 2.9 ).

\subsection{Adverse effects: 8 . Others}

The following subgroups were difficult to place under the distinct categories above and so were collectively grouped under 'others'.

\subsubsection{Occular - any corneal and/or lens opacities}

We identified one relevant trial ( $n=416$, Prien 1968) reporting several occular outcomes in a paper we identified only for the 2016 update (Prien 1970). This single study found evidence of a clear difference between chlorpromazine low dose ( $\leq 400 \mathrm{mg} /$ day) and high dose (> $800 \mathrm{mg} /$ day - all medium term, RR $0.35,95 \% \mathrm{Cl}$ 0.23 to 0.52 , Analysis 2.10). From detailed data within Prien 1970 it seems that high dose disproportionally causes corneal difficulties (RR corneal changes $0.07,95 \% \mathrm{Cl} 0.02$ to 0.30 ).

\subsubsection{Nasal congestion}

In this subgroup we identified one relevant trial $(n=416$, Prien 1968). This single study found no evidence of a clear difference between chlorpromazine low dose ( $\leq 400 \mathrm{mg} /$ day) and high dose (> $800 \mathrm{mg} /$ day - all medium term, RR $1.00,95 \% \mathrm{Cl} 0.14$ to 7.03 , Analysis 2.10).

\section{Sensitivity analysis}

Data for only one of the primary outcomes are available. There are data on extrapyramidal side effects but these are not in the long term. So sensitivity analyses can only be carried out for the first primary outcome of global state: no clinically important improvement in global state at medium term.

All trials were randomised. We were therefore unable to undertake a sensitivity analysis on 'implication of randomisation'. Trials were not of the highest methodological quality (Figure 3), but we judged none to be of high risk of bias in enough domains to undertake any meaningful sensitivity analysis.

With regards to assumptions for lost binary data, in this case people lost to follow-up, these made very little difference. The analysis with assumptions made (Analysis 2.1) and the analysis with complete data only are extremely similar.

Data on the primary outcome were from a single trial and so using a random-effects model made no difference whatsoever.

\section{DISCUSSION}

We only have data on low dose ( $\leq 400 \mathrm{mg} /$ day) versus medium dose (401 mg/day to $800 \mathrm{mg} /$ day) and low dose versus high dose (> 800 $\mathrm{mg}$ /day). Despite over 60 years of use, we do not have any long-term data at all and most data relate to less than 12 weeks duration. 


\section{Summary of main results}

\section{COMPARISON 1. CHLORPROMAZINE LOW DOSE ( $\leq 400 \mathrm{mg}$ / day) versus CHLORPROMAZINE MEDIUM DOSE (>800 mg/day)}

Key findings are presented in the Summary of findings for the main comparison for this comparison.

\subsection{Global state: not improved - short term}

We had pre-stated, before seeing data, that this would be a key outcome. However, only one small $(n=60)$ study reported data and only for the short term. These equivocal data are not convincing of a clear benefit of one dosing regimen over another and we graded these as being at 'moderate' risk of bias (moderate = "Further research is likely to have an important impact on our confidence in the estimate of effect and may change the estimate.").

\subsection{Global state: requiring additional medication (sedation with chloral hydrate or a barbiturate $>$ five times)}

Only one small $(n=50)$ study reported data but for the medium term. There was no clear evidence that one dosing regimen was disadvantaged over another with regards to requiring additional medication. We graded these data as being of 'low' quality (low = "Further research is very likely to have an important impact on our confidence in the estimate of effect and is likely to change the estimate.")

\subsection{Mental state: average endpoint score (PANSS total, high = poor)}

Only one small $(n=60)$ study reported data and only for the short term. These questionable data provide no clear evidence of one dosing regimen providing a clear benefit over another and we graded these as being of 'very low' quality (very low = "We are very uncertain about the estimate.”).

\subsection{Leaving the study early - any reason}

Two $(n=70)$ studies reported the data in the short term. These data provided no clear evidence of members of one dosage group being more likely to leave the study early over the other dosage group. Effectively, roughly equal numbers left each group. We graded these data as being of 'moderate' quality. Very few people left these studies relative to trials completed today. There may be important design methods to be learned from or perhaps the lack of people who left early may have been due to past attitudes with ethical implications.

\subsection{Behaviour: agitation and restlessness - medium term (categorised as adverse event)}

Only one $(n=50)$ small study reported these data in the medium term. These equivocal data are not convincing of a clear benefit of one dosing regimen over another and we graded these as being of' 'very low' quality.

\subsection{Adverse effects: extrapyramidal symptoms (unspecified extrapyramidal symptoms - short term)}

Two $(n=108)$ studies reported these data in the short term. We graded these data as being of 'moderate' quality.

\section{COMPARISON 2. CHLORPROMAZINE LOW DOSE ( $\leq 400 \mathrm{mg}$ / day) versus CHLORPROMAZINE HIGH DOSE (>800 mg/day)}

For these results only data from Prien 1968 were available, a study with 416 patients rated at medium term. We graded these data as 'moderate' in quality (moderate $=$ "Further research is likely to have an important impact on our confidence in the estimate of effect and may change the estimate.").

\subsection{Global state: not improved}

A clear benefit of chlorpromazine high dose over chlorpromazine low dose was found.

\subsection{Leaving the study early - any reason}

A clear difference was found between people leaving the study early with a greater amount leaving the study early being from the high dose group with $25 \%$ or participants leaving the highdose group yet only $15 \%$ leaving the low-dose group. Side effects were accredited very often as being the reason for people in the high-dose group leaving the study. Indeed, High doses of chlorpromazine can be cardiotoxic (Lipka 1988). The high number of cardiovascular side effects causing early terminations supports this. Furthermore, one person in the high-dose group died.

\subsection{Behaviour: deterioration of behaviour (categorised as reason to leave early)}

A clear difference was found with a greater deterioration in behaviour in the low-dose chlorpromazine group compared to the high-dose chlorpromazine group.

\subsection{Adverse effects: extrapyramidal symptoms - unspecified}

A clear difference was found with a greater risk of unspecified extrapyramidal symptoms in the high-dosing regimen group compared to the low-dosing regimen group.

\subsection{Adverse event: death}

No evidence of a clear difference between the two dosing regimens was found.

\subsection{Adverse event - occular changes}

Although we did not include this outcome in our list predesignated for use in the 'Summary of findings' table - perhaps we should have. This is important and this review provides evidence that the higher doses of chlorpromazine, in the form they were given in 1967 to 1988 , were toxic to vision ( $800 \mathrm{mg} /$ day - all medium term, RR $0.35,95 \% \mathrm{Cl} 0.23$ to 0.52 ). This finding, in itself may be enough to discourage the use of chlorpromazine at high doses.

\section{Missing outcomes}

Overall, we were able to report on very little data on one of the most highly used antipsychotic drugs. The review authors of the previous version of this review stated that they hoped that better data would be reported on chlorpromazine dose within 50 years. However, this review has found only one entire study to add to the included studies (Xu 2009), but similarly to the other studies, there were no data on general functioning, behaviour, quality of life/satisfaction with treatment, cognitive functioning, service use or cost of care. 


\section{Overall completeness and applicability of evidence}

\section{Completeness}

Considering that chlorpromazine trials have been published since 1968 , it is surprising that we were only able to identify five studies that were usable for our review. Three of these were short term (up to 12 weeks) while two were medium term (13 to 26 weeks). The trials were relatively short as severe adverse effects such as agranulocytosis, aggravation of depression or even death may occur at a later stage and so may be missed entirely or underreported. Indeed, only one death was reported overall and this was in one of the longer trials (Prien 1968). Furthermore, more time may be necessary to improve symptoms causing impairments in social interaction. This aspect of schizophrenia is likely to be of great importance and concern for those with the disorder. Although rather limited data were provided on patient behaviour, there was no reporting of consequences for patients such as social or life skills.

The outcomes reported focused largely on symptoms of adverse effects. However, data on extrapyramidal symptoms (specifically pseudoparkinsonism, tardive dyskinesia and neuroleptic malignant syndrome) were uncommon or indirect. Cost of care was not mentioned in any of the studies. These topic areas should be given more attention in future studies.

\section{Applicability}

Four of these studies were completed in Western countries20 years ago. Xu 2009 was a more recent study completed in China. These reviews are intended for the world, not just westernised civilisations. Therefore, the study completed in China may be in fact more applicable as China houses about one fifth of the world's population.

All usable studies were hospital-based. Though the setting has no influence on our primary outcomes, some of the secondary outcomes, such as general functioning, can not be assessed correctly under these circumstances.

\section{Quality of the evidence}

The quality of evidence was not very high (Figure 3). Although each study stated to be randomised, the random sequence generation was not described satisfactorily as no unequivocal details were reported. Wode-Helgodt 1978 refers to Armitage 1971, in which their method of restricted randomisation is outlined. Furthermore, allocation concealment was not mentioned in any of the studies. This is particularly surprising and perhaps concerning of Xu 2009 considering how recent the study is. What is more, only Chouinard 1976 and Xu 2009 appeared to be free from selection bias. Nevertheless, all studies except Xu 2009 were blinded correctly with a brief description. Numerous studies were not reported completely (usually missing SD values), or failed to report all the outcomes measured. Although in Chouinard 1976, it is not clear to which treatment group the person who dropped out belonged, we are informed of the last observation carried forward (LOCF) method being employed for the statistical analysis. Clark 1972 did not report to which treatment group people who dropped out belonged, and we were not informed of their approach to analysis for those who dropped out. Furthermore, Prien 1968 does not make clear to the reader how the person who died is accounted for. Clark 1972 may be biased due to their support from Smith, Kline and
French Laboratories. The other studies appeared to be free from other biases.

To conclude, it is likely that there should be an over-estimation of the positive effect of the experimental intervention due to the degree of bias in the included studies (Jüni 2001). Although Clark 1972 was industry-sponsored, it is not an innovative treatment being tested experimentally but an older treatment being tested for optimum dosage. This may offset the over-estimates expected otherwise.

Regarding heterogeneity, few outcomes have more than one study and for those that do, there is no suggestion of heterogeneity from visual inspection or the $1^{2}$ statistic.

\section{Potential biases in the review process}

We may have introduced a potential bias in this update by reading the original review before updating it (Liu 2009).

A potential bias may have been introduced when we did not adhere to the Methods in one instance (see Differences between protocol and review).

Cooper 1973 and Curry 1976 were not randomised and so had to be excluded outright. Andrews 1976; Bartko 1988; Clark 1978; Crane 1968; Janakiramaiah 1982 reported data in a way that made them unusable. Furthermore, Crane 1968 made no data available before the cross-over and so was unusable.

Xu 2009 was the only study for which we could report all the outcomes. In the remaining included studies only a proportion of the outcomes were reported in a usable way. It is possible that the trialists reported outcomes clearly only if they regarded them as important, prohibiting inclusion of potentially meaningful findings. Nonetheless, the studies do not present findings that we would regard with high suspicion of obvious bias.

\section{Agreements and disagreements with other studies or reviews}

We updated the review and checked the information in the previous version of the review. Overall, the updated review is in agreement with the original review (Liu 2009).

We know of no past reviews on this particular area before the original review. The dose analyses of the past have tended to add together several comparisons rather than keeping the data on one compound separate (Davis 1974). We do appreciate how this perspective can also be useful, but it was not the focus of this review.

With new and innovative antipsychotics surfacing, it is unlikely that there would be a renewed commercial interest in chlorpromazine. There is not a potential to make a lot of money from chlorpromazine and so it is unlikely that the pharmaceutical industry would encourage further trials. The current and previous review has brought to light the lack of good quality and relevant trials surrounding dosage of one of the most widely used drugs for psychotic disorders. Indeed, only one relevant trial could be included since the previous review (Xu 2009). All things considered, we think that a review focusing on chlorpromazine dose remains justified. 


\section{AUTHORS' CONCLUSIONS}

\section{Implications for practice}

\section{For people with schizophrenia}

Chlorpromazine demonstrated to have different effects when used in varying doses. When low dose and medium dose are compared in practice, the latter possesses few advantages. There will be less withdrawal retardation in the short term for those taking a medium dose of chlorpromazine. However, there are shortterm symptoms of muscle tension, unspecified extrapyramidal symptoms and abnormal electrocardiogram and in the medium term, and sedation is more likely when taking chlorpromazine at a medium dose. However, the four studies investigating low dose and medium dose are relatively small. For this reason we can not be certain of the reliability of these results. Data on the outcomes were mostly from single studies and as they were quite small, they do not have great statistical power overall.

There is a clinically important improvement when highdose chlorpromazine is given in comparison to low-dose chlorpromazine. However, there were numerous adverse effects more likely to occur when taking a high dose of chlorpromazine. Patients in the high-dose group were more likely to have deterioration of behaviour, constipation, dry mouth, excess salivation, extrapyramidal symptoms (dystonia, parkinsonian reaction), drowsiness, seizures, dizziness and faintness, rashes and itching, photosensitivity and corneal/lens opacities. Furthermore, it must be said that one patient in the high-dose group died after a grand mal seizure even though death was not statistically significant. Being a large study of 208 participants per treatment group, Prien 1968 provides the second comparison with far more statistical power.

\section{For clinicians}

The rarity of studies being done to investigate the optimal dosage of chlorpromazine is particularly disquieting. Most trials performed date from 20 years ago with the exception of Xu 2009. There were more clinical improvements for those in the medium-dose group compared to the low-dose group and indeed in the high-dose group compared to the low-dose group. However, as expected, the rate of adverse effects increased when given a medium or high dose when compared to low dose. Indeed, one patient in the high-dose group died. Benefits of a high dose do not outweigh the adverse effects. There is a clinically important improvement for $13 \%$ for those taking a high dose compared to a low dose of chlorpromazine, but corneal opacities are a real problem for those in the higher-dose group. What is more, there was no significant difference found between the two groups of those 'severely ill'. In summary, there is no evidence supporting the prescription of high-dose chlorpromazine to a patient. While an adequate trial, investigating medium versus high dose is currently nonexistent, we believe the use of medium-dose chlorpromazine to be preferable.

\section{For managers/policy makers}

We found no data for economic outcomes.

\section{Implications for research}

\section{General}

Chlropromazine is one of the most widely used drugs to treat psychosis. Despite being one of the older antipsychotics, there is a very limited number of studies of limiting quality investigating optimal dose. Four usable studies were performed over 20 years ago, while one was performed more recently (Xu 2009). The older studies could perhaps be forgiven for unusable and missing data due to differences in the past of reporting skills. Even though all data were usable in Xu 2009, there was poor reporting of randomisation, allocation concealment and blinding not in keeping with better reporting of today (CONSORT 2009).

\section{Specific}

\subsection{Reviews}

Further research using existing data is justified. Perhaps it may be possible in the next update of this review to include a comparison of flexible doses of chlorpromazine from which we may be able to learn more. Another possibility for the next update is to incorporate an investigation into ultra-low doses of chlorpromazine in the lowdose group.

It may be possible to further investigate the dose effect using metaregression techniques with data such as those presented in the chlorpromazine versus placebo review (Adams 2014).

Excluded trials posed important questions that could be of relevance to other reviews. We suggest the titles for these reviews (Table 1 ) and already existing Cochrane reviews that these studies may fit into.

\subsection{Trials}

Trials were all hospital-based and mostly compared low and medium dose, mostly over the short term.

Should the investigations using past data prove fruitless, we think, and are rather surprised to think, that chlorpromazine dose comparison trials may still be justified. We realise that designing and conducting such trials takes more investment of thought and care than the simple production of a table in a review, but we have given great consideration to the past work. We therefore suggest guidance for the design of a future study in Table 2. Such a study may be possible in situations where chlorpromazine was a first-line drug and in short supply.

\section{A CKN OWLEDGEMENTS}

We would like to thank the staff at the Cochrane Schizophrenia Group for their help and assistance, in particular Hirsto Girgorov for translating a Russian paper, Jun Xia for her help with Chinese papers and Farhad Shokraneh the Information Scientist. Special thanks to Professor Clive Adams for his guidance and support. We have used the generic text supplied by the Cochrane Schizophrenia Group for the Methods section and adapted it to our needs.

We would like to thank Lorna Lawrence for peer reviewing this review. 


\section{R E F E R E N C E S}

\section{References to studies included in this review}

Chouinard 1976 \{published data only\}

Chouinard G, Annable L. Alpha-methyldopa-chlorpromazine combination in schizophrenic patients. Neuropsychobiology 1976;2(2-3):118-26.

\section{Clark 1972 \{published data only\}}

Clark M, Dubowski K, Colmore J. The effect of chlorpromazine on serum cholesterol in chronic schizophrenic patients. Clinical Pharmacology and Therapeutics 1970;11:883-9.

Clark ML, Ramsey HR, Ragland RE, Rahhal DK, Serafetinides EA, Costiloe JP. Chlorpromazine in chronic schizophrenia behavioral dose-response relationships. Psychopharmacology [Psychopharmacologia] 1970;18(3):260-70.

* Clark ML, Ramsey HR, Rahhal DK, Serafetinides EA, Wood FD, Costiloe JP. Chlorpromazine in chronic schizophrenia. The effect of age and hospitalization on behavioral dose-response relationships. Archives of General Psychiatry 1972;27(4):479-83.

Serafetinides EA, Willis D, Clark ML. EEG dose-response relationships of chlorpromazine in chronic schizophrenia: the effects on the various rhythms and on alpha blocking. Biological Psychiatry 1972;4:251-6.

\section{Prien 1968 \{published data only\}}

Ayd FJ. Neuroleptic therapy for chronic schizophrenia. Diseases of the Nervous System 1972;33(1):35-9. [MEDLINE: 5059687]

De Long SL. Incidence and significance of chlorpromazineinduced eye changes. Diseases of the Nervous System 1968;29:19-22.

Gardos G, Cole JO, LaBrie RA. A 12 year follow up study of chronic schizophrenics. Hospital and Community Psychiatry 1982;33(12):983-4

* Prien RF, Cole JO. High dose chlorpromazine therapy in chronic schizophrenia. Report of National Institute of Mental Health - psychopharmacology research branch collaborative study group. Archives of General Psychiatry 1968;18(4):482-95.

Prien RF, Cole JO, Belkin NF. Relapse in chronic schizophrenics following abrupt withdrawal of tranquillizing medication. British Journal of Psychiatry 1968;115(523):679-86.

Prien RF, DeLong SL, Cole JO, Levine J. Ocular changes occurring with prolonged high dose chlorpromazine therapy. Results from a collaborative study. Archives of General Psychiatry 1970;23(5):464-8.

Prien RF, Levine J, Cole JO. High dose therapy in chronic schizophrenia - trifuoperazine. 121st Annual Meeting of the American Psychiatric Association; 1968 May 13-17; Boston (MA). Boston (MA): American Psychiatric Association, 1968.

Prien RF, Levine J, Cole JO. Indications for high dose chlorpromazine therapy in chronic schizophrenia. Diseases of the Nervous System 1970;31(11):739-45.
Prien RF, Levine J, Switalski RW. Discontinuation of chemotherapy for chronic schizophrenics. Hospital and Community Psychiatry 1971;22(1):4-7. [MEDLINE: 4992967]

Wode-Helgodt 1978 \{published data only\}

* Wode-Helgodt B, Borg S, Fyro B, Sedvall G. Clinical effects and drug concentrations in plasma and cerebrospinal fluid in psychotic patients treated with fixed doses of chlorpromazine. Acta Psychiatrica Scandinavica 1978;58(2):149-73.

Wode-Helgodt B, Eneroth P, Fyro B, Gullberg B, Sedvall G. Effect of chlorpromazine treatment on prolactin levels in cerebrospinal fluid and plasma of psychotic patients. Acta Psychiatrica Scandinavica 1977;56(4):280-93.

Wode-Helgodt B, Fyro B, Gullberg B, Sedvall G. Effect of chlorpromazine treatment on monoamine metabolite levels in cerebrospinal fluid of psychotic patients. Acta Psychiatrica Scandinavica 1977;56(2):129-42.

Xu 2009 \{published data only\}

Xu Y, Gao H, Li M, Li X. Different doses of clozapine and chlorpromazine in the treatment of schizophrenia clinical research. Archives of Psychiatry 2009;22(3):203-4.

\section{References to studies excluded from this review}

\section{Altman 1973 \{published data only\}}

Altman H, Mehta D, Evenson RC, Sletten IW. Behavioral effects of drug therapy on psychogeriatric inpatients: I. chlorpromazine and thioridazine. Journal of the American Geriatrics Society 1973;21(6):241-8.

\section{Andrews 1976 \{published data only\}}

Andrews P, Hall JN, Snaith RP. A controlled trial of phenothiazine withdrawal in chronic schizophrenic patients. British Journal of Psychiatry 1976;128:451-5.

Bartko 1988 \{published data only\}

Bartko G, Sztaniszlav D, Olajos S, Bekesy M. Serum chlorpromazine and prolactin levels in paranoid schizophrenic patients and clinical response. Regional Symposium of the World. European Journal of Psychiatry 1988;2(2):109-17. [PsycINFO]

\section{Borison 1991 \{published data only\}}

Borison RL, Diamond BI, Dren AT. Does sigma receptor antagonism predict clinical antipsychotic efficacy?. Psychopharmacology Bulletin 1991;27(2):103-6.

\section{Caffey 1975 \{published data only\}}

Caffey EM, Prien RF. Practical considerations on treatment with antipsychotic preparations. Zhurnal nevropatologii i psikhiatrii imeni s. S. Korsakova 1975;75(9):1399-401.

\section{Casey 1961 \{published data only\}}

Casey JF, Hollister LE, Klett CJ, Lasky JJ, Caffey EM. Combined drug therapy of chronic schizophrenics. Controlled evaluation of placebo, dextro-amphetamine, imipramine, 
isocarboxazid and trifluoperazine added to maintenance doses of chlorpromazine. American Journal of Psychiatry 1961;117:997-1003.

\section{Chen 2002 \{published data only\}}

Chen L. A comparative study of EEG changes in patients treated by risperidone, chlorpromazine and clozpine. Journal of Qiqihar Medical College 2002;23(5):485-6.

\section{Clark 1960 \{published data only\}}

Clark ML, Johnson PC. Amenorrhea and elevated level of serum cholesterol produced by a trifluoro-methylated phenothiazine (SKF-5354-A). The Endocrine Society April 1960;20:641-6.

\section{Clark 1961 \{published data only\}}

Clark ML, Ray TS, Paredes A, Costiloe JP, Chappell JS, Hagans JA, et al. Chlorpromazine in chronic schizophrenic women: I. Experimental design and effects at maximum point of treatment. Psychopharmacologia 1961;2:107-36.

\section{Clark 1967 \{published data only\}}

Clark M, Dubowski K, Colmore J. The effect of chlorpromazine on serum cholesterol in chronic schizophrenic patients. Clinical Pharmacology and Therapeutics 1970;11:883-9.

* Clark ML, Ray TS, Paredes A, Ragland RE, Costiloe JP, Smith CW, et al. Chlorpromazine in women with chronic schizophrenia: the effect on cholesterol levels and cholesterol-behavior relationships. Psychosomatic Medicine 1967;29(6):634-42. [PUBMED: 5582955]

\section{Clark 1970a \{published data only\}}

Clark M, Dubowski K, Colmore J. The effect of chlorpromazine on serum cholesterol in chronic schizophrenic patients. Clinical Pharmacology and Therapeutics 1970;11:883-9.

Clark ML, Kyriakopoiilos A, Ragland RE. Chlorpromazine in chronic schizophrenic women: its effect on thyroid and liver function in relation to serum cholesterol concentration. Pharmacologia Clinica 1970;2(4):227-30.

\section{Clark 1970b \{published data only\}}

Clark M, Dubowski K, Colmore J. The effect of chlorpromazine on serum cholesterol in chronic schizophrenic patients. Clinical Pharmacology and Therapeutics 1970;11:883-9.

Clark ML, Huber WK, Sakata K, Fowles DC, Serafetinides EA. Molindone in chronic schizophrenia. Clinical Pharmacology and Therapeutics 1970;11(5):680-8.

\section{Clark 1978 \{published data only\}}

Clark ML, Kaul PN. A preliminary report on clinical response and blood levels of chlorpromazine and its sulfoxide during chlorpromazine therapy in chronic schizophrenic patients. In: Gottschalk LA, Merlis S editor(s). Pharmacokinetics of Psychoactive Drugs. New York (NY): Spectrum Publications, 1976:191-7.

* Clark ML, Kaul PN, Whitfield LR. Chlorpromazine kinetics and clinical response. Psychopharmacology Bulletin 1978;14(3):43-5.

\section{Cooper 1973 \{published data only\}}

Cooper SF, Albert JM, Hillel J, Caille G. Plasma-level studies of chlorpromazine following the administration of chlorpromazine hydrochloride and chlorpromazine embonate in chronic schizophrenics. Current Therapeutic Research, Clinical and Experimental 1973;15(2):73-7.

Crane 1968 \{published data only\}

Crane GE. Tardive dyskinesia in schizophrenic patients treated with psychotropic drugs. Agressologie 1968;9(2):209-16. [MEDLINE: 5675488; PsycINFO]

\section{Curry 1976 \{published data only\}}

Curry SH. Antipsychotic drugs. I. chlorpromazine: pharmacokinetics, plasma levels and clinical response. In: Burrows GD, Norman T editor(s). Plasma Levels of Psychotropic Drugs and Clinical Response. New York (NY): Marcel Dekker, 1978.

* Curry SH. Metabolism and kinetics of chlorpromazine in relation to effect. In: Sedvall G, Uvnas B, Zotterman Y editor(s). Antipsychotic Drugs: Pharmacodynamics and Pharmacokinetics. Oxford: Pergamon Press, 1976:343-52.

\section{Danion 1992 \{published data only\}}

Danion JM, Peretti S, Grange D, Bilik M, Imbs JL, Singer L. Effects of chlorpromazine and lorazepam on explicit memory, repetition priming and cognitive skill learning in healthy volunteers. Psychopharmacology [Psychopharmacologia] 1992;108(3):345-51.

\section{Eitan 1992 \{published data only\}}

Eitan N, Levin Y, Ben Artzi E, Levy A, Neumann M. Effects of antipsychotic drugs on memory functions of schizophrenic patients. Acta Psychiatrica Scandinavica 1992;85(1):74-6.

\section{Gibbs 1956 \{published data only\}}

Gibbs JJ, Wilkens B, Lauterbach CG. A controlled clinical psychiatric study of chlorpromazine. Journal of Clinical and Experimental Psychopathology 1957;18:269-83.

* Gibbs JJ, Wilkens B, Lauterbach CG. A controlled clinical psychiatric study of the drug chlorpromazine. American Journal of Psychiatry 1956; Vol. 113:254-5.

Green 1996 \{published data only\}

Green JF, King DJ. The effects of chlorpromazine and lorazepam on abnormal antisaccade and no-saccade distractibility. Biological Psychiatry 1998;44:709-15.

* Green JF, McElholm A, King DJ. A comparison of the sedative and amnestic effects of chlorpromazine and lorazepam. Psychopharmacology 1996;128:67-73.

\section{Hartley 1978 \{published data only\}}

Hartley L, Henry T, Couper-Smartt J. Chlorpromazine and serial reaction performance. British Journal of Psychology 1978;69:271-6.

Janakiramaiah 1982 \{published data only\}

Janakiramaiah N, Channabasavanna SM, Narashimha Murthy NS. ECT-chlorpromazine combination versus 
chlorpromazine alone in acutely schizophrenic patients. Acta Psychiatrica Scandinavica 1982;66(6):464-70.

\section{Jeste 1977 \{published data only\}}

Jeste DV, Olgiati SG, Ghali AY. Masking of tardive dyskinesia with four times-a-day administration of chlorpromazine. Diseases of the Nervous System 1977;38(9):755-8.

\section{Joshi 1982 \{published data only\}}

Joshi VG, Nagesh R, Eswaran S, Nagesh R, Pai M, Matthews G, et al. Vitamins B1, B6, and B12 in the adjunctive treatment of schizophrenia - further studies to examine the effect of reduction of chlorpromazine dosage. Journal of Orthomolecular Psychiatry 1982;11(1):45-9.

\section{Kalyanasundaram 1981 \{published data only\}}

Kalyanasundaram S, Shrikhande SA, Machado TA, Kapur RL. Single daily dose chlorpromazine therapy in psychosis. An evaluation. Acta Psychiatrica Scandinavica 1981;64(2):158-66.

\section{Lehmann 1983 \{published data only\}}

Lehmann HE, Wilson WH, Deutsch M. Minimal maintenance medication: effects of three dose schedules on relapse rates and symptoms in chronic schizophrenic outpatients. Comprehensive Psychiatry 1983; Vol. 24, issue 4:293-303. [MEDLINE: 6136389]

\section{Ota 1974 \{published data only\}}

Ota KY, Kurland AA, Rocha J, Block BA. A comparison of the relative clinical efficacy of two chlorpromazine (CPZ) preparations. Current Therapeutic Research, Clinical and Experimental 1974;16(9):1014-21.

\section{Pigache 1993 \{published data only\}}

Pigache RM. Effects of placebo, orphenadrine, and rising doses of chlorpromazine, on PAT performance in chronic schizophrenia. A two year longitudinal study. Schizophrenia Research 1993;10(1):51-9.

\section{Schiele 1959 \{published data only\}}

Schiele B. Comparison of low and high dosage procedures in chlorpromazine therapy. Psychiatric Quarterly 1959;33:252-9.

\section{Sukegawa 2008 \{published data only\}}

Sukegawa T, Ito T, Hasegawa M, Mizuno Y, Inagaki A, Sakamoto $\mathrm{H}$, et al. A randomized controlled trial on the dose reduction and simplification for polypharmacy of antipsychotics. Tottori Journal of Clinical Research 2008;1:169-81.

\section{Sukegawa 2012 \{published data only\}}

Sukegawa T. Implementation of appropriate administration of antipsychotics - measures to reduce high-dose multiple antipsychotics. Nihon Rinsho 2013;71(4):712-7.

Sukegawa T. Measures to reduce high-dose multiple antipsychotics in Japan. Seishin Shinkeigaku Zasshi 2012;114(6):696-701.
Sukegawa 2014 \{published data only\}

Sukegawa T, Inagaki A, Yamanouchi Y, Inada T, Yoshio T, Yoshimura R, et al. Study protocol: safety correction of high dose antipsychotic polypharmacy in Japan. BMC Psychiatry 2014;14(1):103

\section{Yuan-Guang 1994 \{published data only\}}

Yuan-Guang C, Guang-Rong X, Jing Ping Z. A study on the relationship between the chlorpromazine plasma levels and clinical response to chlorpromazine administrations in the schizophrenics. Chinese Journal of Neurology and Psychiatry 1994;27(3):153-5.

\section{Additional references}

\section{Adams 2013}

Adams CE, Bergman H, Irving CB, Lawrie S. Haloperidol versus placebo for schizophrenia. Cochrane Database of Systematic Reviews. John Wiley \& Sons, Ltd, 2013, issue 11. [DOI: 10.1002/14651858.CD003082.pub3; CD003082]

\section{Adams 2014}

Adams CE, Awad G, Rathbone J, Thornley B, SoaresWeiser K. Chlorpromazine versus placebo for schizophrenia. Cochrane Database of Systematic Reviews 2014, Issue 1. [DOI: 10.1002/14651858.CD000284.pub3]

\section{Altman 1996}

Altman DG, Bland JM. Detecting skewness from summary information. BMJ 1996;313:1200. [OLZ020600]

\section{Armitage 1971}

Armitage P. Statistical Methods in Medical Research. OxfordEdinburgh (UK): Blackwell Scientific Publications, 1971.

\section{Barbato 1998}

Barbato A. Schizophrenia and Public Health. Geneva: World Health Organization, 1998. [WHO/MSA/NAM/97.6]

\section{Bazire 2014}

Bazire S. Psychotropic Drug Directory 2014. Norwich (UK): Page Bros Ltd, 2014.

\section{Bland 1997}

Bland JM. Statistics notes. Trials randomised in clusters. BMJ 1997;315:600.

\section{BNF 2014}

Joint Fomulary Committee. British National Formulary. 8th Edition. London (UK): BMJ Group and Pharmaceutical Press, 2014.

\section{Boissel 1999}

Boissel JP, Cucherat M, Li W, Chatellier G, Gueyffier F, Buyse $M$, et al. The problem of therapeutic efficacy indices. 3. Comparison of the indices and their use [Aperçu sur la problématique des indices d'efficacité thérapeutique, 3 : comparaison des indices et utilisation. Groupe d'Etude des Indices D'efficacite]. Therapie 1999;54(4):405-11. 


\section{Bollini 1994}

Bollini P. Antipsychotic drugs: is more worse? A meta analysis of the published randomised control trials. Psychological Medicine 1994;24:307-16.

\section{Carpenter 1994}

Carpenter WT Jr, Buchanan RW. Schizophrenia. New England Journal of Medicine 1994;330(10):681-90.

\section{Clark 1970}

Clark M, Dubowski K, Colmore J. The effect of chlorpromazine on serum cholesterol in chronic schizophrenic patients. Clinical Pharmacology and Therapeutics 1970;11:883-9.

\section{Davis 1974}

David JM. Dose equivalence of the antipsychotic drugs. Journal of Psychiatric Research 1974;11:65-9.

\section{de Oliveira Marques 2004}

de Oliveira Marques L, Soares B, de Lima MS. Trifluoperazine for schizophrenia. Cochrane Database of Systematic Reviews. John Wiley \& Sons, Ltd, 2004, issue 1. [DOI: 10.1002/14651858.CD003545.pub2; CD003545]

\section{Deeks 2000}

Deeks J. Issues in the selection for meta-analyses of binary data. 8th International Cochrane Colloquium; 2000 Oct 25-28th; Cape Town, South Africa. Cape Town, 2000.

\section{Deeks 2011}

Deeks JJ, Higgins JPT, Altman DG editor(s). Chapter 9: Analysing data and undertaking meta-analyses. In: Higgins JPT, Green S editor(s). Cochrane Handbook for Systematic Reviews of Interventions Version 5.1.0 (updated March 2011). The Cochrane Collaboration, 2011. Available from handbook.cochrane.org.

\section{Divine 1992}

Divine GW, Brown JT, Frazer LM. The unit of analysis error in studies about physicians' patient care behavior. Journal of General Internal Medicine 1992;7:623-9.

\section{Dold 2015}

Dold M, Samara MT, Li C, Tardy M, Leucht S. Haloperidol versus first-generation antipsychotics for the treatment of schizophrenia and other psychotic disorders. Cochrane Database of Systematic Reviews. John Wiley \& Sons, Ltd, 2015, issue 1. [DOI: 10.1002/14651858.CD009831.pub2; CD009831]

\section{Donner 2002}

Donner A, Klar N. Issues in the meta-analysis of cluster randomized trials. Statistics in Medicine 2002;21:2971-80.

\section{Egger 1997}

Egger M, Davey-Smith G, Schneider M, Minder CSO. Bias in meta-analysis detected by a simple, graphical test. BMJ 1997;13:629-34.

\section{Elbourne 2002}

Elbourne DR, Altman DG, Higgins JP, Curtin F, Worthington HV, Vail A. Meta-analyses involving cross-over trials: methodological issues. International Journal of Epidemiology 2002;31(1):140-9.

\section{Endicott 1976}

Endicott J, Spitzer R, Gleiss J, Cohen CJ. The global assessment scale. A procedure to measuring overall severity of psychiatric disturbance. Archives of General Psychiatry 1976;33:766-71.

\section{Essali 2009}

Essali A, Al-Haj HN, Li C, Rathbone J. Clozapine versus typical neuroleptic medication for schizophrenia. Cochrane Database of Systematic Reviews. John Wiley \& Sons, Ltd, 2009, issue 1. [DOI: 10.1002/14651858.CD000059.pub2; CD000059]

\section{Fenton 2007}

Fenton M, Rathbone J, Reilly J. Thioridazine for schizophrenia. Cochrane Database of Systematic Reviews. John Wiley \& Sons, Ltd, 2007, issue 3. [DOI: 10.1002/14651858.CD001944.pub2; CD001944]

\section{Furukawa 2006}

Furukawa TA, Barbui C, Cipriani A, Brambilla P, Watanabe N. Imputing missing standard deviations in meta-analyses can provide accurate results. Journal of Clinical Epidemiology 2006;59(7):7-10.

\section{Geddes 2000}

Geddes JR, Freemantle N, Harrison P, Bebbington PE. Atypical antipsychotics in the treatment of schizophrenia: a systematic overview and meta-regression analysis. BMJ 2000;321:1371-6.

\section{Gulliford 1999}

Gulliford MC, Ukoumunne OC, Chinn S. Components of variance and intraclass correlations for the design of communitybased surveys and intervention studies: data from the Health Survey for England 1994. American Journal of Epidemiology 1999;149:876-83.

\section{Guy 1976}

Guy W. Early Clinical Drug Evaluation (ECDEU) Assessment Manual for Psychopharmacology. Washington, DC: National Institute of Mental Health, 1976:217-22.

\section{Higgins 2003}

Higgins JPT, Thompson SG, Deeks JJ, Altman DG. Measuring inconsistency in meta-analyses. BMJ 2003;327:557-60.

\section{Higgins 2008}

Higgins, JPT, Green S, editor(s). Cochrane Handbook for Systematic Reviews of Interventions. Chichester (UK): John Wiley \& Sons, 2008.

\section{Higgins 2011}

Higgins JPT, Green S, editor(s). Chapter 7: Selecting studies and collecting data. In: Higgins JPT, Green S editor(s), Cochrane Handbook for Systematic Reviews of Interventions Version 5.1.0 (updated March 2011). The Cochrane Collaboration, 2011. Available from handbook.cochrane.org.

\section{Higgins 2011a}

Higgins JPT, Altman DG, Sterne JAC, editor(s). Chapter 8: Assessing risk of bias in included studies. In: Higgins JPT, Green S editor(s). Cochrane Handbook for Systematic Reviews of 
Interventions Version 5.1.0 (updated March 2011). The Cochrane Collaboration, 2011. Available from handbook.cochrane.org.

\section{Hunter 2003}

Hunter R, Kennedy E, Song F, Gadon L, Irving CB. Risperidone versus typical antipsychotic medication for schizophrenia. Cochrane Database of Systematic Reviews. John Wiley \& Sons, Ltd, 2003, issue 2. [DOI: 10.1002/14651858.CD000440; CD000440]

\section{Hutton 2009}

Hutton JL. Number needed to treat and number needed to harm are not the best way to report and assess the results of randomised clinical trials. British Journal of Haematology 2009;146(1):27-30.

\section{Jüni 2001}

Jüni P, Altman DG, Egger M. Systematic reviews in health care: assessing the quality of controlled clinical trials. BMJ 2001;323:42-6.

\section{Kay 1986}

Kay SR, Opler LA, Fiszbein A. Positive and Negative Syndrome Scale (PANSS) Manual. North Tonawanda (NY): Multi-Health Systems, 1986.

\section{Koch 2014}

Koch K, Mansi K, Haynes E, Adams CE, Sampson S, Furtado VA. Trifluoperazine versus placebo for schizophrenia. Cochrane Database of Systematic Reviews. John Wiley \& Sons, Ltd, 2014, issue 1. [DOI: 10.1002/14651858.CD010226.pub2; CD010226]

\section{Komossa 2011}

Komossa K, Rummel-Kluge C, Schwarz S, Schmid F, Hunger H, Kissling W, et al. Risperidone versus other atypical antipsychotics for schizophrenia. Cochrane Database of Systematic Reviews. John Wiley \& Sons, Ltd, 2011, issue 1. [DOI: 10.1002/14651858.CD006626.pub2; CD006626]

\section{Kumar 2005}

Kumar A, Strech D. Zuclopenthixol dihydrochloride for schizophrenia. Cochrane Database of Systematic Reviews. John Wiley \& Sons, Ltd, 2005, issue 4. [DOI: 10.1002/14651858.CD005474; CD005474]

\section{Leucht 2003}

Leucht S, Wahlbeck K, Hamann J, Kissling W. New generation antipsychotics versus low-potency conventional antipsychotics: a systematic review and meta-analysis. Lancet 2003;361:1581-9.

\section{Leucht 2005}

Leucht S, Kane JM, Kissling W, Hamann J, Etschel E, Engel RR. What does the PANSS mean?. Schizophrenia Research 2005;79(2-3):231-8. [PUBMED: 15982856]

\section{Leucht 2005a}

Leucht S, Kane JM, Kissling W, Hamann J, Etschel E, Engel R. Clinical implications of brief psychiatric rating scale scores. British Journal of Psychiatry 2005;187:366-71. [PUBMED: 16199797]

\section{Leucht 2008}

Leucht C, Kitzmantel M, Kane J, Leucht S, Chua WL. Haloperidol versus chlorpromazine for schizophrenia. Cochrane Database of Systematic Reviews. John Wiley \& Sons, Ltd, 2008, issue 1. [DOI: 10.1002/14651858.CD004278.pub2; CD004278]

\section{Lipka 1988}

Lipka LJ, Lathers CM, Roberts J. Does chlorpromazine produce cardiac arrhythmia via the central nervous system?. Journal of Clinical Pharmacology 1988;28(11):968-83.

\section{Magalhaes 2016}

Magalhães Pedro VS, Dean O, Andreazza AC, Berk M, Kapczinski F. Antioxidant treatments for schizophrenia. Cochrane Database of Systematic Reviews. John Wiley \& Sons, Ltd, 2016, issue 2. [DOI: 10.1002/14651858.CD008919.pub2; CD008919]

\section{Marshall 2000}

Marshall M, Lockwood A, Bradley C, Adams C, Joy C, Fenton M. Unpublished rating scales: a major source of bias in randomised controlled trials of treatments for schizophrenia. British Journal of Psychiatry 2000;176:249-52.

\section{MHF 2014}

Statistics on Mental Health. Factsheet. Mental Health Foundation 2014.

\section{Overall 1962}

Overall JE, Gorham DR. The brief psychiatric rating scale. Psychological Reports 1962;10:799-812.

\section{Prien 1970}

Prien RF, DeLong SL, Cole JO, Levine J. Ocular changes occurring with prolonged high dose chlorpromazine therapy. Results from a collaborative study. Archives of General Psychiatry 1970;23(5):464-8. [MEDLINE: 5478574; MEDLINE: 71030994]

\section{Rummel-Kluge 2006}

Rummel-Kluge C, Kissling W, Leucht S. Antidepressants for the negative symptoms of schizophrenia. Cochrane Database of Systematic Reviews. John Wiley \& Sons, Ltd, 2006, issue 3. [DOI: 10.1002/14651858.CD005581.pub2; CD005581]

\section{Saha 2016}

Saha KB, Bo L, Zhao S, Xia J, Sampson S, Zaman RU. Chlorpromazine versus atypical antipsychotic drugs for schizophrenia. Cochrane Database of Systematic Reviews. John Wiley \& Sons, Ltd, 2016, issue 4. [DOI: 10.1002/14651858.CD010631.pub2; CD010631]

\section{Schünemann 2008}

Schünemann HJ, Oxman AD, Vist GE, Higgins JPT, Deeks JJ, Glasziou P, et al. Chapter 12: Interpreting results and drawing conclusions. In: Higgins JPT, Green S editor(s). Cochrane Handbook for Systematic Reviews of Interventions. The Cochrane Collaboration, 2008:359-83. 


\section{Schünemann 2011}

Schünemann HJ, Oxman AD, Vist GE, Higgins JPT, Deeks JJ, Glasziou P, et al. Chapter 12: Interpreting results and drawing conclusions. In Higgins JPT, Green S (editors), Cochrane Handbook for Systematic Reviews of Interventions Version 5.1.0 (updated March 2011). The Cochrane Collaboration, 2011. Available from www.cochrane-handbook.org.

\section{Seeman 2002}

Seeman P. Atypical antipsychotics: mechanism of action. Canadian Journal of Psychiatry 2002;47(1):27-38.

\section{Simpson 1970}

Simpson GM, Angus JWS. A rating scale for extrapyramidal side effects. Acta Psychiatrica Scandinavacia 1970;212:11-9.

\section{Sterne 2011}

Sterne JAC, Egger M, Moher D, editor(s). Chapter 10: Addressing reporting biases. In: Higgins JPT, Green S editor(s). Cochrane Handbook for Systematic Reviews of Intervention. Version 5.1.0 (updated March 2011). The Cochrane Collaboration, 2011. Available from handbook.cochrane.org.

\section{Tardy 2014}

Tardy M, Huhn M, Kissling W, Engel RR, Leucht S. Haloperidol versus low-potency first-generation antipsychotic drugs for schizophrenia. Cochrane Database of Systematic Reviews. John Wiley \& Sons, Ltd, 2014, issue 7. [DOI: 10.1002/14651858.CD009268.pub2; CD009268]

\section{Tardy 2014a}

Tardy M, Dold M, Engel RR, Leucht S. Trifluoperazine versus lowpotency first-generation antipsychotic drugs for schizophrenia. Cochrane Database of Systematic Reviews. John Wiley \& Sons, Ltd, 2014, issue 7. [DOI: 10.1002/14651858.CD009396.pub2; CD009396]

\section{Turner 2007}

Turner T. Chlorpromazine: unlocking psychosis. BMJ 2007;334(Suppl 1):s7. [PUBMED: 17204765]

\section{Tuunainen 2000}

Tuunainen A, Wahlbeck K. Newer atypical antipsychotic medication versus clozapine for schizophrenia. Cochrane

\section{CHARACTERISTICS OF STUDIES}

Characteristics of included studies [ordered by study ID]
Database of Systematic Reviews. John Wiley \& Sons, Ltd, 2000, issue 2. [DOI: 10.1002/14651858.CD000966; CD000966]

\section{Ukoumunne 1999}

Ukoumunne OC, Gulliford MC, Chinn S, Sterne JAC, Burney PGJ. Methods for evaluating area-wide and organisation-based intervention in health and health care: a systematic review. Health Technology Assessment 1999;3(5):1-75.

\section{Weinberger 2001}

Weinberger DR, Egan MF, Bertolino A, Callicott JH, Mattay VS, Lipska BK, et al. Prefrontal neurons and the genetics of schizophrenia. Biological Psychiatry 2001;50(11):825-44.

\section{Weinberger 2011}

Weinberger DR, Harrison PJ. Schizophrenia. 3rd Edition. Chichester (UK): Wiley-Blackwell, 2011.

\section{WHO 2001}

World Health Organisation. The World Health Report 2001 Mental Health: New Understanding, New Hope. www.who.int/ whr/2001/en/ (accessed 20 January 2017).

\section{WHO 2013}

World Health Organisation. WHO Model List of Essential Medicines. apps.who.int/iris/bitstream/10665/93142/1/ EML_18_eng.pdf?ua=1. 18th (April 2013) (accessed 20 January 2017).

\section{Xia 2009}

Xia J, Adams CE, Bhagat N, Bhagat V, Bhoopathi P, El-Sayeh H, et al. Loss to outcomes stakeholder survey: the LOSS study. Psychiatric Bulletin 2009;33(7):254-7.

\section{References to other published versions of this review Liu 2009}

Liu X, De Haan S. Chlorpromazine dose for people with schizophrenia. Cochrane Database of Systematic Reviews 2009, Issue 2. [DOI: 10.1002/14651858.CD007778]

* Indicates the major publication for the study

Chouinard 1976

Methods Allocation: randomised - block randomised into 11 groups. Blindness: double-blind.

Duration: 8 weeks (after 2 weeks of stabilisation).

Diagnosis: schizophrenia.
Participants 55.
Age: $20-57$ (mean 38.5).
Sex: 30 males, 25 females.
History: a primary hospital diagnosis of schizophrenia confirmed by the research psychiatrist; pres-
ence of two or more of the following symptoms or behaviours: thought or speech disturbances, cata-


Chouinard 1976 (Continued)

tonic motor behaviour, paranoid ideation, hallucinations, delusional thinking other than paranoid, blunted or inappropriate affect and disturbance of social behaviour and interpersonal relations.

Excluded: patients with physical illness, childhood schizophrenia, chronic or acute brain syndrome, mental deficiency (IQ below 70), alcoholism, epilepsy or drug addiction.

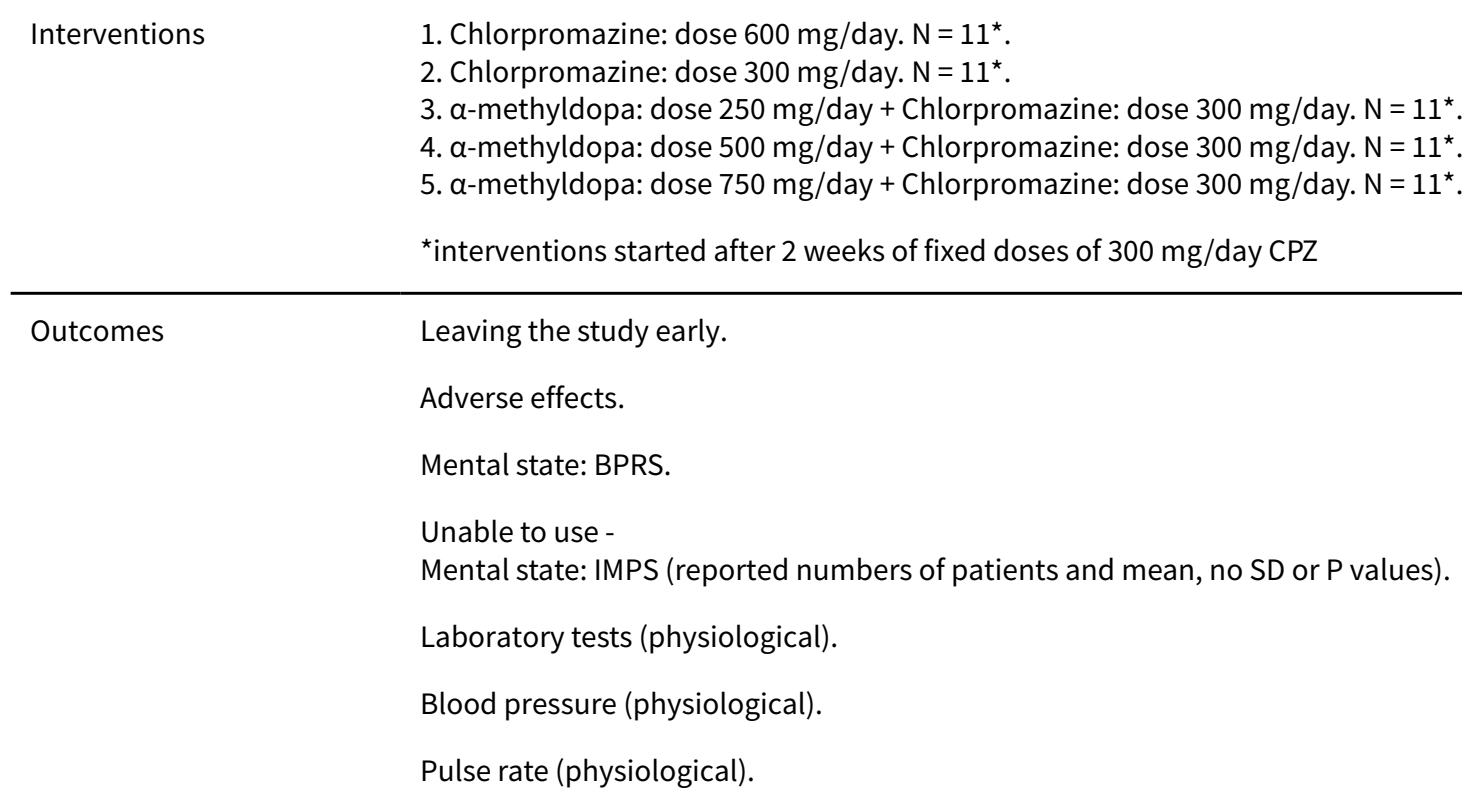

Notes

Lost to follow-up: 1 patient lost during 5th week, assumed not treatment related. Reason given: he had a habit of leaving the hospital without authorisation. Unclear which treatment group he belonged to. Plan to assume that from one of the $\alpha$-methyldopa groups ( $3 / 5$ chance of this).

\section{Risk of bias}

\begin{tabular}{|c|c|c|}
\hline Bias & Authors' judgement & Support for judgement \\
\hline $\begin{array}{l}\text { Random sequence genera- } \\
\text { tion (selection bias) }\end{array}$ & Unclear risk & $\begin{array}{l}\text { Quote: "within a block: patients were then randomly assigned" pp119, p3. } \\
\text { Comment: Block randomised, no further details. }\end{array}$ \\
\hline $\begin{array}{l}\text { Allocation concealment } \\
\text { (selection bias) }\end{array}$ & Unclear risk & Not mentioned. \\
\hline $\begin{array}{l}\text { Blinding (performance } \\
\text { bias and detection bias) } \\
\text { All outcomes }\end{array}$ & Low risk & $\begin{array}{l}\text { Quote: "double-blind conditions", "identical-appearing tablets...administered } \\
\text { three times a day" pp119, p6. } \\
\text { Comment: probably done (double, tablets of identical appearance, same } \\
\text { amount of tablets and treatment scheme to all patients). }\end{array}$ \\
\hline $\begin{array}{l}\text { Incomplete outcome data } \\
\text { (attrition bias) } \\
\text { All outcomes }\end{array}$ & Unclear risk & $\begin{array}{l}\text { Quote: "one male patient left the hospital without authorization during the 5th } \\
\text { week of treatment" pp120, p4. } \\
\text { Comment: } 1 \text { person lost to follow-up, data at the time of loss ( } 5 \text { th week) re- } \\
\text { ported as end data. }\end{array}$ \\
\hline $\begin{array}{l}\text { Selective reporting (re- } \\
\text { porting bias) }\end{array}$ & Low risk & All outcomes reported. \\
\hline Other bias & Low risk & $\begin{array}{l}\text { Quote: "This study was supported in part by the Medical Research Council of } \\
\text { Canada and by an FCAC grant (Financial Consumer Agency of Canada, Que- } \\
\text { bec)" pp125,p3. }\end{array}$ \\
\hline
\end{tabular}


Clark 1972

$\begin{array}{ll}\text { Methods } & \text { Allocation: randomised - block randomised but not specified how. } \\ \text { Blindness: double-blind. } \\ \text { Duration: } 24 \text { weeks (after } 12 \text { weeks of 'dry-out'). }\end{array}$

Duration: 24 weeks (after 12 weeks of 'dry-out').

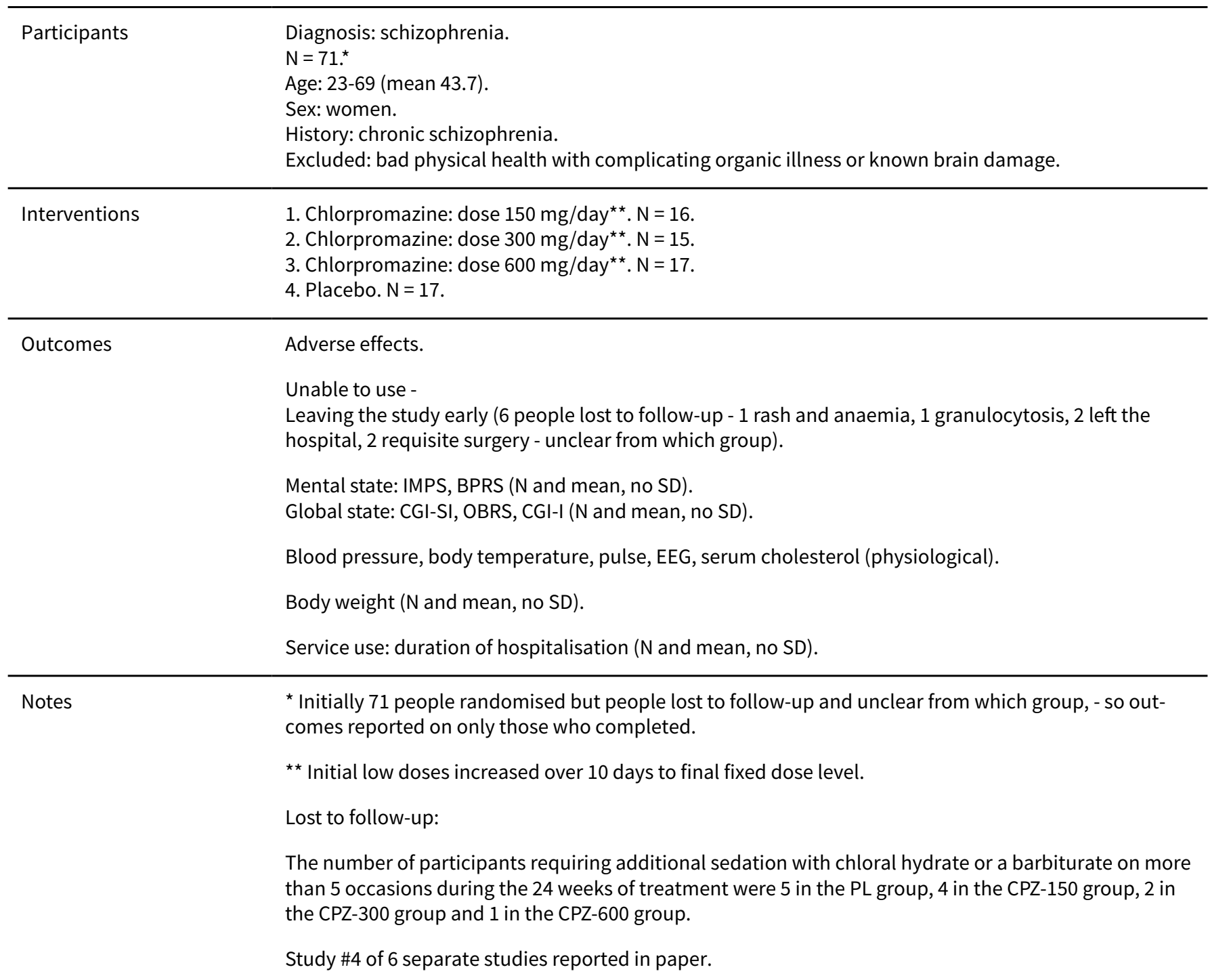

\section{Risk of bias}

Bias Authors' judgement Support for judgement

Random sequence genera- Unclear risk tion (selection bias)

Quote: "each treatment group was first subdivided by age at the time of beginning the study" pp479, p6

Comment: Block randomisation, no details.

\begin{tabular}{lll}
\hline $\begin{array}{l}\text { Allocation concealment } \\
\text { (selection bias) }\end{array}$ & Unclear risk & Not mentioned. \\
\hline $\begin{array}{l}\text { Blinding (performance } \\
\text { bias and detection bias) } \\
\text { All outcomes }\end{array}$ & Low risk & $\begin{array}{l}\text { Quote: "double-blind study" pp479, p5; "all patients received the same volume } \\
\text { of medication (10 mL twice daily) but in different concentration" pp262, p1 }\end{array}$ \\
\hline
\end{tabular}


Clark 1972 (Continued)

Comment: probably done.

\begin{tabular}{ll}
\hline $\begin{array}{l}\text { Incomplete outcome data } \\
\text { (attrition bias) }\end{array}$ & High risk \\
All outcomes & Comment: $8 \%$ loss to follow-up ignored in analyses.
\end{tabular}

Selective reporting (re- High risk
porting bias)
Quote: "one subject dropped out because of rash and anaemia, one because of agranulocytosis, two because of elopement from the hospital and two be- cause of requisite surgery" pp263, p2.
Comment: clinical outcomes reported by group of allocation, leaving the study not reported by group of allocation.

\begin{tabular}{ll}
\hline Other bias & $\begin{array}{l}\text { Quote: "The authors are grateful to Mr. Robert C. Zwahlen of Smith, Kline and } \\
\text { French Laboratories for generous supplies of medication for this study" pp269, } \\
\text { p5. }\end{array}$ \\
Comment: we are unclear if this support went beyond supply of medication.
\end{tabular}

Prien 1968

\begin{tabular}{ll} 
Methods & Allocation: randomised. \\
& Blindness: double-blind. \\
& Duration: 24 weeks. \\
\hline Participants & Diagnosis: schizophrenia. \\
& A $=838$. \\
& Se: $19-55$ (mean 41.6). \\
& History: chronic schizophrenia. \\
& Excluded: organic brain disease (including lobotomy), mental deficiency $($ IQ $<70$ ), medical conditions \\
& constraining use of high doses.
\end{tabular}

\begin{tabular}{ll}
\hline Interventions & 1. Chlorpromazine: dose $300 \mathrm{mg} /$ day. $\mathrm{N}=208$. \\
2. Chlorpromazine: dose $2000 \mathrm{mg} /$ day. $\mathrm{N}=208^{*}$. & \\
& 3. Conventional treatment (doctor's choice). $\mathrm{N}=210$. \\
& 4. Placebo. $\mathrm{N}=212$. \\
& * In gradual increasing doses, reaching the maximal doses after 45 days. \\
\hline Outcomes & Global state: GIS, GSIS, GAS, relapse. \\
& Adverse effects. \\
& Leaving the study early. \\
& Unable to use - \\
Global state: relapse (only data of placebo group reported), failure of therapy (not specified for the en- \\
tire group of low dose CPZ). \\
Service outcomes: DRI (no data specified). \\
Mental state: IMPS (no data specified). \\
Behaviour: NOSIE (no data specified). \\
Ocular changes (lens change, corneal change, skin changes, photosensitivity, visual acuity). \\
\hline Notes
\end{tabular}

\section{Risk of bias}


Prien 1968 (Continued)

\section{Bias Authors' judgement Support for judgement}

Random sequence genera- Unclear risk Quote: "randomly assigned to four treatment groups" pp483, p5.

tion (selection bias)

Comment: no details provided.

Allocation concealment $\quad$ Unclear risk $\quad$ Not mentioned.
(selection bias)

\begin{tabular}{|c|c|c|}
\hline $\begin{array}{l}\text { Blinding (performance } \\
\text { bias and detection bias) }\end{array}$ & Low risk & $\begin{array}{l}\text { Quote: "The low dose and placebo group also received liquid concentrate, on } \\
\text { a double-blind basis" pp483, p6. }\end{array}$ \\
\hline
\end{tabular}

All outcomes

Comment: identical liquid administration. Blinding probably done.

Incomplete outcome data Low risk

(attrition bias)

All outcomes
Lost to follow-up: 51 of high dose group (41 disabling adverse effects, 10 other), 31 of low-dose group (4 disabling adverse effects, 27 other).

Selective reporting (re- High risk
porting bias)

No SD for several outcomes, several outcomes not reported (see above). Only data of patients evaluated by same rater at pretreatment and termination reported in general state, CGI-SI (aka GSIS) - reviewers equally divided remaining patients over low- and high-dose groups, assuming similar rates of adverse effects for those who did have data recorded (see Methods, Missing data).

Other bias Low risk

Quote: "This investigation was supported by Public Health Service grants...from the National Institute of Mental Health, and Public Health Service" pp494,p6.

Wode-Helgodt 1978

$\begin{array}{ll}\text { Methods } & \text { Allocation: randomised. } \\ & \text { Blindness: double-blind. } \\ & \text { Duration: } 4 \text { weeks (after } 7 \text { days placebo). }\end{array}$

Diagnosis: psychosis of schizophrenic type.
Participants
Age: $19-57$ years, mean 30 years.
Sex: 20 males, 28 females.
History: emergency ward patients. Presence of thought disorder, delusions or auditory hallucinations.
Excluded: antipsychotic drug treatment during month preceding study, presence of complicating so-
matic illness or organic brain disease, alcoholism or drug abuse, manic or depressive psychosis, bor-
derline cases, those admitted with confusional state when psychotic symptoms did not persist when
confusion cleared, unable to co-operate, showing severe suicidal or aggressive impulses.

1. Chlorpromazine: dose $200 \mathrm{mg} /$ day. $\mathrm{N}=15$.
2. Chlorpromazine: dose $400 \mathrm{mg} /$ day. $\mathrm{N}=18$.
3. Chlorpromazine: dose $600 \mathrm{mg} /$ day. $\mathrm{N}=15$.

Additional medication: Nitrazepam 5-10 mg ( $\mathrm{N}=30)$ for sleep, diazepam $5 \mathrm{mg}(\mathrm{N}=18)$ for daytime sedation - not reported by group. Commented as: results not deviating significantly from those of the remaining patients, therefore additional medication was disregarded in final evaluation.

Leaving the study early.
Adverse effects: modified Simpson and Angus.


Wode-Helgodt 1978 (Continued)

Unable to use -

Mental state: CPRS (presented in graphical form, unable to extract data).

General functioning: GRS (presented in graphical form, unable to extract data).

Prolactin levels in CSF (physiological).

Prolactin levels in plasma (physiological).

Total prolactin, FSH, LH, TSH and oestradiol in CSF (physiological).

Total prolactin, FSH, LH, TSH and oestradiol in plasma (physiological).

Monoamine metabolite (HVA, MOPEG and 5-HIAA) levels in CSF (physiological).

Notes

One man had diabetes mellitus and was treated with insulin (64 IU daily). Commented that the results obtained with this patient were similar to those seen in the rest of the group.

\section{Risk of bias}

\section{Bias}

Random sequence genera- Low risk tion (selection bias)

\section{Authors' judgement Support for judgement}

Quote: "A research assistant not involved in the project attempted to assign an equal number of men and women to each dose using the technique of restricted randomisation (Armitage (1971))" pp152, p1.

Comment: Stratified randomisation attempted. Armitage 1971 was referenced with no further explanation.

Allocation concealment Unclear risk Not mentioned.

(selection bias)

Blinding (performance Low risk

bias and detection bias)

All outcomes
Quote: "For drug administration the "double-dummy technique" was used, i.e. every patient received the same total number of tablets containing CPZ or placebo. The appearance of the placebo tablets was identical to those containing CPZ" pp152, p1.

Comment: double-dummy technique probably done, same tablet numbers and shape.
Incomplete outcome data Low risk (attrition bias)

All outcomes
Quote: "Four patients dropped out before the 2-week evaluation since dose had to be adjusted for ethical reasons. Thus a man and a woman on $600 \mathrm{mg}$ showed extreme somnolence, requiring dose reduction. In a man on $400 \mathrm{mg}$ and a woman on $200 \mathrm{mg}$ the doses were increased because of insufficient effect on the severe psychosis. Another six patients dropped out after the 2 week, but the 4-week, evaluation. In a woman and a man on $400 \mathrm{mg}$, the dose was increased due to insufficient antipsychotic effect. A man on $400 \mathrm{mg}$ who was markedly improved clinically was omitted because of severe elevation of transaminase levels. Another man on $200 \mathrm{mg}$ and a woman on $400 \mathrm{mg}$ were also both quite well and insisted on being discharged from the hospital. A woman on 600mg refused further medication" pp154,p5.

Comment: loss to follow-up described from each group in detail.

Selective reporting (re- High risk $\quad$ For some scales only graphs without numeric data.
porting bias)

Other bias Low risk

\begin{abstract}
Quote: "This investigation was supported by grants from the Swedish Medical Research Council (No. 21X-02291, 14X-03560), National Institutes of Health, Bethesda, Maryland, and USA (MH 27254-01), F.Hoffmann-La Roche, Basle, Switzerland, 'Forenade Liv' Mutual Group Life Insurance Company, Stockholm, Sweden, Svenska Lakaresallskapet: Anton och Dorothea Bexelius Minnesfond, Bror Gadelius Minnesfond, Karolinska Institutets Fonder, AB Leo, Sweden, and Magnus Bergvalls Stiftelse” pp171, p2.
\end{abstract}


Xu 2009

\begin{tabular}{|c|c|}
\hline \multirow[t]{3}{*}{ Methods } & $\begin{array}{l}\text { Allocation: randomised (divided into large-dose group and small-dose group according to the odd-even } \\
\text { number). }\end{array}$ \\
\hline & Blindness: Not mentioned. \\
\hline & Duration: 8 weeks. \\
\hline
\end{tabular}

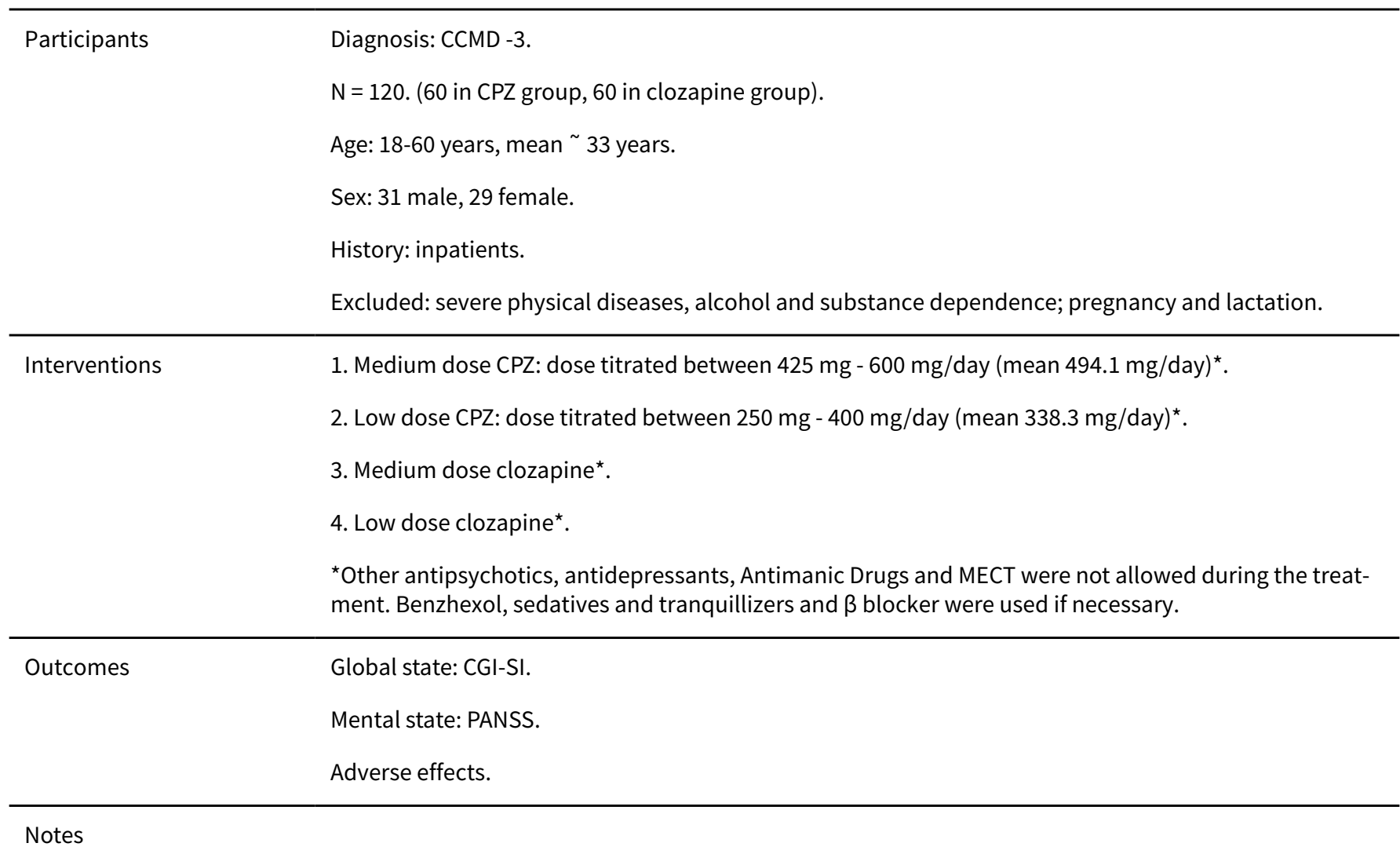

\section{Risk of bias}

Bias Authors' judgement Support for judgement

Random sequence genera- Unclear risk $\quad$ Randomised. No detailed information was described in the study.
tion (selection bias)

\begin{tabular}{|c|c|c|}
\hline $\begin{array}{l}\text { Allocation concealment } \\
\text { (selection bias) }\end{array}$ & Unclear risk & Not mentioned. No detailed information was described in the study. \\
\hline $\begin{array}{l}\text { Blinding (performance } \\
\text { bias and detection bias) } \\
\text { All outcomes }\end{array}$ & Unclear risk & Not mentioned. No detail information was described in the study. \\
\hline $\begin{array}{l}\text { Incomplete outcome data } \\
\text { (attrition bias) } \\
\text { All outcomes }\end{array}$ & Low risk & All outcomes were reported. \\
\hline
\end{tabular}


Xu 2009 (Continued)

Selective reporting (re- Low risk $\quad$ No selective reporting was found.
porting bias)

Other bias Low risk Not obvious.

BPRS - Brief Psychiatric Rating Scale

CCMD-3 - Chinese Classification of Mental Disorders Version 3

CGI-I - Clinical Global Impression - Improvement scale

CGI-SI - Clinical Global Impression - Severity of Illness scale

CPRS - Comprehensive Psychopathological Rating Scale

$\mathrm{CPZ}$ - Chlorpromazine

CSF - cerebrospinal fluid

DRI - Discharge Readiness Inventory

EEG - electroencephalogram

FSH - follicle-stimulating hormone

GIS - Global Improvement Scale (aka CGI-I)

GRS - Global Rating Scale

GSIS - Global Severity of Illness Scale (aka CGI-SI)

GAS - Global Assessment Scale

IMPS - Inpatient Multidimensional Psychiatric Scale

IU - international unit

$\mathrm{LH}$ - luteinizing hormone

NOSIE - Nurse's Observation Scale for Inpatient Evaluation

OBRS - Oklahoma Behaviour Rating Scale

PANSS- Positive And Negative Syndrome Scale

TSH - thyroid-stimulating hormone

Characteristics of excluded studies [ordered by study ID]

\begin{tabular}{ll}
\hline Study & Reason for exclusion \\
\hline Altman 1973 & Allocation: randomised (times 3 factorial design). \\
& Participants: psychogeriatric inpatients (total = 151, 81 completed with schizophrenia). \\
& Interventions: CPZ vs thioridazine and bed time dose vs day time fractional doses and $30 \mathrm{mg}$ vs 60 \\
& mg vs $90 \mathrm{mg}$ vs $120 \mathrm{mg}$. All CPZ doses 'low' according to definitions in this review. \\
& Outcomes: leaving early, 'response', behaviour (needing chlordiazepoxide, MIBS), side effects - \\
no usable data, all reported for total group and not for people with schizophrenia, all regression \\
scores rather than averages or binary outcomes.
\end{tabular}

Andrews $1976 \quad$ Allocation: randomised.

Participants: people with schizophrenia.

Interventions: CPZ 50-100 mg/day vs CPZ 150-200 mg/day vs CPZ >200 mg/day.

Outcomes: unable to use - 7 patients received between $300 \mathrm{mg}$ and $4450 \mathrm{mg}$ - data not presented

in such a way to use within this review.

Bartko $1988 \quad$ Allocation: randomised.

Participants: people with schizophrenia.

Interventions: CPZ $300 \mathrm{mg}$ /day vs CPZ $450 \mathrm{mg}$ /day vs CPZ $700 \mathrm{mg}$ /day.

Outcomes: data reported by CPZ serum levels, not by original group of randomisation.

Borison $1991 \quad$ Allocation: randomised, "double-blind".

Participants: people with schizophrenia. 


\begin{tabular}{ll}
\hline Study & Reason for exclusion \\
\hline & $\begin{array}{l}\text { Interventions: rimcazole } 20 \mathrm{mg}-80 \mathrm{mg} / \text { day vs rimcazole } 100 \mathrm{mg}-400 \mathrm{mg} / \mathrm{day} \text { vs CPZ } 400 \mathrm{mg}-1600 \\
\mathrm{mg} / \text { day vs placebo. }\end{array}$ \\
\hline Caffey 1975 & Allocation: "double-blind", randomisation not stated. \\
& Participants: people with schizophrenia. \\
Interventions: study 1- continuous use of antipsychotics vs antipsychotics 5 days/week vs antipsy- \\
chotics 4 days/week. Study 2 - antiparkinsonian treatment vs placebo as an adjunct to antipsy- \\
chotics.
\end{tabular}

Casey $1961 \quad$ Allocation: randomised, "double-blind".
Participants: men with schizophrenia who are physically healthy but apathetic and withdrawn.
Interventions: Combination of CPZ with: dextroamphetamine vs isocarboxazid vs trifluoperazine vs
imipramine vs placebo, not dose.

\begin{tabular}{ll}
\hline Chen 2002 & Allocation: not stated (possibly CCT). \\
& Participants: people with schizophrenia. \\
& Interventions: risperidone vs chlorpromazine vs clozapine. \\
\hline Clark 1960 & Allocation: not randomised, case series. \\
\hline Clark 1961 & $\begin{array}{l}\text { Allocation: randomised (table of random numbers). } \\
\text { Participants: people with schizophrenia. } \\
\text { Interventions: Given different doses to each other, often changing over the weeks and potentially } \\
\text { sliding between dosage categories. }\end{array}$
\end{tabular}

\begin{tabular}{ll}
\hline Clark 1967 & Allocation: randomised, table of random numbers (Study \#1 and \#2 of Clark 1970). \\
& Participants: women with chronic schizophrenia. \\
Interventions: placebo vs rapidly increasing doses to a maximum of chlorpromazine $800 \mathrm{mg} /$ day, \\
not comparing doses.
\end{tabular}

Clark 1970a Allocation: randomised, "double-blind" (Study \#3 of Clark 1970).

Participants: women with chronic schizophrenia.

Interventions: placebo vs rapidly increasing doses to the point of toxicity or to a maximum of CPZ $800 \mathrm{mg} /$ day, not comparing doses.

\begin{tabular}{ll}
\hline Clark 1970b & $\begin{array}{l}\text { Allocation: randomised, "double-blind" (Study \#6 of Clark 1970). } \\
\text { Participants: people with chronic schizophrenia. } \\
\text { Interventions: placebo vs chlorpromazine } 800 \mathrm{mg} / \text { day vs clopenthixol, not comparing doses. }\end{array}$ \\
\hline Clark 1978 & $\begin{array}{l}\text { Allocation: randomised. } \\
\text { Participants: people with schizophrenia. } \\
\text { Interventions: CPZ } 200 \mathrm{mg} / \mathrm{m}^{2} / \text { day vs CPZ } 600 \mathrm{mg} / \mathrm{m}^{2} / \text { day. } \\
\text { Outcomes: unable to use - one paper reported outcomes for } 4 / 25 \text { people, second paper reports da- } \\
\text { ta on blood pressure - unable to present. }\end{array}$ \\
\hline
\end{tabular}

\begin{tabular}{ll}
\hline Cooper 1973 & Allocation: not randomised, cross-over investigating plasma levels. \\
\hline Crane 1968 & Allocation: randomised, cross-over. \\
& Participants: people with schizophrenia. \\
Interventions: different doses of CPZ given for 6 months, then 6 months of different drugs 'as pre- \\
scribed'. \\
Outcome: no data available before cross-over, $60 \%$ loss to follow-up. \\
\hline
\end{tabular}




Study Reason for exclusion

\section{Curry 1976}

Danion 1992

Allocation: not randomised, case series investigating plasma levels.

Allocation: randomised.

\begin{tabular}{|c|c|}
\hline Eitan 1992 & $\begin{array}{l}\text { Allocation: "assigned", "double-blind", cross-over, implied randomisation. } \\
\text { Participants: people with schizophrenia. } \\
\text { Interventions: chlorpromazine, thioridazine, trifluoperazine, haloperidol, placebo (sodium bicar- } \\
\text { bonate) administered at } 90 \text {-min intervals - order of administration randomised, not dose. }\end{array}$ \\
\hline Gibbs 1956 & $\begin{array}{l}\text { Allocation: randomised. } \\
\text { Participants: people with schizophrenia. } \\
\text { Interventions: chlorpromazine } 75 \mathrm{mg} / \text { day }-125 \mathrm{mg} / \text { day vs chlorpromazine } 150 \mathrm{mg} / \mathrm{day} \text { - } 450 \mathrm{mg} / \\
\text { day - not clearly fitting within the categories pre-stated in protocol for low and medium dose. }\end{array}$ \\
\hline Green 1996 & $\begin{array}{l}\text { Allocation: randomised, cross-over. } \\
\text { Participants: healthy people, not people with schizophrenia. }\end{array}$ \\
\hline Hartley 1978 & $\begin{array}{l}\text { Allocation: all people received the } 3 \text { drug treatments, "order determined by Latin Square". } \\
\text { Participants: healthy men, not people with schizophrenia. }\end{array}$ \\
\hline Janakiramaiah 1982 & $\begin{array}{l}\text { Allocation: randomised. } \\
\text { Participants: people with schizophrenia. } \\
\text { Interventions: CPZ } 300 \mathrm{mg} / \text { day vs CPZ } 500 \mathrm{mg} / \text { day. } \\
\text { Outcomes: no usable data - BPRS score (no SD), incomplete data not addressed, movement disor- } \\
\text { der adverse effects, global impression both assessed - but no data. }\end{array}$ \\
\hline Jeste 1977 & $\begin{array}{l}\text { Allocation: randomised, crossover. } \\
\text { Participants: outpatients with schizophrenia diagnosed with persistent dyskinesia (total = 3). } \\
\text { Interventions: schedule A (weeks } 1 \& 2(0), 3 \& 4(\text { four times a day), } 5(0), 6 \& 7 \text { (once daily), } 8(0), 9 \& 10 \\
\text { (four times a day), } 11(0), 12 \& 13 \text { (once daily), } 14(0) .) \text { vs schedule } B(\text { weeks } 1 \& 2(0), 3 \& 4 \text { (once daily), } \\
5(0), 6 \& 7 \text { (once daily), } 8(0), 9 \& 10 \text { (once daily), } 11(0), 12 \& 13 \text { (four times a day).), not dose. }\end{array}$ \\
\hline
\end{tabular}

Participants: healthy people, not people with schizophrenia.

Allocation: "assigned", "double-blind", cross-over, implied randomisation.

Participants: people with schizophrenia.

Interventions: chlorpromazine, thioridazine, trifluoperazine, haloperidol, placebo (sodium bicar-

Allocation: randomised.

Participants: people with schizophrenia.

terventions: chlorpromazine $75 \mathrm{mg} /$ day

Joshi 1982 Allocation: randomised, "double-blind".

Participants: people with schizophrenia (untreated Acute Schizophrenic Psychosis).

Interventions: 4 groups of varying CPZ doses with daily injection of vitamin preparation (containing $\mathrm{B} 1, \mathrm{~B} 6$ and $\mathrm{B} 12)$ vs placebo.

Kalyanasundaram $1981 \quad$ Allocation: randomised, "double-blind".

Participants: acutely psychotic people.

Interventions: bed time dose of CPZ vs day time fractional doses of CPZ.

Lehmann 1983

Allocation: randomised, but the procedure was not entirely successful (top p295).

Participants: hospitalised chronic psychotic people.

Interventions: high vs low chlorpromazine equivalent dosages - unclear what antipsychotic drugs were used.
Allocation: randomised, "double-blind", cross-over. 


\begin{tabular}{ll}
\hline Study & Reason for exclusion \\
\hline Participants: hospitalised chronic psychotic people. \\
Interventions: CPZ preparation A vs CPZ preparation B. Comparison of different brands, not differ- \\
ent doses.
\end{tabular}

\section{Pigache 1993}

Schiele 1959 Allocation: "blindness" achieved by randomisation of duration of treatment time periods, not dose.

Allocation: "carefully matched".

Participants: people with serious mental illnesses.

Interventions: high vs low dose CPZ, dose of CPZ adapted to patients response, not fixed dose.

\section{Sukegawa 2008}

Allocation: randomised.

Participants: inpatients with schizophrenia.

Interventions: all participants given 3 or more antipsychotics with total dosage more than $1500 \mathrm{mg}$ CPZ equivalence (mg CP), RAS group vs control group with continuation of polypharmacy, multiple antipsychotics.

\section{Sukegawa 2012}

Allocation: randomised.

Participants: people with schizophrenia.

Interventions: all participants undergo dose reduction of antipsychotic drugs (for low potency drugs: dose decreased with $25 \mathrm{mg}$ CP or lower per week. For high potency drugs: dose decreased with $50 \mathrm{mg}$ CP or lower per week), multiple antipsychotics.

\section{Sukegawa 2014}

Allocation: randomised.

Participants: people with schizophrenia, aged 20 or over.

Interventions: control group vs dose reduction (dose decreased to $80 \%$ or less than the initial dose over 3-6 months according to SCAP method), multiple antipsychotics.

Yuan-Guang 1994

Allocation: randomised.

Participants: inpatients with schizophrenia.

Interventions: CPZ $100 \mathrm{mg}$ (three time a day) vs CPZ $100 \mathrm{mg}$ (three time a day) + trihexyphenidyl 2 $\mathrm{mg}$ (three time a day) vs CPZ $200 \mathrm{mg}$ (three time a day) + trihexyphenidyl $2 \mathrm{mg}$ (three time a day), both CPZ doses 'low' according to definitions in this review.

\section{CPZ - Chlorpromzine}

MIBS - Missouri Inpatient Behaviour Scale

CCT - Controlled clinical trial

BPRS - Brief Psychiatric Rating Scale

RAS - Reduction and Simplification of Antipsychotics

mg CP - chlorpromazine equivalence

SCAP - Safety Correction of High Dose Antipsychotic Polypharmacy

\section{DATA AND ANALYSES}


Comparison 1. CHLORPROMAZINE LOW DOSE ( $\leq 400 \mathrm{mg} /$ day) vs MEDIUM DOSE (401-800 mg/day)

\begin{tabular}{|c|c|c|c|c|}
\hline Outcome or subgroup title & No. of studies & $\begin{array}{l}\text { No. of partici- } \\
\text { pants }\end{array}$ & Statistical method & Effect size \\
\hline $\begin{array}{l}1 \text { Global state: } 1 . \text { Not improved - short } \\
\text { term (CGI-SI) }\end{array}$ & 1 & 60 & $\begin{array}{l}\text { Risk Ratio (M-H, Fixed, 95\% } \\
\text { Cl) }\end{array}$ & $0.83[0.28,2.44]$ \\
\hline $\begin{array}{l}2 \text { Global state: } 2 \text {. Requiring addition- } \\
\text { al medication (sedation with chloral } \\
\text { hydrate or a barbiturate }>5 \text { times) - } \\
\text { medium term }\end{array}$ & 1 & 50 & $\begin{array}{l}\text { Risk Ratio (M-H, Fixed, 95\% } \\
\mathrm{Cl})\end{array}$ & $3.09[0.40,23.64]$ \\
\hline 3 Leaving the study early & 2 & & $\begin{array}{l}\text { Risk Ratio (M-H, Fixed, 95\% } \\
\mathrm{Cl})\end{array}$ & Subtotals only \\
\hline 3.1 any reason & 2 & 70 & $\begin{array}{l}\text { Risk Ratio (M-H, Fixed, 95\% } \\
\mathrm{Cl})\end{array}$ & $1.06[0.32,3.55]$ \\
\hline 3.2 adverse effects & 1 & 48 & $\begin{array}{l}\text { Risk Ratio (M-H, Fixed, 95\% } \\
\mathrm{Cl} \text { ) }\end{array}$ & $0.23[0.02,2.32]$ \\
\hline 3.3 inefficacy of treatment & 1 & 48 & $\begin{array}{l}\text { Risk Ratio (M-H, Fixed, 95\% } \\
\mathrm{Cl} \text { ) }\end{array}$ & $4.24[0.24,74.01]$ \\
\hline 3.4 other reason & 2 & 70 & $\begin{array}{l}\text { Risk Ratio (M-H, Fixed, 95\% } \\
\mathrm{Cl})\end{array}$ & $0.91[0.09,9.27]$ \\
\hline $\begin{array}{l}4 \text { Mental state: } 1 \text { a. Average endpoint } \\
\text { score (BPRS total, high = poor) }\end{array}$ & 1 & & $\begin{array}{l}\text { Mean Difference (IV, Fixed, } \\
95 \% \mathrm{CI})\end{array}$ & Subtotals only \\
\hline 4.1 anxious depression & 1 & 22 & $\begin{array}{l}\text { Mean Difference (IV, Fixed, } \\
95 \% \mathrm{CI})\end{array}$ & $-0.60[-1.35,0.15]$ \\
\hline 4.2 thinking disturbance & 1 & 22 & $\begin{array}{l}\text { Mean Difference (IV, Fixed, } \\
95 \% \mathrm{CI})\end{array}$ & $2.60[-0.24,5.44]$ \\
\hline 4.3 withdrawal retardation & 1 & 22 & $\begin{array}{l}\text { Mean Difference (IV, Fixed, } \\
95 \% \mathrm{CI})\end{array}$ & $-2.0[-3.76,-0.24]$ \\
\hline $\begin{array}{l}5 \text { Mental state: } 1 b \text {. Average endpoint } \\
\text { score (PANSS total and subscores, } \\
\text { high = poor) }\end{array}$ & 1 & & $\begin{array}{l}\text { Mean Difference (IV, Fixed, } \\
95 \% \mathrm{CI})\end{array}$ & Subtotals only \\
\hline 5.1 negative & 1 & 60 & $\begin{array}{l}\text { Mean Difference (IV, Fixed, } \\
95 \% \mathrm{CI})\end{array}$ & $-0.17[-2.34,2.00]$ \\
\hline 5.2 positive & 1 & 60 & $\begin{array}{l}\text { Mean Difference (IV, Fixed, } \\
95 \% \mathrm{CI})\end{array}$ & $-0.24[-1.98,1.50]$ \\
\hline 5.3 total & 1 & 60 & $\begin{array}{l}\text { Mean Difference (IV, Fixed, } \\
95 \% \mathrm{CI})\end{array}$ & $0.36[-5.39,6.11]$ \\
\hline $\begin{array}{l}6 \text { Adverse effects: } 1 \text {. Central nervous } \\
\text { system - extrapyramidal symptoms }\end{array}$ & 4 & & $\begin{array}{l}\text { Risk Ratio (M-H, Fixed, 95\% } \\
\mathrm{Cl})\end{array}$ & Subtotals only \\
\hline 6.1 akathisia - short term & 2 & 70 & $\begin{array}{l}\text { Risk Ratio (M-H, Fixed, 95\% } \\
\text { Cl) }\end{array}$ & $1.37[0.28,6.68]$ \\
\hline
\end{tabular}




\begin{tabular}{|c|c|c|c|c|}
\hline Outcome or subgroup title & No. of studies & $\begin{array}{l}\text { No. of partici- } \\
\text { pants }\end{array}$ & Statistical method & Effect size \\
\hline 6.2 akinesia - short term & 1 & 22 & $\begin{array}{l}\text { Risk Ratio (M-H, Fixed, 95\% } \\
\mathrm{Cl})\end{array}$ & $0.5[0.05,4.75]$ \\
\hline 6.3 dystonia - short term & 2 & 70 & $\begin{array}{l}\text { Risk Ratio (M-H, Fixed, 95\% } \\
\mathrm{Cl})\end{array}$ & $0.24[0.05,1.29]$ \\
\hline 6.4 gait disturbance - short term & 1 & 48 & $\begin{array}{l}\text { Risk Ratio (M-H, Fixed, 95\% } \\
\mathrm{Cl})\end{array}$ & $0.36[0.11,1.17]$ \\
\hline 6.5 muscle tension - short term & 1 & 48 & $\begin{array}{l}\text { Risk Ratio (M-H, Fixed, 95\% } \\
\mathrm{Cl})\end{array}$ & $0.15[0.03,0.67]$ \\
\hline 6.6 rigidity - elbow - short term & 1 & 48 & $\begin{array}{l}\text { Risk Ratio (M-H, Fixed, 95\% } \\
\mathrm{Cl} \text { ) }\end{array}$ & $0.53[0.21,1.31]$ \\
\hline 6.7 rigidity - unspecified - short term & 1 & 22 & $\begin{array}{l}\text { Risk Ratio (M-H, Fixed, 95\% } \\
\mathrm{Cl})\end{array}$ & $1.0[0.07,14.05]$ \\
\hline 6.8 tremor - short term & 2 & 70 & $\begin{array}{l}\text { Risk Ratio (M-H, Fixed, 95\% } \\
\mathrm{Cl} \text { ) }\end{array}$ & $0.44[0.17,1.10]$ \\
\hline $\begin{array}{l}6.9 \text { unspecified extrapyramidal symp- } \\
\text { toms - short term }\end{array}$ & 2 & 108 & $\begin{array}{l}\text { Risk Ratio (M-H, Fixed, 95\% } \\
\mathrm{Cl})\end{array}$ & $0.47[0.30,0.74]$ \\
\hline $\begin{array}{l}6.10 \text { unspecified extrapyramidal } \\
\text { symptoms - medium term }\end{array}$ & 1 & 50 & $\begin{array}{l}\text { Risk Ratio (M-H, Fixed, 95\% } \\
\mathrm{Cl})\end{array}$ & $0.26[0.05,1.27]$ \\
\hline 7 Adverse effects: 2 . Anticholinergic & 3 & & $\begin{array}{l}\text { Risk Ratio (M-H, Fixed, 95\% } \\
\mathrm{Cl} \text { ) }\end{array}$ & Subtotals only \\
\hline 7.1 blurred vision - short term & 1 & 48 & $\begin{array}{l}\text { Risk Ratio (M-H, Fixed, 95\% } \\
\text { Cl) }\end{array}$ & $0.30[0.06,1.63]$ \\
\hline $\begin{array}{l}7.2 \text { ejaculation disturbance - short } \\
\text { term }\end{array}$ & 1 & 20 & $\begin{array}{l}\text { Risk Ratio (M-H, Fixed, 95\% } \\
\mathrm{Cl} \text { ) }\end{array}$ & $0.0[0.0,0.0]$ \\
\hline 7.3 erectile disturbance - short term & 1 & 20 & $\begin{array}{l}\text { Risk Ratio (M-H, Fixed, 95\% } \\
\mathrm{Cl} \text { ) }\end{array}$ & $0.0[0.0,0.0]$ \\
\hline 7.4 constipation - short term & 2 & 70 & $\begin{array}{l}\text { Risk Ratio (M-H, Fixed, 95\% } \\
\mathrm{Cl})\end{array}$ & $1.82[0.42,7.99]$ \\
\hline 7.5 constipation - medium term & 1 & 50 & $\begin{array}{l}\text { Risk Ratio (M-H, Fixed, 95\% } \\
\mathrm{Cl})\end{array}$ & $0.11[0.01,2.09]$ \\
\hline 7.6 salivation - dry mouth - short term & 2 & 70 & $\begin{array}{l}\text { Risk Ratio (M-H, Fixed, 95\% } \\
\mathrm{Cl})\end{array}$ & $1.16[0.58,2.34]$ \\
\hline 7.7 salivation - too much - short term & 1 & 48 & $\begin{array}{l}\text { Risk Ratio (M-H, Fixed, 95\% } \\
\mathrm{Cl} \text { ) }\end{array}$ & $0.09[0.00,1.85]$ \\
\hline 7.8 tachycardia - short term & 1 & 22 & $\begin{array}{l}\text { Risk Ratio (M-H, Fixed, 95\% } \\
\mathrm{Cl} \text { ) }\end{array}$ & $0.5[0.05,4.75]$ \\
\hline
\end{tabular}




\begin{tabular}{|c|c|c|c|c|}
\hline Outcome or subgroup title & No. of studies & $\begin{array}{l}\text { No. of partici- } \\
\text { pants }\end{array}$ & Statistical method & Effect size \\
\hline $\begin{array}{l}7.9 \text { urinary disturbance/trouble start- } \\
\text { ing urination - short term }\end{array}$ & 2 & 70 & $\begin{array}{l}\text { Risk Ratio (M-H, Fixed, 95\% } \\
\mathrm{Cl})\end{array}$ & $3.0[0.37,24.58]$ \\
\hline 8 Adverse effects: 3 . Cardiovascular & 4 & & $\begin{array}{l}\text { Risk Ratio (M-H, Fixed, 95\% } \\
\mathrm{Cl} \text { ) }\end{array}$ & Subtotals only \\
\hline $\begin{array}{l}8.1 \text { electrocardiogram abnormal - } \\
\text { short term }\end{array}$ & 1 & 60 & $\begin{array}{l}\text { Risk Ratio (M-H, Fixed, 95\% } \\
\text { Cl) }\end{array}$ & $0.22[0.05,0.94]$ \\
\hline $\begin{array}{l}8.2 \text { orthostatic symptoms (faint, } \\
\text { dizzy, weak) - short term }\end{array}$ & 1 & 22 & $\begin{array}{l}\text { Risk Ratio (M-H, Fixed, 95\% } \\
\text { Cl) }\end{array}$ & $2.0[0.21,18.98]$ \\
\hline $\begin{array}{l}8.3 \text { orthostatic symptoms - medium } \\
\text { term }\end{array}$ & 1 & 50 & $\begin{array}{l}\text { Risk Ratio (M-H, Fixed, 95\% } \\
\mathrm{Cl} \text { ) }\end{array}$ & $0.11[0.01,2.09]$ \\
\hline 8.4 tachycardia - short term & 1 & 22 & $\begin{array}{l}\text { Risk Ratio (M-H, Fixed, 95\% } \\
\mathrm{Cl} \text { ) }\end{array}$ & $0.5[0.05,4.75]$ \\
\hline 8.5 vertigo - short term & 1 & 50 & $\begin{array}{l}\text { Risk Ratio (M-H, Fixed, 95\% } \\
\mathrm{Cl} \text { ) }\end{array}$ & $1.03[0.21,5.07]$ \\
\hline $\begin{array}{l}9 \text { Adverse effects: } 4 \text {. Central nervous } \\
\text { system - other than extrapyramidal } \\
\text { symptoms }\end{array}$ & 4 & & $\begin{array}{l}\text { Risk Ratio (M-H, Fixed, 95\% } \\
\mathrm{Cl} \text { ) }\end{array}$ & Subtotals only \\
\hline 9.1 depression - medium term & 1 & 50 & $\begin{array}{l}\text { Risk Ratio (M-H, Fixed, 95\% } \\
\mathrm{Cl})\end{array}$ & $0.0[0.0,0.0]$ \\
\hline 9.2 drowsiness - short term & 1 & 22 & $\begin{array}{l}\text { Risk Ratio (M-H, Fixed, 95\% } \\
\mathrm{Cl} \text { ) }\end{array}$ & $1.0[0.47,2.14]$ \\
\hline 9.3 EEG abnormal - short term & 1 & 60 & $\begin{array}{l}\text { Risk Ratio (M-H, Fixed, 95\% } \\
\mathrm{Cl} \text { ) }\end{array}$ & $0.78[0.33,1.82]$ \\
\hline 9.4 head feels heavy - short term & 1 & 48 & $\begin{array}{l}\text { Risk Ratio (M-H, Fixed, 95\% } \\
\mathrm{Cl} \text { ) }\end{array}$ & $0.15[0.02,1.34]$ \\
\hline 9.5 headache - short term & 1 & 48 & $\begin{array}{l}\text { Risk Ratio (M-H, Fixed, 95\% } \\
\mathrm{Cl} \text { ) }\end{array}$ & $2.35[0.12,46.22]$ \\
\hline 9.6 sedation - medium term & 1 & 50 & $\begin{array}{l}\text { Risk Ratio (M-H, Fixed, 95\% } \\
\mathrm{Cl} \text { ) }\end{array}$ & $0.17[0.05,0.55]$ \\
\hline 9.7 somnolence - short term & 1 & 48 & $\begin{array}{l}\text { Risk Ratio (M-H, Fixed, 95\% } \\
\mathrm{Cl} \text { ) }\end{array}$ & $1.10[0.59,2.08]$ \\
\hline 9.8 vertigo - short term & 1 & 48 & $\begin{array}{l}\text { Risk Ratio (M-H, Fixed, 95\% } \\
\mathrm{Cl} \text { ) }\end{array}$ & $0.91[0.19,4.43]$ \\
\hline 10 Adverse effects: 5. Dermatological & 2 & & $\begin{array}{l}\text { Risk Ratio (M-H, Fixed, 95\% } \\
\mathrm{Cl})\end{array}$ & Subtotals only \\
\hline 10.1 dermatitis - medium term & 1 & 50 & $\begin{array}{l}\text { Risk Ratio (M-H, Fixed, 95\% } \\
\mathrm{Cl})\end{array}$ & $1.59[0.07,37.03]$ \\
\hline
\end{tabular}




\begin{tabular}{|c|c|c|c|c|}
\hline Outcome or subgroup title & No. of studies & $\begin{array}{l}\text { No. of partici- } \\
\text { pants }\end{array}$ & Statistical method & Effect size \\
\hline 10.2 rash - short term & 1 & 22 & $\begin{array}{l}\text { Risk Ratio (M-H, Fixed, 95\% } \\
\mathrm{Cl})\end{array}$ & $1.33[0.39,4.62]$ \\
\hline $\begin{array}{l}10.3 \text { rash - 'photosensitivity: erythe- } \\
\text { ma' - medium term }\end{array}$ & 1 & 50 & $\begin{array}{l}\text { Risk Ratio (M-H, Fixed, 95\% } \\
\text { Cl) }\end{array}$ & $0.52[0.03,7.74]$ \\
\hline $\begin{array}{l}11 \text { Adverse effects: } 6 \text {. Endocrine and } \\
\text { metabolic }\end{array}$ & 2 & & $\begin{array}{l}\text { Risk Ratio (M-H, Fixed, 95\% } \\
\text { Cl) }\end{array}$ & Subtotals only \\
\hline 11.1 amenorrhoea - short term & 1 & 28 & $\begin{array}{l}\text { Risk Ratio (M-H, Fixed, 95\% } \\
\text { Cl) }\end{array}$ & $0.47[0.03,6.74]$ \\
\hline 11.2 lactation - short term & 1 & 28 & $\begin{array}{l}\text { Risk Ratio (M-H, Fixed, 95\% } \\
\mathrm{Cl} \text { ) }\end{array}$ & $0.17[0.01,3.73]$ \\
\hline 11.3 metrorrhagia - medium term & 1 & 50 & $\begin{array}{l}\text { Risk Ratio (M-H, Fixed, 95\% } \\
\mathrm{Cl} \text { ) }\end{array}$ & $0.18[0.01,4.11]$ \\
\hline 12 Adverse effects: 7. Gastrointestinal & 3 & & $\begin{array}{l}\text { Risk Ratio (M-H, Fixed, 95\% } \\
\mathrm{Cl} \text { ) }\end{array}$ & Subtotals only \\
\hline 12.1 constipation - short term & 2 & 70 & $\begin{array}{l}\text { Risk Ratio (M-H, Fixed, 95\% } \\
\mathrm{Cl} \text { ) }\end{array}$ & $1.82[0.42,7.99]$ \\
\hline 12.2 constipation - medium term & 1 & 50 & $\begin{array}{l}\text { Risk Ratio (M-H, Fixed, 95\% } \\
\mathrm{Cl} \text { ) }\end{array}$ & $0.11[0.01,2.09]$ \\
\hline 12.3 unspecified - short term & 1 & 22 & $\begin{array}{l}\text { Risk Ratio (M-H, Fixed, 95\% } \\
\mathrm{Cl} \text { ) }\end{array}$ & $5.0[0.27,93.55]$ \\
\hline 13 Adverse effects: 8 . Genitourinary & 2 & & $\begin{array}{l}\text { Risk Ratio (M-H, Fixed, 95\% } \\
\mathrm{Cl} \text { ) }\end{array}$ & Subtotals only \\
\hline $\begin{array}{l}13.1 \text { urinary disturbance/trouble } \\
\text { starting urination - short term }\end{array}$ & 2 & 70 & $\begin{array}{l}\text { Risk Ratio (M-H, Fixed, 95\% } \\
\mathrm{Cl} \text { ) }\end{array}$ & $3.0[0.37,24.58]$ \\
\hline 14 Adverse effects: 9. Haematological & 1 & & $\begin{array}{l}\text { Risk Ratio (M-H, Fixed, 95\% } \\
\mathrm{Cl})\end{array}$ & Subtotals only \\
\hline 14.1 agranulocytosis - medium term & 1 & 50 & $\begin{array}{l}\text { Risk Ratio (M-H, Fixed, 95\% } \\
\mathrm{Cl})\end{array}$ & $1.59[0.07,37.03]$ \\
\hline 14.2 anaemia - medium term & 1 & 50 & $\begin{array}{l}\text { Risk Ratio (M-H, Fixed, 95\% } \\
\mathrm{Cl} \text { ) }\end{array}$ & $1.59[0.07,37.03]$ \\
\hline 15 Adverse effects: 10 . Hepatological & 1 & & $\begin{array}{l}\text { Risk Ratio (M-H, Fixed, 95\% } \\
\mathrm{Cl} \text { ) }\end{array}$ & Subtotals only \\
\hline $\begin{array}{l}15.1 \text { abnormal liver function - short } \\
\text { term }\end{array}$ & 1 & 60 & $\begin{array}{l}\text { Risk Ratio (M-H, Fixed, 95\% } \\
\mathrm{Cl} \text { ) }\end{array}$ & $1.33[0.33,5.45]$ \\
\hline 16 Adverse effects: 11 . Others & 2 & & $\begin{array}{l}\text { Risk Ratio (M-H, Fixed, 95\% } \\
\mathrm{Cl} \text { ) }\end{array}$ & Subtotals only \\
\hline
\end{tabular}




\begin{tabular}{|c|c|c|c|c|}
\hline Outcome or subgroup title & No. of studies & $\begin{array}{l}\text { No. of partici- } \\
\text { pants }\end{array}$ & Statistical method & Effect size \\
\hline $\begin{array}{l}16.1 \text { agitation and restlessness - } \\
\text { medium term }\end{array}$ & 1 & 50 & $\begin{array}{l}\text { Risk Ratio (M-H, Fixed, 95\% } \\
\mathrm{Cl} \text { ) }\end{array}$ & $1.59[0.07,37.03]$ \\
\hline 16.2 excitement - short term & 1 & 22 & $\begin{array}{l}\text { Risk Ratio (M-H, Fixed, 95\% } \\
\mathrm{Cl})\end{array}$ & $1.0[0.07,14.05]$ \\
\hline $\begin{array}{l}16.3 \text { restlessness, insomnia - short } \\
\text { term }\end{array}$ & 1 & 22 & $\begin{array}{l}\text { Risk Ratio (M-H, Fixed, 95\% } \\
\text { Cl) }\end{array}$ & $0.75[0.22,2.60]$ \\
\hline
\end{tabular}

Analysis 1.1. Comparison 1 CHLORPROMAZINE LOW DOSE ( $\leq 400 \mathrm{mg} /$ day) vs MEDIUM DOSE (401-800 mg/day), Outcome 1 Global state: 1. Not improved - short term (CGI-SI).

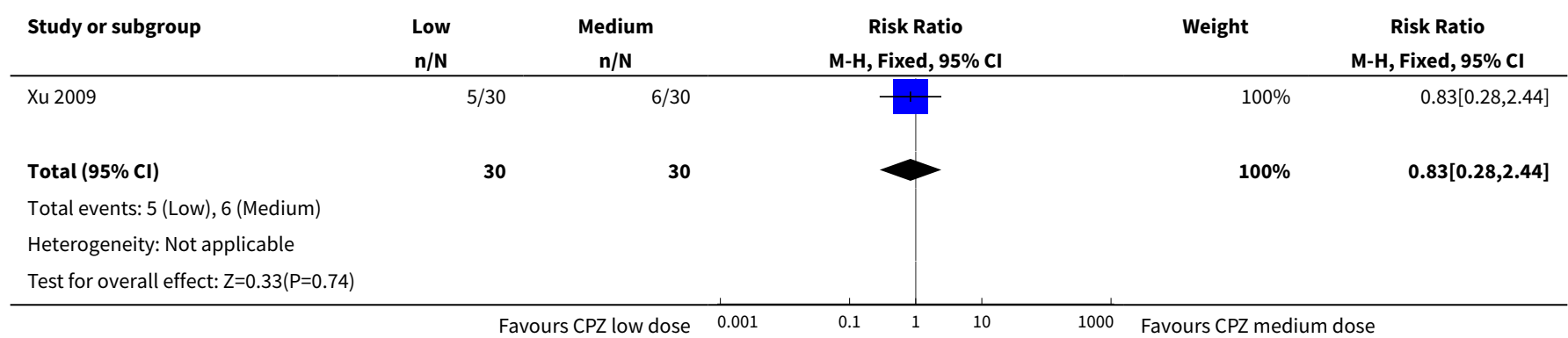

Analysis 1.2. Comparison 1 CHLORPROMAZINE LOW DOSE ( $\leq 400 \mathrm{mg} /$ day) vs MEDIUM DOSE (401-800 mg/day), Outcome 2 Global state: 2. Requiring additional medication (sedation with chloral hydrate or a barbiturate $>5$ times) - medium term.

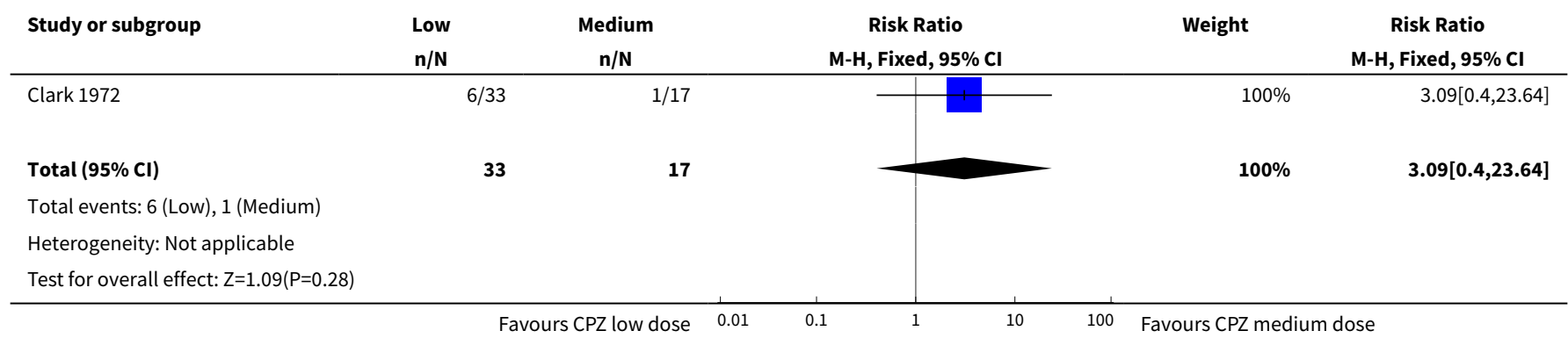

Analysis 1.3. Comparison 1 CHLORPROMAZINE LOW DOSE ( $\leq 400 \mathrm{mg} /$ day) vs MEDIUM DOSE (401-800 mg/day), Outcome 3 Leaving the study early.

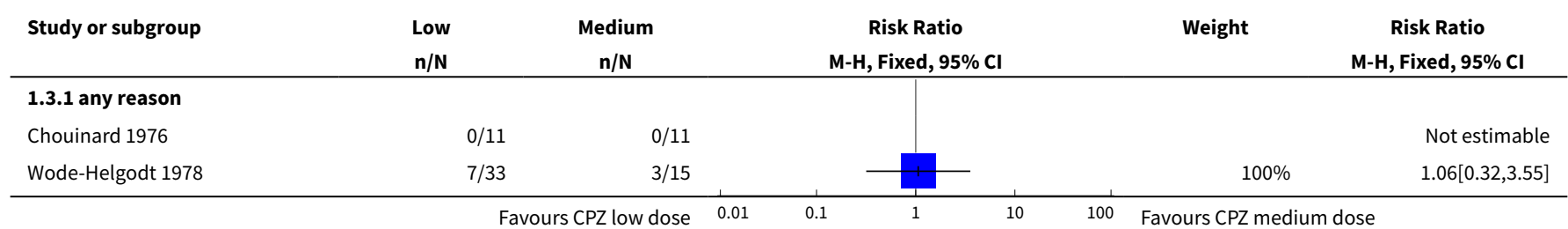




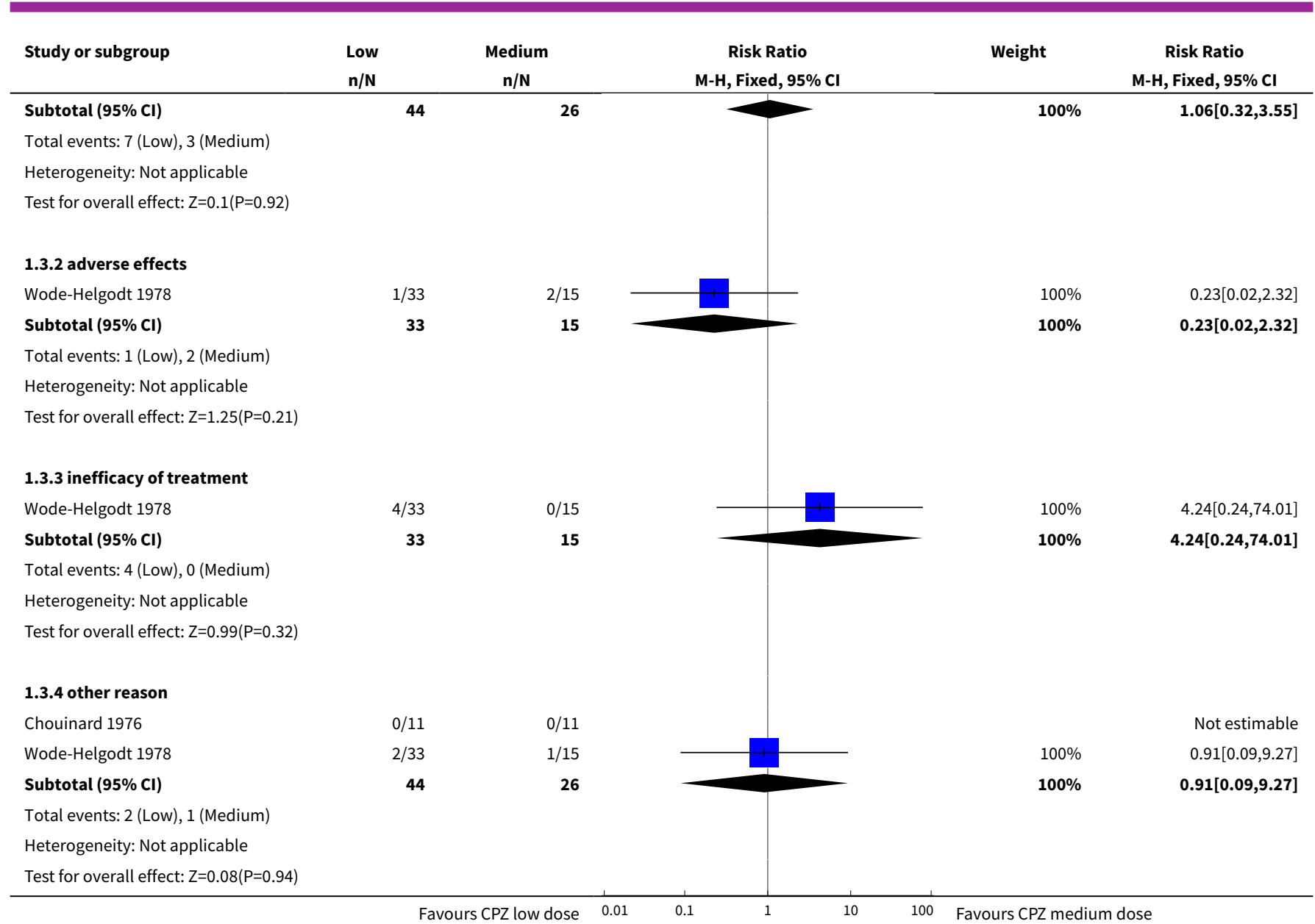

Analysis 1.4. Comparison 1 CHLORPROMAZINE LOW DOSE ( $\leq 400 \mathrm{mg} /$ day) vs MEDIUM DOSE (401-800 mg/day), Outcome 4 Mental state: 1a. Average endpoint score (BPRS total, high = poor).

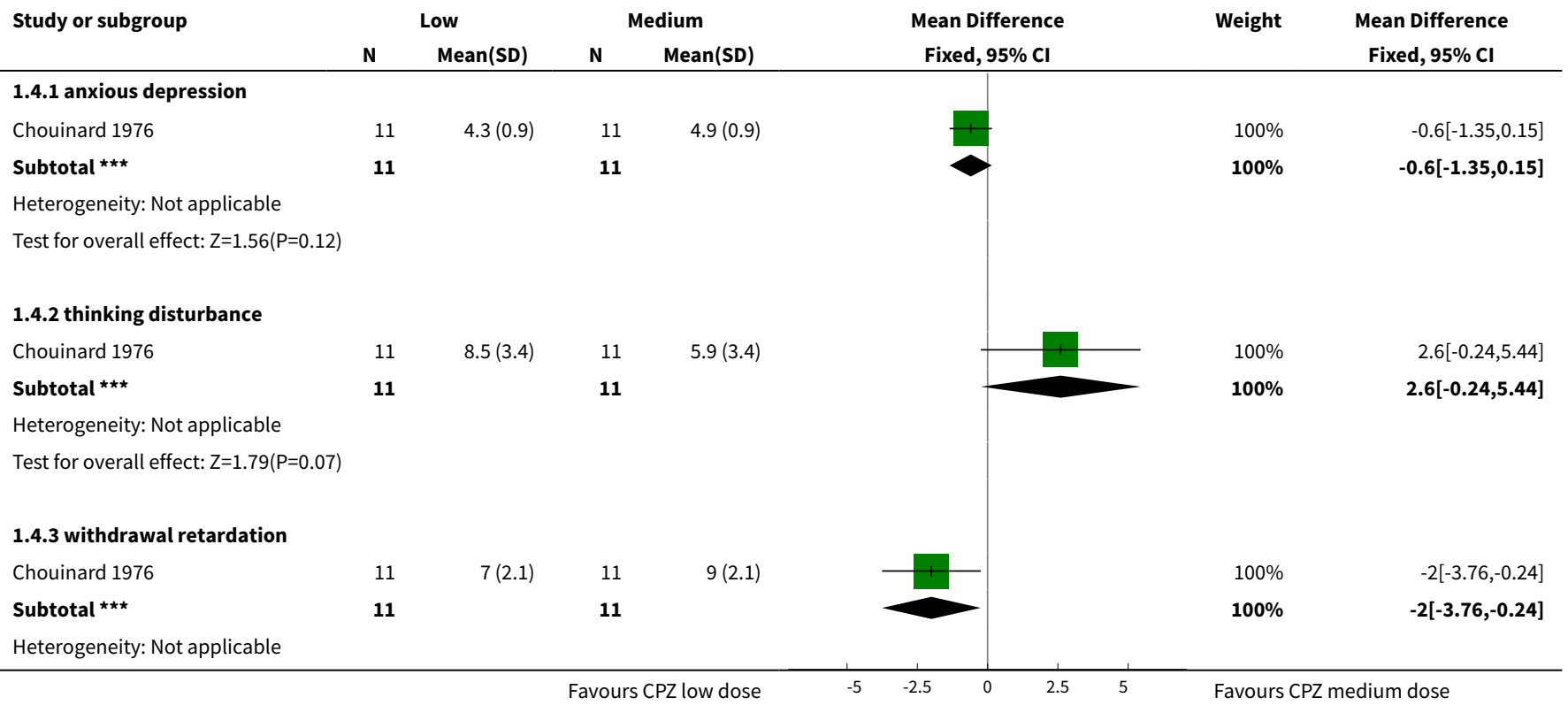




\begin{tabular}{|c|c|c|c|c|c|c|c|}
\hline \multirow[t]{2}{*}{ Study or subgroup } & Low & \multicolumn{2}{|c|}{ Medium } & \multirow{2}{*}{\multicolumn{2}{|c|}{$\begin{array}{c}\text { Mean Difference } \\
\text { Fixed, } 95 \% \mathrm{Cl}\end{array}$}} & \multirow[t]{2}{*}{ Weight } & \multirow{2}{*}{$\begin{array}{c}\text { Mean Difference } \\
\text { Fixed, } 95 \% \mathrm{Cl}\end{array}$} \\
\hline & $\operatorname{Mean}(\mathrm{SD})$ & $\mathbf{N}$ & $\operatorname{Mean}(S D)$ & & & & \\
\hline \multicolumn{8}{|c|}{ Test for overall effect: $Z=2.23(P=0.03)$} \\
\hline \multicolumn{8}{|c|}{ Test for subgroup differences: $\mathrm{Chi}^{2}=7.31, \mathrm{df}=1(\mathrm{P}=0.03), \mathrm{I}^{2}=72.64 \%$} \\
\hline
\end{tabular}

Analysis 1.5. Comparison 1 CHLORPROMAZINE LOW DOSE ( $\leq 400 \mathrm{mg} /$ day) vs MEDIUM DOSE (401-800 $\mathrm{mg} /$ day), Outcome 5 Mental state: $1 \mathrm{~b}$. Average endpoint score (PANSS total and subscores, high = poor).

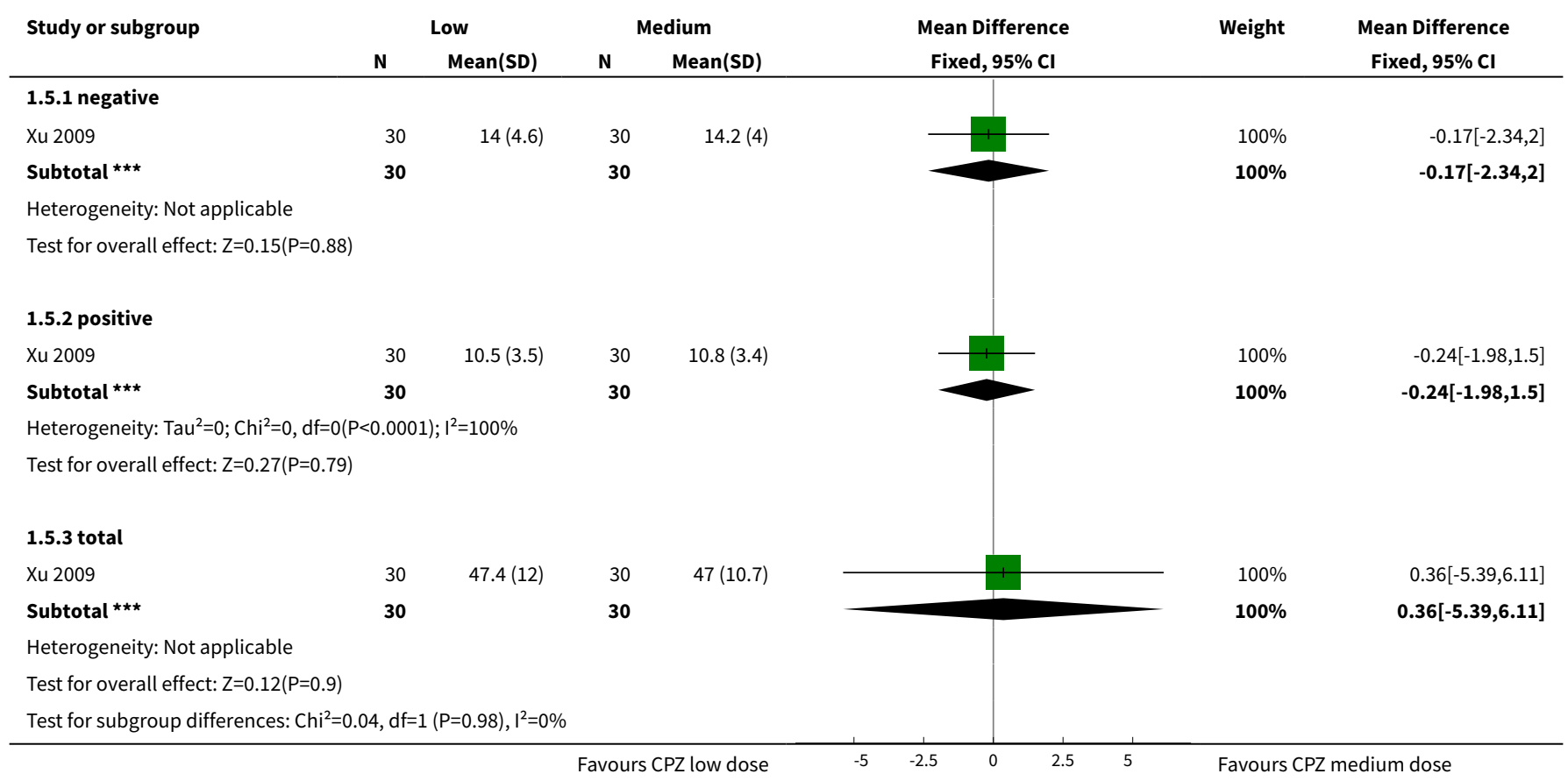

\section{Analysis 1.6. Comparison 1 CHLORPROMAZINE LOW DOSE ( $\leq 400 \mathrm{mg} /$ day) vs MEDIUM DOSE (401-800 $\mathrm{mg} /$ day), Outcome 6 Adverse effects: 1. Central nervous system - extrapyramidal symptoms.}

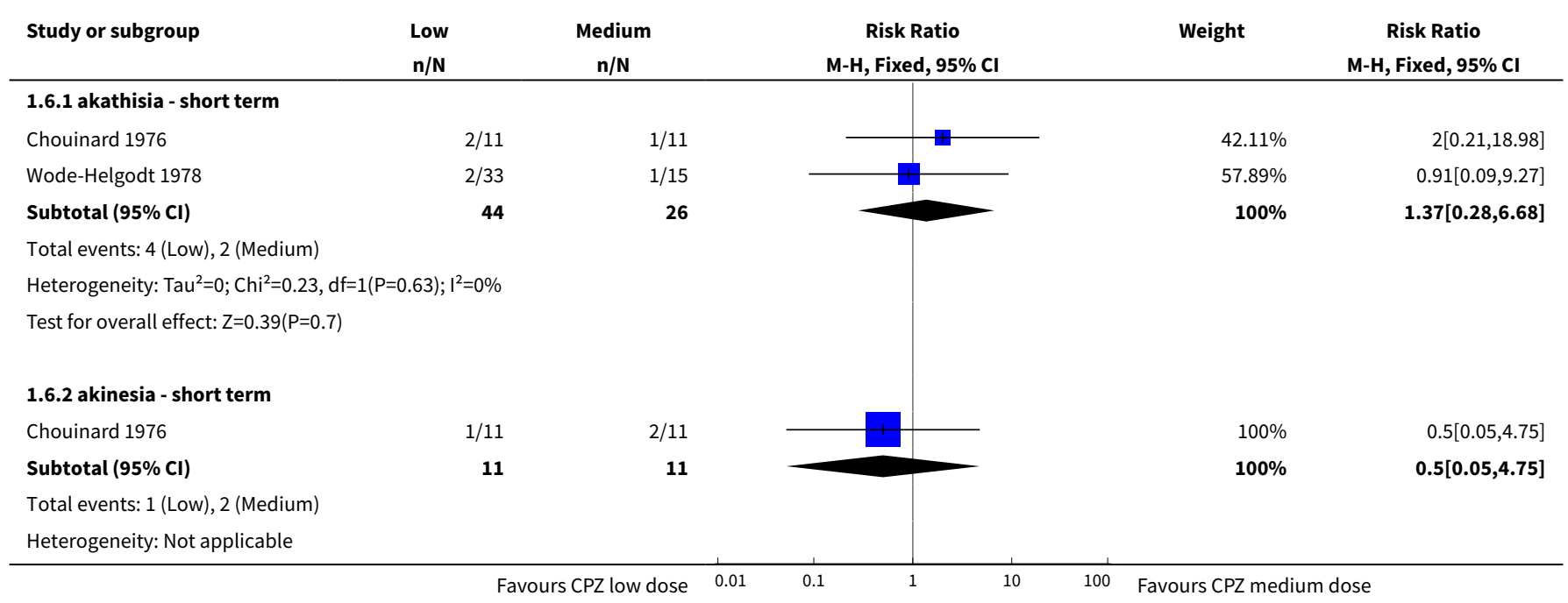




\begin{tabular}{lcccc} 
& & & & \\
Study or subgroup & Low & Medium & Risk Ratio & Risk Ratio \\
& $\mathrm{n} / \mathrm{N}$ & $\mathrm{n} / \mathrm{N}$ & $\mathrm{M}-\mathrm{H}$, Fixed, $95 \% \mathrm{Cl}$ & $\mathrm{M}-\mathrm{H}, \mathrm{Fixed}, 95 \% \mathrm{Cl}$ \\
\hline
\end{tabular}

Test for overall effect: $\mathrm{Z}=0.6(\mathrm{P}=0.55)$

1.6.3 dystonia - short term

Chouinard 1976

Wode-Helgodt 1978

Subtotal $(95 \% \mathrm{Cl})$

Total events: 1 (Low), 4 (Medium)

Heterogeneity: $\mathrm{Tau}^{2}=0 ; \mathrm{Chi}^{2}=0.78, \mathrm{df}=1(\mathrm{P}=0.38) ; \mathrm{I}^{2}=0 \%$

Test for overall effect: $Z=1.66(P=0.1)$

1.6.4 gait disturbance - short term

Wode-Helgodt 1978

Subtotal $(95 \% \mathrm{CI})$

Total events: 4 (Low), 5 (Medium)

Heterogeneity: Not applicable

Test for overall effect: $Z=1.7(P=0.09)$

\subsection{5 muscle tension - short term}

Wode-Helgodt 1978

Subtotal $(95 \% \mathrm{Cl})$

Total events: 2 (Low), 6 (Medium)

Heterogeneity: Not applicable

Test for overall effect: $Z=2.5(P=0.01)$

\subsection{6 rigidity - elbow - short term}

Wode-Helgodt 1978

Subtotal $(95 \% \mathrm{Cl})$

Total events: 7 (Low), 6 (Medium)

Heterogeneity: Not applicable

Test for overall effect: $Z=1.38(P=0.17)$

1.6.7 rigidity - unspecified - short term

Chouinard 1976

Subtotal $(95 \% \mathrm{Cl})$

11

Total events: 1 (Low), 1 (Medium)

Heterogeneity: Not applicable

Test for overall effect: Not applicable

\subsection{8 tremor - short term}

Chouinard 1976

Wode-Helgodt 1978

Subtotal $(95 \% \mathrm{Cl})$

$6 / 33$

Total events: 6 (Low), 7 (Medium)

Heterogeneity: $\mathrm{Tau}^{2}=0 ; \mathrm{Chi}^{2}=0.04, \mathrm{df}=1(\mathrm{P}=0.85) ; \mathrm{I}^{2}=0 \%$

Test for overall effect: $Z=1.76(P=0.08)$

1.6.9 unspecified extrapyramidal symptoms - short term

Wode-Helgodt 1978

Xu 2009

$13 / 33$

$6 / 30$

63

Subtotal $(95 \% \mathrm{Cl})$

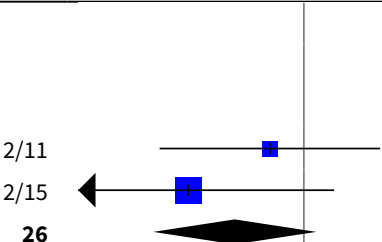

$37.04 \%$

$0.5[0.05,4.75]$

$62.96 \%$

$0.09[0,1.85]$

$100 \%$

$0.24[0.05,1.29]$

$100 \%$

$0.36[0.11,1.17]$

$100 \%$

$0.36[0.11,1.17]$

$100 \%$

$0.15[0.03,0.67]$

$100 \%$

$0.15[0.03,0.67]$
$100 \%$

$100 \%$

$100 \%$

$100 \%$

$15.38 \%$

$84.62 \%$

$100 \%$
$0.53[0.21,1.31]$

$0.53[0.21,1.31]$

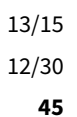

45
$59.83 \%$

$40.17 \%$

$100 \%$
$1[0.07,14.05]$
$1[0.07,14.05]$
$0.33[0.02,7.39]$

$0.45[0.18,1.18]$

$0.44[0.17,1.1]$

Total events: 19 (Low), 25 (Medium)

Heterogeneity: $\mathrm{Tau}^{2}=0 ; \mathrm{Chi}^{2}=0.04, \mathrm{df}=1(\mathrm{P}=0.83) ; \mathrm{I}^{2}=0 \%$

Copyright ( 2017 The Cochrane Collaboration. Published by John Wiley \& Sons, Ltd. 


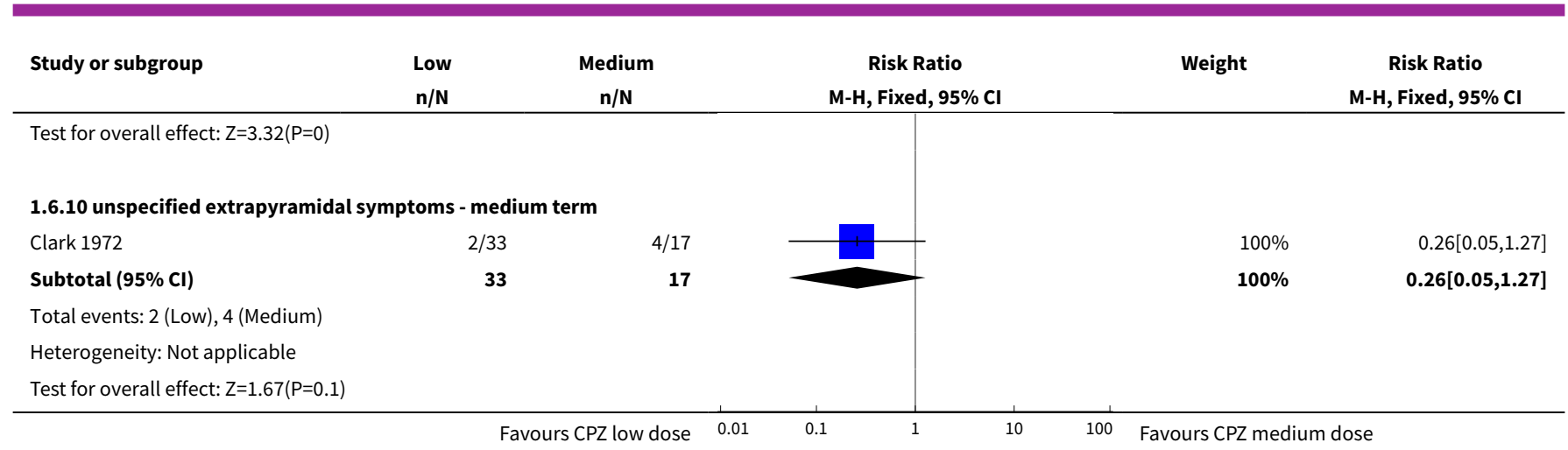

Analysis 1.7. Comparison 1 CHLORPROMAZINE LOW DOSE ( $\leq 400 \mathrm{mg} /$ day) vs MEDIUM DOSE (401-800 mg/day), Outcome 7 Adverse effects: 2. Anticholinergic.

\begin{tabular}{|c|c|c|c|c|c|}
\hline Study or subgroup & $\begin{array}{l}\text { Low } \\
\mathrm{n} / \mathrm{N} \\
\end{array}$ & $\begin{array}{c}\text { Medium } \\
\mathrm{n} / \mathrm{N} \\
\end{array}$ & $\begin{array}{c}\text { Risk Ratio } \\
\text { M-H, Fixed, 95\% Cl } \\
\end{array}$ & Weight & $\begin{array}{c}\text { Risk Ratio } \\
\text { M-H, Fixed, 95\% Cl }\end{array}$ \\
\hline \multicolumn{6}{|c|}{ 1.7.1 blurred vision - short term } \\
\hline Wode-Helgodt 1978 & $2 / 33$ & $3 / 15$ & & $100 \%$ & $0.3[0.06,1.63]$ \\
\hline Subtotal $(95 \% \mathrm{Cl})$ & 33 & 15 & & $100 \%$ & $0.3[0.06,1.63]$ \\
\hline \multicolumn{6}{|c|}{ Total events: 2 (Low), 3 (Medium) } \\
\hline \multicolumn{6}{|c|}{ Heterogeneity: Not applicable } \\
\hline \multicolumn{6}{|c|}{ 1.7.2 ejaculation disturbance - short term } \\
\hline Wode-Helgodt 1978 & $0 / 14$ & $0 / 6$ & & & Not estimable \\
\hline Subtotal $(95 \% \mathrm{Cl})$ & 14 & 6 & & & Not estimable \\
\hline \multicolumn{6}{|c|}{ Total events: 0 (Low), 0 (Medium) } \\
\hline \multicolumn{6}{|c|}{ Heterogeneity: Not applicable } \\
\hline \multicolumn{6}{|c|}{ 1.7.3 erectile disturbance - short term } \\
\hline Wode-Helgodt 1978 & $0 / 14$ & $0 / 6$ & & & Not estimable \\
\hline Subtotal $(95 \% \mathrm{Cl})$ & 14 & 6 & & & Not estimable \\
\hline \multicolumn{6}{|c|}{ Total events: 0 (Low), 0 (Medium) } \\
\hline \multicolumn{6}{|c|}{ Heterogeneity: Not applicable } \\
\hline \multicolumn{6}{|c|}{ Test for overall effect: Not applicable } \\
\hline \multicolumn{6}{|c|}{ 1.7.4 constipation - short term } \\
\hline Chouinard 1976 & $2 / 11$ & $2 / 11$ & - & $74.63 \%$ & $1[0.17,5.89]$ \\
\hline Wode-Helgodt 1978 & $4 / 33$ & $0 / 15$ & 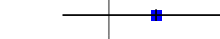 & $25.37 \%$ & $4.24[0.24,74.01]$ \\
\hline Subtotal $(95 \% \mathrm{Cl})$ & 44 & 26 & & $100 \%$ & $1.82[0.42,7.99]$ \\
\hline \multicolumn{6}{|c|}{ Total events: 6 (Low), 2 (Medium) } \\
\hline \multicolumn{6}{|c|}{ 1.7.5 constipation - medium term } \\
\hline Clark 1972 & $0 / 33$ & $2 / 17$ & - & $100 \%$ & $0.11[0.01,2.09]$ \\
\hline Subtotal $(95 \% \mathrm{CI})$ & 33 & 17 & & $100 \%$ & $0.11[0.01,2.09]$ \\
\hline \multicolumn{6}{|c|}{ Total events: 0 (Low), 2 (Medium) } \\
\hline Heterogeneity: Not a & & & & & \\
\hline
\end{tabular}




\begin{tabular}{|c|c|c|c|c|c|}
\hline Study or subgroup & $\begin{array}{l}\text { Low } \\
\mathrm{n} / \mathrm{N}\end{array}$ & $\begin{array}{c}\text { Medium } \\
n / N\end{array}$ & $\begin{array}{c}\text { Risk Ratio } \\
\text { M-H, Fixed, 95\% Cl }\end{array}$ & Weight & $\begin{array}{c}\text { Risk Ratio } \\
\text { M-H, Fixed, 95\% Cl }\end{array}$ \\
\hline \multicolumn{3}{|c|}{ Test for overall effect: $Z=1.48(P=0.14)$} & & & \\
\hline \multicolumn{6}{|c|}{ 1.7.6 salivation - dry mouth - short term } \\
\hline Chouinard 1976 & $4 / 11$ & $3 / 11$ & 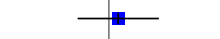 & $30.38 \%$ & $1.33[0.39,4.62]$ \\
\hline Subtotal $(95 \% \mathrm{Cl})$ & 44 & 26 & & $100 \%$ & $1.16[0.58,2.34]$ \\
\hline \multicolumn{6}{|c|}{ Total events: 16 (Low), 8 (Medium) } \\
\hline \multicolumn{6}{|c|}{ Heterogeneity: $\mathrm{Tau}^{2}=0 ; \mathrm{Chi}^{2}=0.07, \mathrm{df}=1(\mathrm{P}=0.79) ; \mathrm{I}^{2}=0 \%$} \\
\hline \multicolumn{6}{|c|}{ Test for overall effect: $Z=0.43(P=0.67)$} \\
\hline \multicolumn{6}{|c|}{ 1.7.7 salivation - too much - short term } \\
\hline Subtotal $(95 \% \mathrm{Cl})$ & 33 & 15 & & $100 \%$ & $0.09[0,1.85]$ \\
\hline \multicolumn{6}{|c|}{ Total events: 0 (Low), 2 (Medium) } \\
\hline \multicolumn{6}{|c|}{ Heterogeneity: Not applicable } \\
\hline \multicolumn{6}{|c|}{ Test for overall effect: $Z=1.56(P=0.12)$} \\
\hline \multicolumn{6}{|c|}{ 1.7.8 tachycardia - short term } \\
\hline Chouinard 1976 & $1 / 11$ & $2 / 11$ & & $100 \%$ & $0.5[0.05,4.75]$ \\
\hline Subtotal $(95 \% \mathrm{Cl})$ & 11 & 11 & & $100 \%$ & $0.5[0.05,4.75]$ \\
\hline \multicolumn{6}{|c|}{ Total events: 1 (Low), 2 (Medium) } \\
\hline \multicolumn{6}{|c|}{ Heterogeneity: Not applicable } \\
\hline \multicolumn{6}{|c|}{ Test for overall effect: $Z=0.6(P=0.55)$} \\
\hline \multicolumn{6}{|c|}{ 1.7.9 urinary disturbance/trouble starting urination - short term } \\
\hline Subtotal $(95 \% \mathrm{Cl})$ & 44 & 26 & & $100 \%$ & $3[0.37,24.58]$ \\
\hline \multicolumn{6}{|c|}{ Total events: 3 (Low), 1 (Medium) } \\
\hline \multicolumn{6}{|c|}{ Heterogeneity: Not applicable } \\
\hline Test for overall effect & & & & & \\
\hline
\end{tabular}

Analysis 1.8. Comparison 1 CHLORPROMAZINE LOW DOSE ( $\leq 400 \mathrm{mg} /$ day) vs MEDIUM DOSE (401-800 mg/day), Outcome 8 Adverse effects: 3. Cardiovascular.

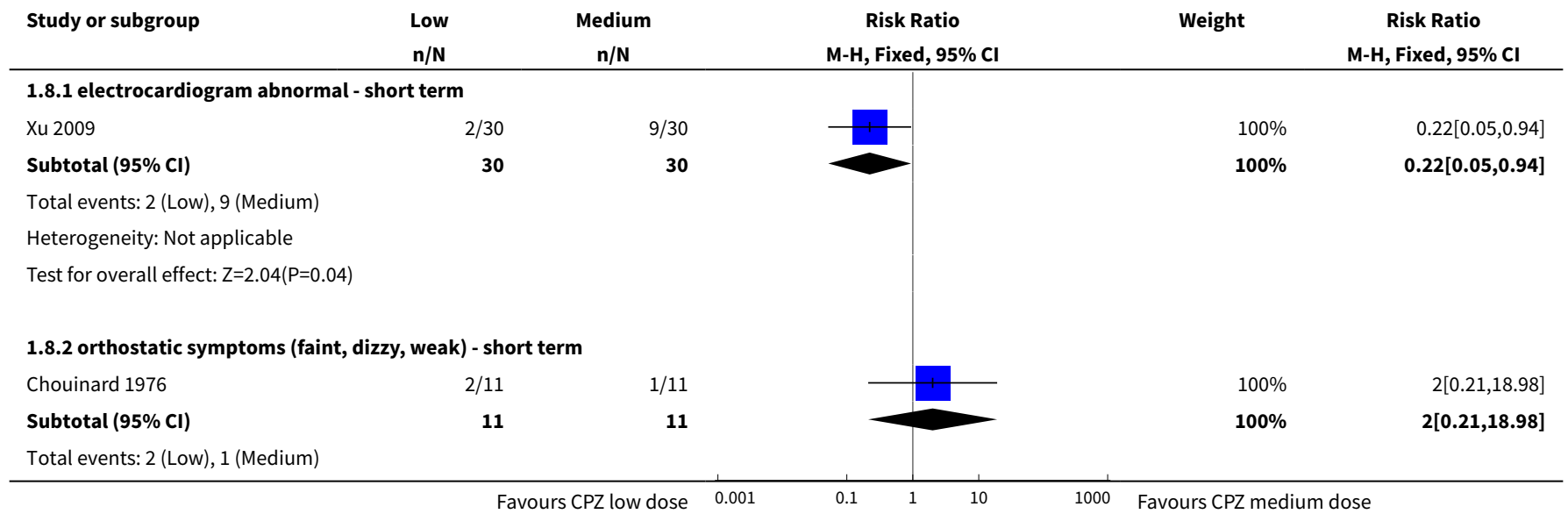




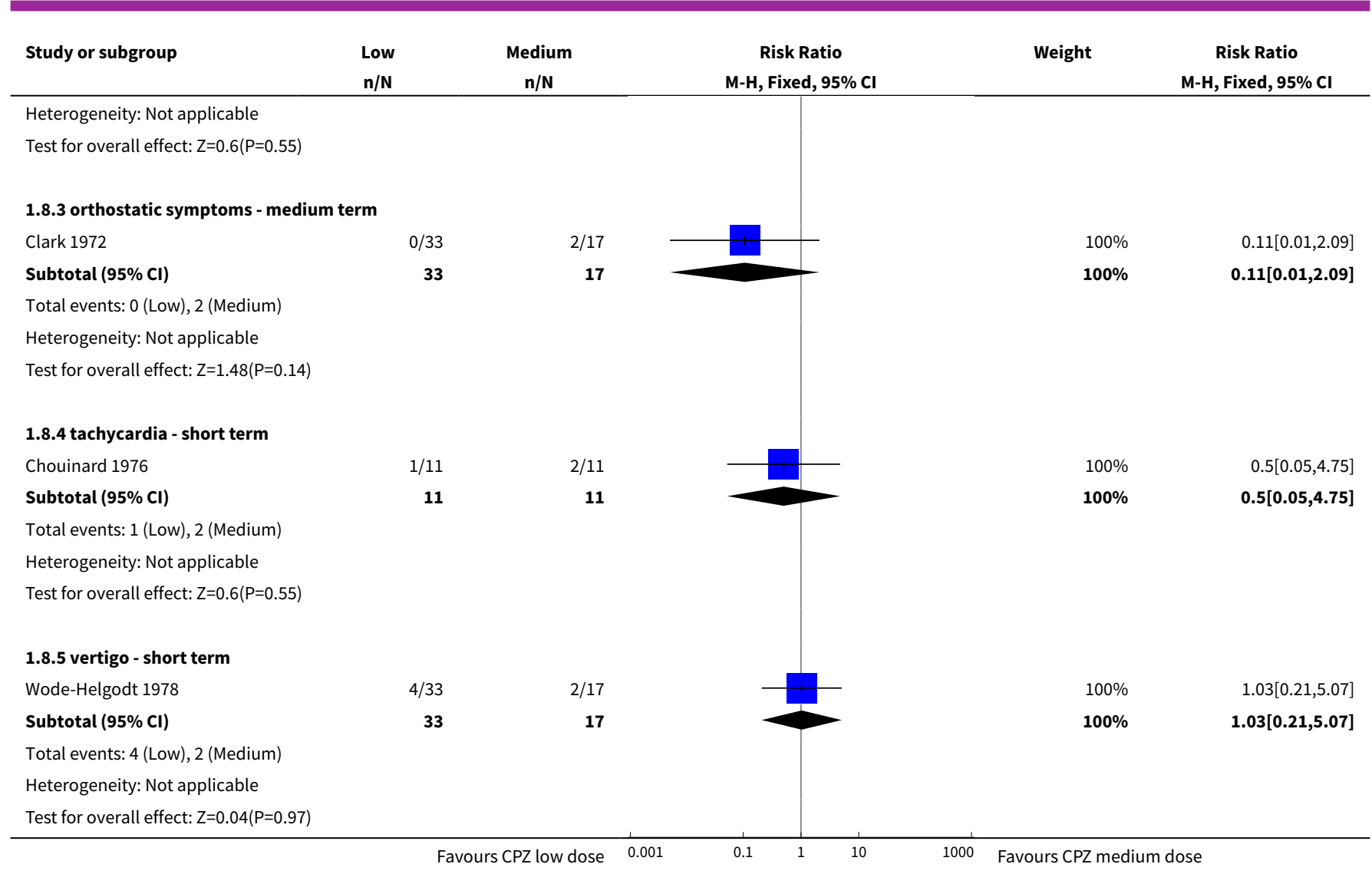

Analysis 1.9. Comparison 1 CHLORPROMAZINE LOW DOSE ( $\leq 400 \mathrm{mg} / \mathrm{day}$ ) vs MEDIUM DOSE (401-800 $\mathrm{mg} /$ day), Outcome 9 Adverse effects: 4. Central nervous system - other than extrapyramidal symptoms.

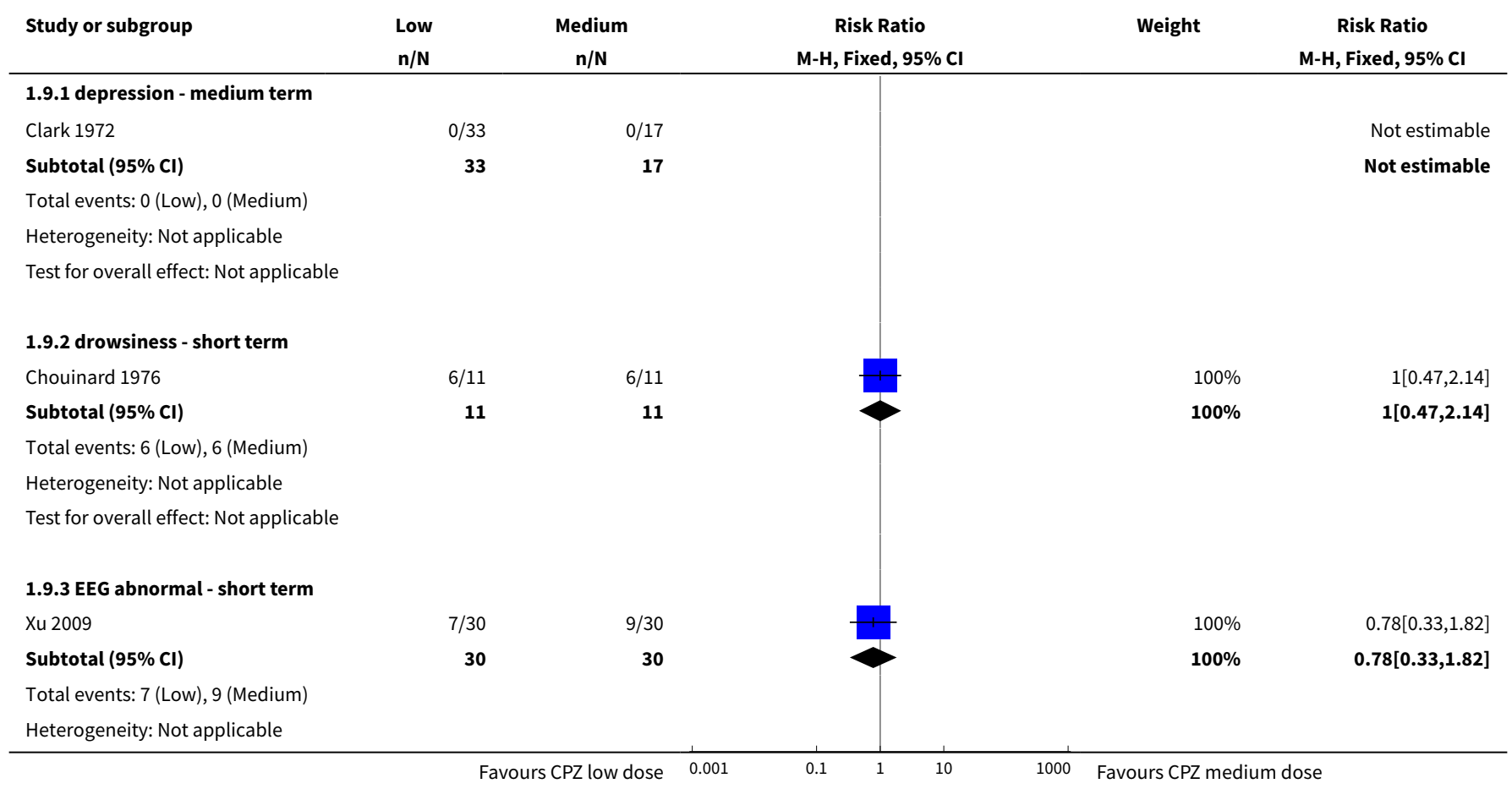




\begin{tabular}{|c|c|c|c|c|c|}
\hline Study or subgroup & $\begin{array}{l}\text { Low } \\
\mathrm{n} / \mathrm{N}\end{array}$ & $\begin{array}{c}\text { Medium } \\
\mathrm{n} / \mathrm{N}\end{array}$ & $\begin{array}{c}\text { Risk Ratio } \\
\text { M-H, Fixed, 95\% Cl }\end{array}$ & Weight & $\begin{array}{c}\text { Risk Ratio } \\
\text { M-H, Fixed, 95\% Cl }\end{array}$ \\
\hline \multicolumn{6}{|c|}{ Test for overall effect: $Z=0.58(P=0.56)$} \\
\hline \multicolumn{6}{|c|}{ 1.9.4 head feels heavy - short term } \\
\hline Wode-Helgodt 1978 & $1 / 33$ & $3 / 15$ & & $100 \%$ & $0.15[0.02,1.34]$ \\
\hline \multicolumn{6}{|c|}{ Total events: 1 (Low), 3 (Medium) } \\
\hline \multicolumn{6}{|c|}{ Heterogeneity: Not applicable } \\
\hline \multicolumn{6}{|c|}{ Test for overall effect: $Z=1.7(P=0.09)$} \\
\hline \multicolumn{6}{|c|}{ 1.9.5 headache - short term } \\
\hline Wode-Helgodt 1978 & $2 / 33$ & $0 / 15$ & + & $100 \%$ & $2.35[0.12,46.22]$ \\
\hline \multicolumn{6}{|c|}{ Total events: 2 (Low), 0 (Medium) } \\
\hline \multicolumn{6}{|c|}{ Heterogeneity: Not applicable } \\
\hline \multicolumn{6}{|c|}{ Test for overall effect: $Z=0.56(P=0.57)$} \\
\hline \multicolumn{6}{|c|}{ 1.9.6 sedation - medium term } \\
\hline Clark 1972 & $3 / 33$ & $9 / 17$ & & $100 \%$ & $0.17[0.05,0.55]$ \\
\hline Subtotal $(95 \% \mathrm{Cl})$ & 33 & 17 & & $100 \%$ & $0.17[0.05,0.55]$ \\
\hline \multicolumn{6}{|c|}{ Total events: 3 (Low), 9 (Medium) } \\
\hline \multicolumn{6}{|c|}{ Heterogeneity: Not applicable } \\
\hline \multicolumn{6}{|c|}{ Test for overall effect: $Z=2.96(P=0)$} \\
\hline \multicolumn{6}{|c|}{ 1.9.7 somnolence - short term } \\
\hline Wode-Helgodt 1978 & $17 / 33$ & $7 / 15$ & & $100 \%$ & $1.1[0.59,2.08]$ \\
\hline \multicolumn{6}{|c|}{ Heterogeneity: Not applicable } \\
\hline \multicolumn{6}{|c|}{ Test for overall effect: $Z=0.31(P=0.76)$} \\
\hline \multicolumn{6}{|c|}{ 1.9.8 vertigo - short term } \\
\hline Wode-Helgodt 1978 & $4 / 33$ & $2 / 15$ & & $100 \%$ & $0.91[0.19,4.43]$ \\
\hline Subtotal $(95 \% \mathrm{CI})$ & 33 & 15 & & $100 \%$ & $0.91[0.19,4.43]$ \\
\hline \multicolumn{6}{|c|}{ Total events: 4 (Low), 2 (Medium) } \\
\hline \multicolumn{6}{|c|}{ Heterogeneity: Not applicable } \\
\hline Test for overall effect & & & & & \\
\hline
\end{tabular}

Analysis 1.10. Comparison 1 CHLORPROMAZINE LOW DOSE ( $\leq 400 \mathrm{mg} /$ day) vs MEDIUM DOSE (401-800 mg/day), Outcome 10 Adverse effects: 5. Dermatological.

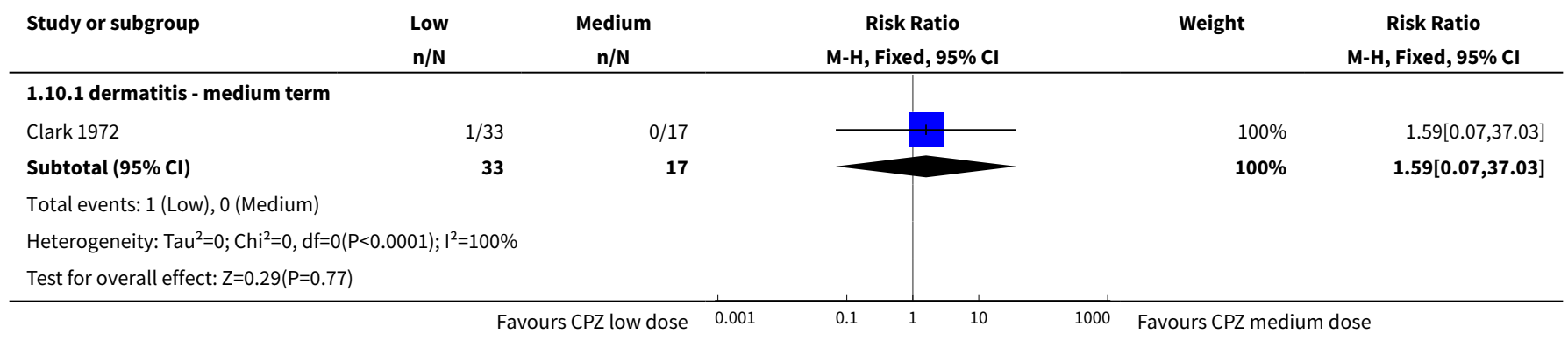




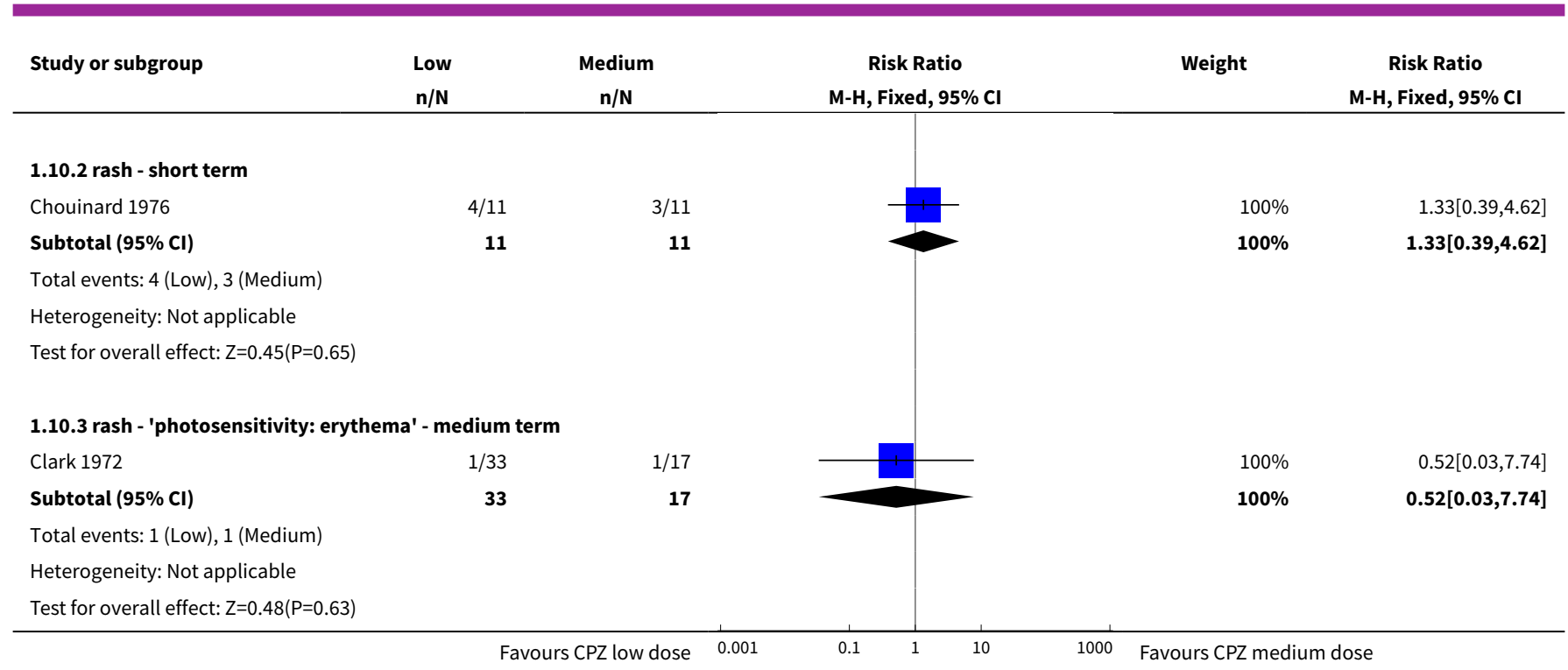

\section{Analysis 1.11. Comparison 1 CHLORPROMAZINE LOW DOSE ( $\leq 400 \mathrm{mg} /$ day) vs MEDIUM DOSE (401-800 mg/day), Outcome 11 Adverse effects: 6. Endocrine and metabolic.}

\begin{tabular}{|c|c|c|c|c|c|}
\hline Study or subgroup & $\begin{array}{l}\text { Low } \\
\mathrm{n} / \mathrm{N}\end{array}$ & $\begin{array}{c}\text { Medium } \\
n / N\end{array}$ & $\begin{array}{c}\text { Risk Ratio } \\
\text { M-H, Fixed, 95\% Cl }\end{array}$ & Weight & $\begin{array}{c}\text { Risk Ratio } \\
\text { M-H, Fixed, 95\% Cl }\end{array}$ \\
\hline \multicolumn{6}{|c|}{ 1.11.1 amenorrhoea - short term } \\
\hline Wode-Helgodt 1978 & $1 / 19$ & $1 / 9$ & & $100 \%$ & $0.47[0.03,6.74]$ \\
\hline Subtotal $(95 \% \mathrm{CI})$ & 19 & 9 & & $100 \%$ & $0.47[0.03,6.74]$ \\
\hline \multicolumn{6}{|c|}{ Total events: 1 (Low), 1 (Medium) } \\
\hline \multicolumn{6}{|c|}{ Heterogeneity: $\mathrm{Tau}^{2}=0 ; \mathrm{Chi}^{2}=0, \mathrm{df}=0(\mathrm{P}<0.0001) ; \mathrm{I}^{2}=100 \%$} \\
\hline \multicolumn{6}{|c|}{ 1.11.2 lactation - short term } \\
\hline Wode-Helgodt 1978 & $0 / 19$ & $1 / 9$ & & $100 \%$ & $0.17[0.01,3.73]$ \\
\hline Subtotal $(95 \% \mathrm{Cl})$ & 19 & 9 & & $100 \%$ & $0.17[0.01,3.73]$ \\
\hline \multicolumn{6}{|c|}{ Total events: 0 (Low), 1 (Medium) } \\
\hline \multicolumn{6}{|c|}{ Heterogeneity: Not applicable } \\
\hline \multicolumn{6}{|c|}{ 1.11.3 metrorrhagia - medium term } \\
\hline Clark 1972 & $0 / 33$ & $1 / 17$ & & $100 \%$ & $0.18[0.01,4.11]$ \\
\hline Subtotal $(95 \% \mathrm{Cl})$ & 33 & 17 & & $100 \%$ & $0.18[0.01,4.11]$ \\
\hline \multicolumn{6}{|c|}{ Total events: 0 (Low), 1 (Medium) } \\
\hline \multicolumn{6}{|c|}{ Heterogeneity: Not applicable } \\
\hline Test for overall effect & & & & & \\
\hline
\end{tabular}


Analysis 1.12. Comparison 1 CHLORPROMAZINE LOW DOSE ( $\leq 400 \mathrm{mg} /$ day) vs MEDIUM DOSE (401-800 mg/day), Outcome 12 Adverse effects: 7. Gastrointestinal.

\begin{tabular}{|c|c|c|c|c|c|}
\hline Study or subgroup & $\begin{array}{l}\text { Low } \\
\mathrm{n} / \mathrm{N}\end{array}$ & $\begin{array}{c}\text { Medium } \\
\mathrm{n} / \mathrm{N}\end{array}$ & $\begin{array}{c}\text { Risk Ratio } \\
\text { M-H, Fixed, 95\% Cl }\end{array}$ & Weight & $\begin{array}{c}\text { Risk Ratio } \\
\text { M-H, Fixed, 95\% Cl }\end{array}$ \\
\hline \multicolumn{6}{|c|}{ 1.12.1 constipation - short term } \\
\hline Chouinard 1976 & $2 / 11$ & $2 / 11$ & & $74.63 \%$ & $1[0.17,5.89]$ \\
\hline Wode-Helgodt 1978 & $4 / 33$ & $0 / 15$ & & $25.37 \%$ & $4.24[0.24,74.01]$ \\
\hline Subtotal $(95 \% \mathrm{CI})$ & 44 & 26 & & $100 \%$ & $1.82[0.42,7.99]$ \\
\hline \multicolumn{6}{|c|}{ Total events: 6 (Low), 2 (Medium) } \\
\hline \multicolumn{6}{|c|}{ Test for overall effect: $Z=0.79(P=0.43)$} \\
\hline \multicolumn{6}{|c|}{ 1.12.2 constipation - medium term } \\
\hline Clark 1972 & $0 / 33$ & $2 / 17$ & & $100 \%$ & $0.11[0.01,2.09]$ \\
\hline Subtotal $(95 \% \mathrm{Cl})$ & 33 & 17 & & $100 \%$ & $0.11[0.01,2.09]$ \\
\hline \multicolumn{6}{|c|}{ Total events: 0 (Low), 2 (Medium) } \\
\hline \multicolumn{6}{|c|}{ Heterogeneity: Not applicable } \\
\hline \multicolumn{6}{|c|}{ Test for overall effect: $Z=1.48(P=0.14)$} \\
\hline \multicolumn{6}{|c|}{ 1.12.3 unspecified - short term } \\
\hline Chouinard 1976 & $2 / 11$ & $0 / 11$ & & $100 \%$ & $5[0.27,93.55]$ \\
\hline Subtotal $(95 \% \mathrm{CI})$ & 11 & 11 & & $100 \%$ & $5[0.27,93.55]$ \\
\hline \multicolumn{6}{|c|}{ Total events: 2 (Low), 0 (Medium) } \\
\hline \multicolumn{6}{|c|}{ Heterogeneity: Not applicable } \\
\hline Test for overall effect & & & & & \\
\hline
\end{tabular}

Analysis 1.13. Comparison 1 CHLORPROMAZINE LOW DOSE ( $\leq 400 \mathrm{mg} /$ day) vs MEDIUM DOSE (401-800 mg/day), Outcome 13 Adverse effects: 8. Genitourinary.

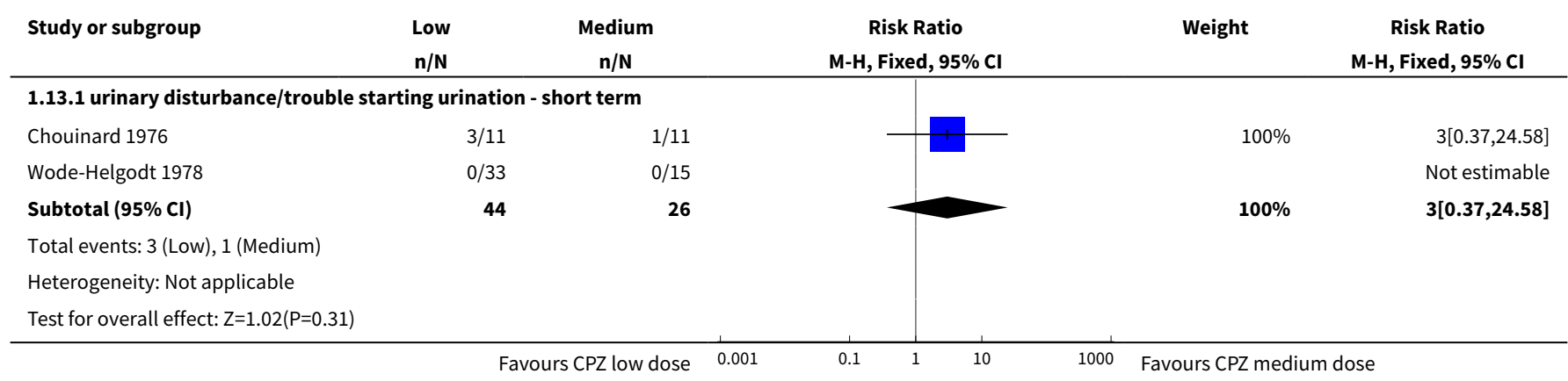

Analysis 1.14. Comparison 1 CHLORPROMAZINE LOW DOSE ( $\leq 400 \mathrm{mg} /$ day) vs MEDIUM DOSE (401-800 mg/day), Outcome 14 Adverse effects: 9. Haematological.

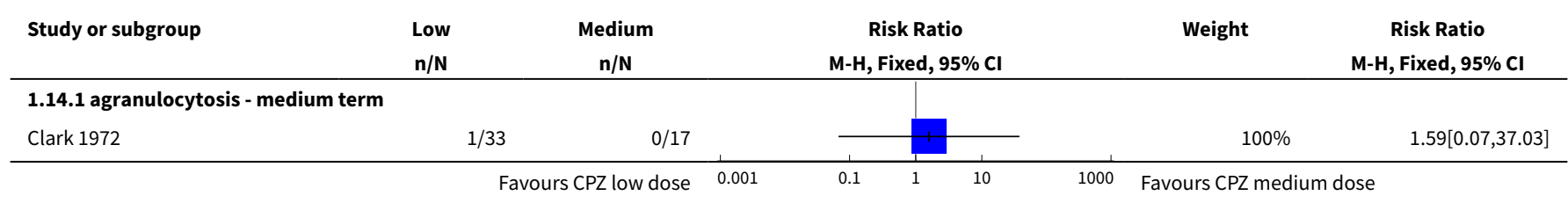




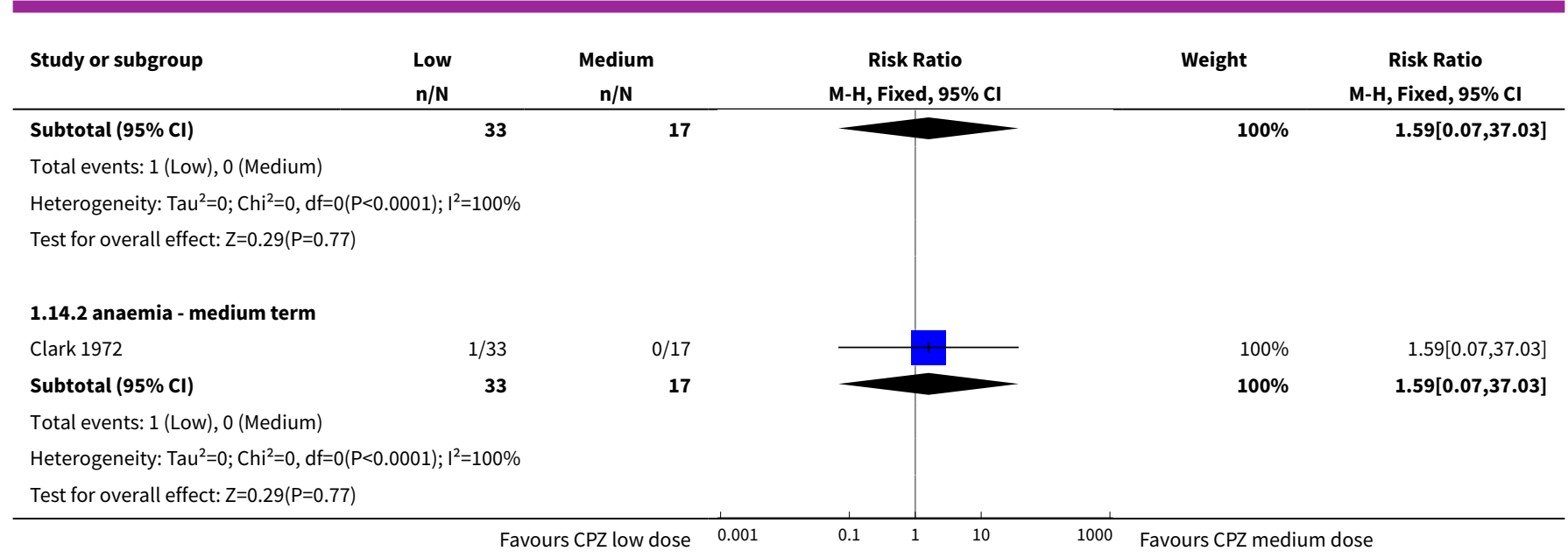

Analysis 1.15. Comparison 1 CHLORPROMAZINE LOW DOSE ( $\leq 400 \mathrm{mg} /$ day) vs MEDIUM DOSE (401-800 mg/day), Outcome 15 Adverse effects: 10 . Hepatological.

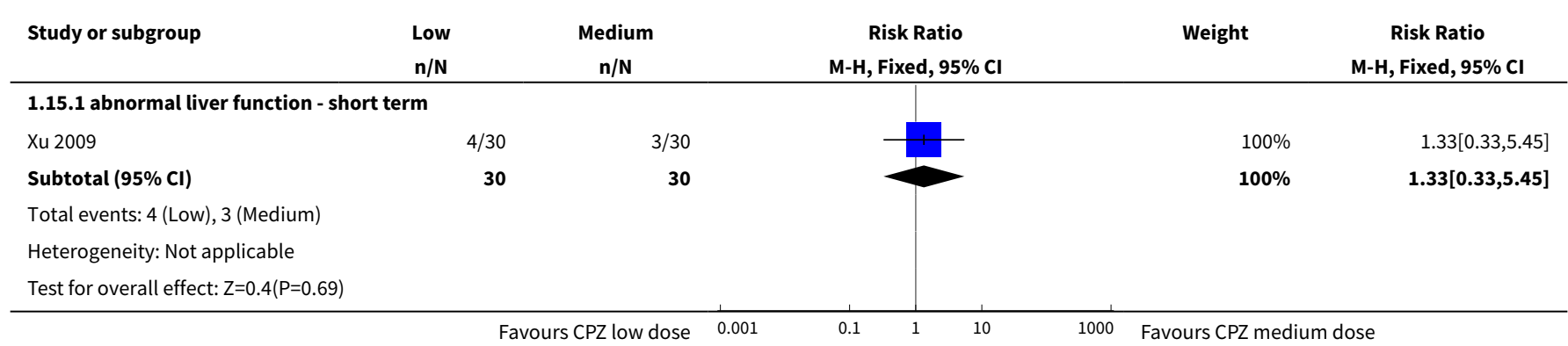

Analysis 1.16. Comparison 1 CHLORPROMAZINE LOW DOSE ( $\leq 400 \mathrm{mg} /$ day) vs MEDIUM DOSE (401-800 mg/day), Outcome 16 Adverse effects: 11. Others.

\begin{tabular}{|c|c|c|c|c|c|}
\hline Study or subgroup & $\begin{array}{l}\text { Low } \\
\mathrm{n} / \mathrm{N}\end{array}$ & $\begin{array}{c}\text { Medium } \\
n / N\end{array}$ & $\begin{array}{c}\text { Risk Ratio } \\
\text { M-H, Fixed, 95\% Cl }\end{array}$ & Weight & $\begin{array}{c}\text { Risk Ratio } \\
\text { M-H, Fixed, 95\% Cl }\end{array}$ \\
\hline \multicolumn{6}{|c|}{ 1.16.1 agitation and restlessness - medium term } \\
\hline Clark 1972 & $1 / 33$ & $0 / 17$ & & $100 \%$ & $1.59[0.07,37.03]$ \\
\hline Subtotal $(95 \% \mathrm{CI})$ & 33 & 17 & & $100 \%$ & $1.59[0.07,37.03]$ \\
\hline \multicolumn{6}{|c|}{ Total events: 1 (Low), 0 (Medium) } \\
\hline \multicolumn{6}{|c|}{ Heterogeneity: Tau $^{2}=0 ; \mathrm{Chi}^{2}=0, \mathrm{df}=0(\mathrm{P}<0.0001) ; \mathrm{I}^{2}=100 \%$} \\
\hline \multicolumn{6}{|c|}{ Test for overall effect: $Z=0.29(P=0.77)$} \\
\hline \multicolumn{6}{|c|}{ 1.16.2 excitement - short term } \\
\hline Chouinard 1976 & $1 / 11$ & $1 / 11$ & & $100 \%$ & $1[0.07,14.05]$ \\
\hline Subtotal $(95 \% \mathrm{Cl})$ & 11 & 11 & & $100 \%$ & $1[0.07,14.05]$ \\
\hline \multicolumn{6}{|c|}{ Total events: 1 (Low), 1 (Medium) } \\
\hline \multicolumn{6}{|c|}{ Heterogeneity: Not applicable } \\
\hline \multicolumn{6}{|c|}{ 1.16.3 restlessness, insomnia - short term } \\
\hline Chouinard 1976 & $3 / 11$ & $4 / 11$ & & $100 \%$ & $0.75[0.22,2.6]$ \\
\hline
\end{tabular}




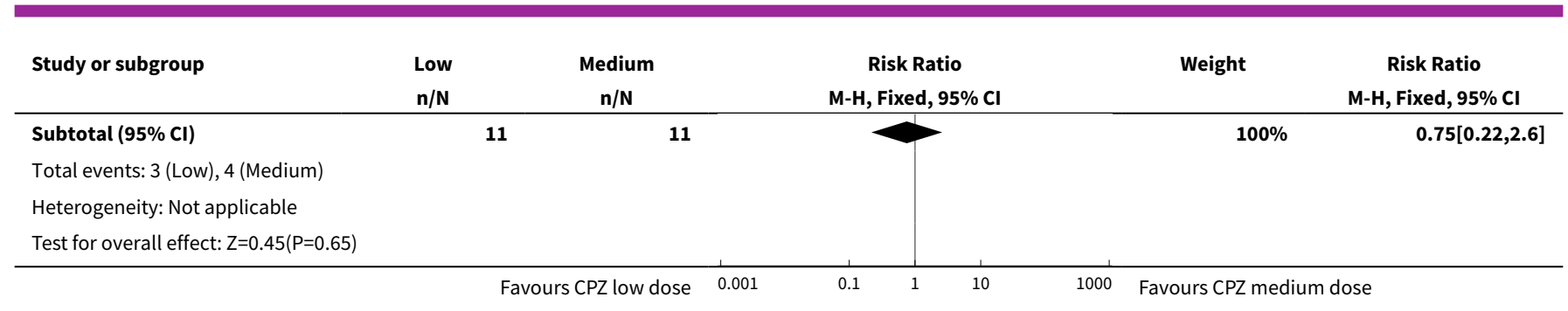

\section{Comparison 2. CHLORPROMAZINE LOW DOSE ( $\leq 400 \mathrm{mg} /$ day) vS HIGH DOSE ( $>800 \mathrm{mg} / \mathrm{day}$ - all medium term)}

\begin{tabular}{|c|c|c|c|c|}
\hline Outcome or subgroup title & No. of studies & $\begin{array}{l}\text { No. of partici- } \\
\text { pants }\end{array}$ & Statistical method & Effect size \\
\hline $\begin{array}{l}1 \text { Global state: Not improved, } \\
\text { severely ill, relapse (GAS) }\end{array}$ & 1 & & Risk Ratio (M-H, Fixed, 95\% CI) & Subtotals only \\
\hline $\begin{array}{l}1.1 \text { no clinically important im- } \\
\text { provement }\end{array}$ & 1 & 416 & Risk Ratio (M-H, Fixed, 95\% CI) & $1.13[1.01,1.25]$ \\
\hline 1.2 severely ill & 1 & 416 & Risk Ratio (M-H, Fixed, 95\% Cl) & $1.09[0.96,1.24]$ \\
\hline 1.3 relapse & 1 & 416 & Risk Ratio (M-H, Fixed, 95\% CI) & $2.25[1.17,4.32]$ \\
\hline 2 Leaving the study early & 1 & & Risk Ratio (M-H, Fixed, 95\% Cl) & Subtotals only \\
\hline 2.1 any reason & 1 & 416 & Risk Ratio (M-H, Fixed, 95\% CI) & $0.60[0.40,0.89]$ \\
\hline 2.2 adverse effects & 1 & 416 & Risk Ratio (M-H, Fixed, 95\% CI) & $0.10[0.03,0.26]$ \\
\hline 2.3 death & 1 & 416 & Risk Ratio (M-H, Fixed, 95\% CI) & $0.33[0.01,8.14]$ \\
\hline 2.4 deterioration of behaviour & 1 & 416 & Risk Ratio (M-H, Fixed, 95\% Cl) & $2.7[1.34,5.44]$ \\
\hline $\begin{array}{l}3 \text { Adverse effects: } 1 \text {. Central } \\
\text { nervous system - extrapyrami- } \\
\text { dal symptoms }\end{array}$ & 1 & & Risk Ratio (M-H, Fixed, 95\% Cl) & Subtotals only \\
\hline 3.1 akathisia & 1 & 416 & Risk Ratio (M-H, Fixed, 95\% Cl) & $1.0[0.55,1.83]$ \\
\hline 3.2 dystonia & 1 & 416 & Risk Ratio (M-H, Fixed, 95\% Cl) & $0.11[0.02,0.45]$ \\
\hline 3.3 parkinsonian reaction & 1 & 416 & Risk Ratio (M-H, Fixed, 95\% CI) & $0.52[0.30,0.90]$ \\
\hline $\begin{array}{l}3.4 \text { required antiparkinsonian } \\
\text { medication }\end{array}$ & 1 & 416 & Risk Ratio (M-H, Fixed, 95\% Cl) & $0.39[0.26,0.59]$ \\
\hline 3.5 unspecified & 1 & 416 & Risk Ratio (M-H, Fixed, 95\% Cl) & $0.43[0.32,0.59]$ \\
\hline $\begin{array}{l}4 \text { Adverse effects: } 2 \text {. Anti- } \\
\text { cholinergic symptoms }\end{array}$ & 1 & & Risk Ratio (M-H, Fixed, 95\% Cl) & Subtotals only \\
\hline 4.1 blurred vision & 1 & 416 & Risk Ratio (M-H, Fixed, 95\% CI) & $0.2[0.01,4.14]$ \\
\hline 4.2 constipation & 1 & 416 & Risk Ratio (M-H, Fixed, 95\% Cl) & $0.27[0.09,0.79]$ \\
\hline
\end{tabular}




\begin{tabular}{|c|c|c|c|c|}
\hline Outcome or subgroup title & No. of studies & $\begin{array}{l}\text { No. of partici- } \\
\text { pants }\end{array}$ & Statistical method & Effect size \\
\hline $\begin{array}{l}4.3 \text { salivation - too little (dry } \\
\text { mouth) }\end{array}$ & 1 & 416 & Risk Ratio (M-H, Fixed, 95\% Cl) & $0.21[0.07,0.61]$ \\
\hline 4.4 salivation - too much & 1 & 416 & Risk Ratio (M-H, Fixed, 95\% Cl) & $0.2[0.04,0.90]$ \\
\hline 4.5 urinary disturbance & 1 & 416 & Risk Ratio (M-H, Fixed, 95\% Cl) & $0.5[0.09,2.70]$ \\
\hline $\begin{array}{l}5 \text { Adverse effects: } 3 \text {. Central } \\
\text { nervous system - other than } \\
\text { extrapyramidal symptoms }\end{array}$ & 1 & & Risk Ratio (M-H, Fixed, 95\% Cl) & Subtotals only \\
\hline 5.1 drowsiness & 1 & 416 & Risk Ratio (M-H, Fixed, 95\% Cl) & $0.39[0.27,0.57]$ \\
\hline 5.2 seizures & 1 & 416 & Risk Ratio (M-H, Fixed, 95\% Cl) & $0.17[0.04,0.74]$ \\
\hline $\begin{array}{l}6 \text { Adverse effects: } 4 \text {. Cardiovas- } \\
\text { cular }\end{array}$ & 1 & & Risk Ratio (M-H, Fixed, 95\% Cl) & Subtotals only \\
\hline 6.1 dizziness, faintness & 1 & 416 & Risk Ratio (M-H, Fixed, 95\% Cl) & $0.3[0.16,0.56]$ \\
\hline 6.2 peripheral oedema & 1 & 416 & Risk Ratio (M-H, Fixed, 95\% Cl) & $0.33[0.07,1.63]$ \\
\hline 6.3 syncope & 1 & 416 & Risk Ratio (M-H, Fixed, 95\% Cl) & $0.5[0.09,2.70]$ \\
\hline $\begin{array}{l}7 \text { Adverse effects: 5. Dermato- } \\
\text { logical }\end{array}$ & 1 & & Risk Ratio (M-H, Fixed, 95\% Cl) & Subtotals only \\
\hline 7.1 photosensitivity & 1 & 416 & Risk Ratio (M-H, Fixed, 95\% Cl) & $0.09[0.03,0.24]$ \\
\hline 7.2 rashes, itching & 1 & 416 & Risk Ratio (M-H, Fixed, 95\% Cl) & $0.13[0.03,0.58]$ \\
\hline $\begin{array}{l}8 \text { Adverse effects: } 6 \text {. Gastroin- } \\
\text { testinal }\end{array}$ & 1 & & Risk Ratio (M-H, Fixed, 95\% Cl) & Subtotals only \\
\hline 8.1 constipation & 1 & 416 & Risk Ratio (M-H, Fixed, 95\% Cl) & $0.27[0.09,0.79]$ \\
\hline 8.2 diarrhoea & 1 & 416 & Risk Ratio (M-H, Fixed, 95\% Cl) & $0.5[0.09,2.70]$ \\
\hline 8.3 nausea, vomiting & 1 & 416 & Risk Ratio (M-H, Fixed, 95\% Cl) & $0.67[0.19,2.33]$ \\
\hline $\begin{array}{l}9 \text { Adverse effects: } 7 \text {. Genitouri- } \\
\text { nary }\end{array}$ & 1 & & Risk Ratio (M-H, Fixed, 95\% Cl) & Subtotals only \\
\hline 9.1 urinary disturbance & 1 & 416 & Risk Ratio (M-H, Fixed, 95\% Cl) & $0.5[0.09,2.70]$ \\
\hline 10 Adverse effects: 8 . Others & 1 & & Risk Ratio (M-H, Fixed, 95\% Cl) & Subtotals only \\
\hline $\begin{array}{l}10.1 \text { occular - any lens/corneal } \\
\text { opacities }\end{array}$ & 1 & 416 & Risk Ratio (M-H, Fixed, 95\% Cl) & $0.35[0.23,0.52]$ \\
\hline $\begin{array}{l}10.2 \text { occular - corneal changes } \\
\text { only }\end{array}$ & 1 & 416 & Risk Ratio (M-H, Fixed, 95\% Cl) & $0.07[0.02,0.30]$ \\
\hline $\begin{array}{l}10.3 \text { occular - lens changes on- } \\
\text { ly }\end{array}$ & 1 & 416 & Risk Ratio (M-H, Fixed, 95\% Cl) & $1.75[0.88,3.46]$ \\
\hline
\end{tabular}




\begin{tabular}{lllll}
\hline Outcome or subgroup title & No. of studies & $\begin{array}{l}\text { No. of partici- } \\
\text { pants }\end{array}$ & Statistical method & Effect size \\
\hline $\begin{array}{l}10.4 \text { occular - lens and corneal } \\
\text { changes }\end{array}$ & 1 & 416 & Risk Ratio (M-H, Fixed, 95\% Cl) & $0.06[0.02,0.26]$ \\
\hline 10.5 nasal congestion & 1 & 416 & Risk Ratio (M-H, Fixed, $95 \% \mathrm{Cl})$ & $1.0[0.14,7.03]$ \\
\hline
\end{tabular}

Analysis 2.1. Comparison 2 CHLORPROMAZINE LOW DOSE ( $\leq 400 \mathrm{mg} /$ day) vs HIGH DOSE (>800 $\mathrm{mg} /$ day - all medium term), Outcome $1 \mathrm{Global}$ state: Not improved, severely ill, relapse (GAS).

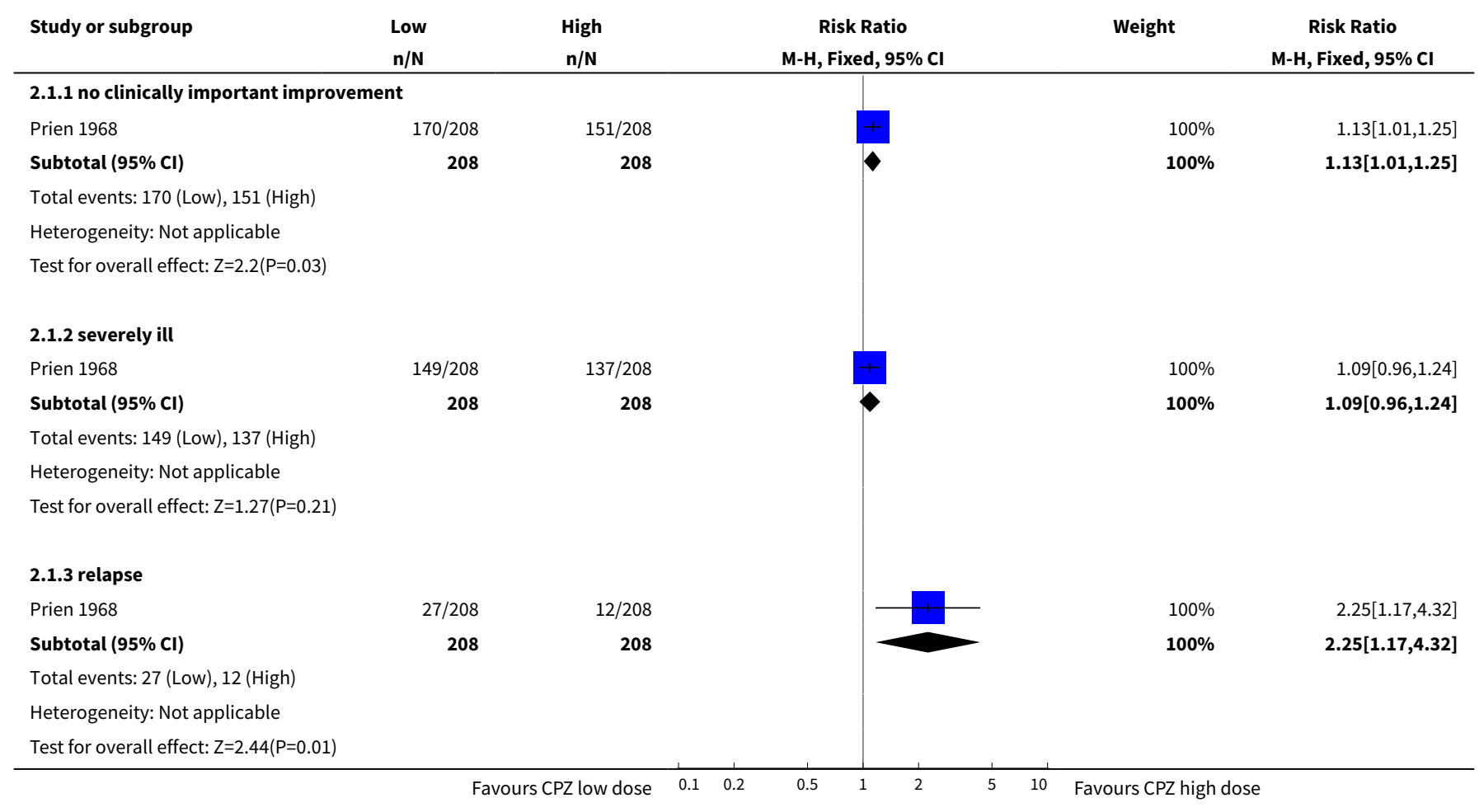

Analysis 2.2. Comparison 2 CHLORPROMAZINE LOW DOSE ( $\leq 400 \mathrm{mg} / \mathrm{day}$ ) vs HIGH DOSE ( $>800 \mathrm{mg} /$ day - all medium term), Outcome 2 Leaving the study early.

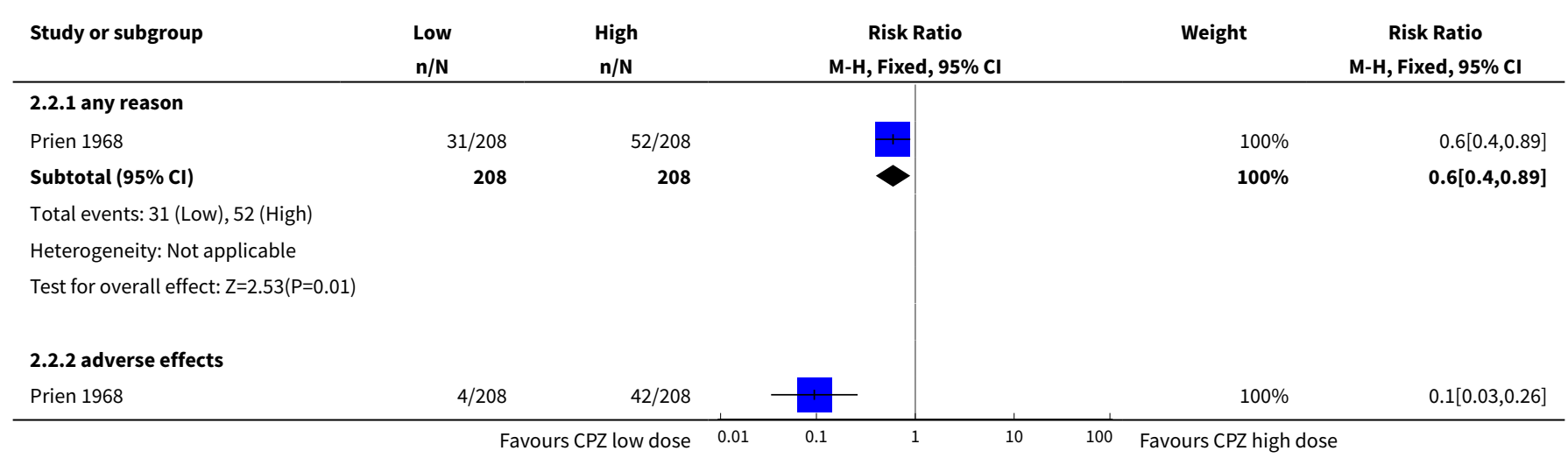




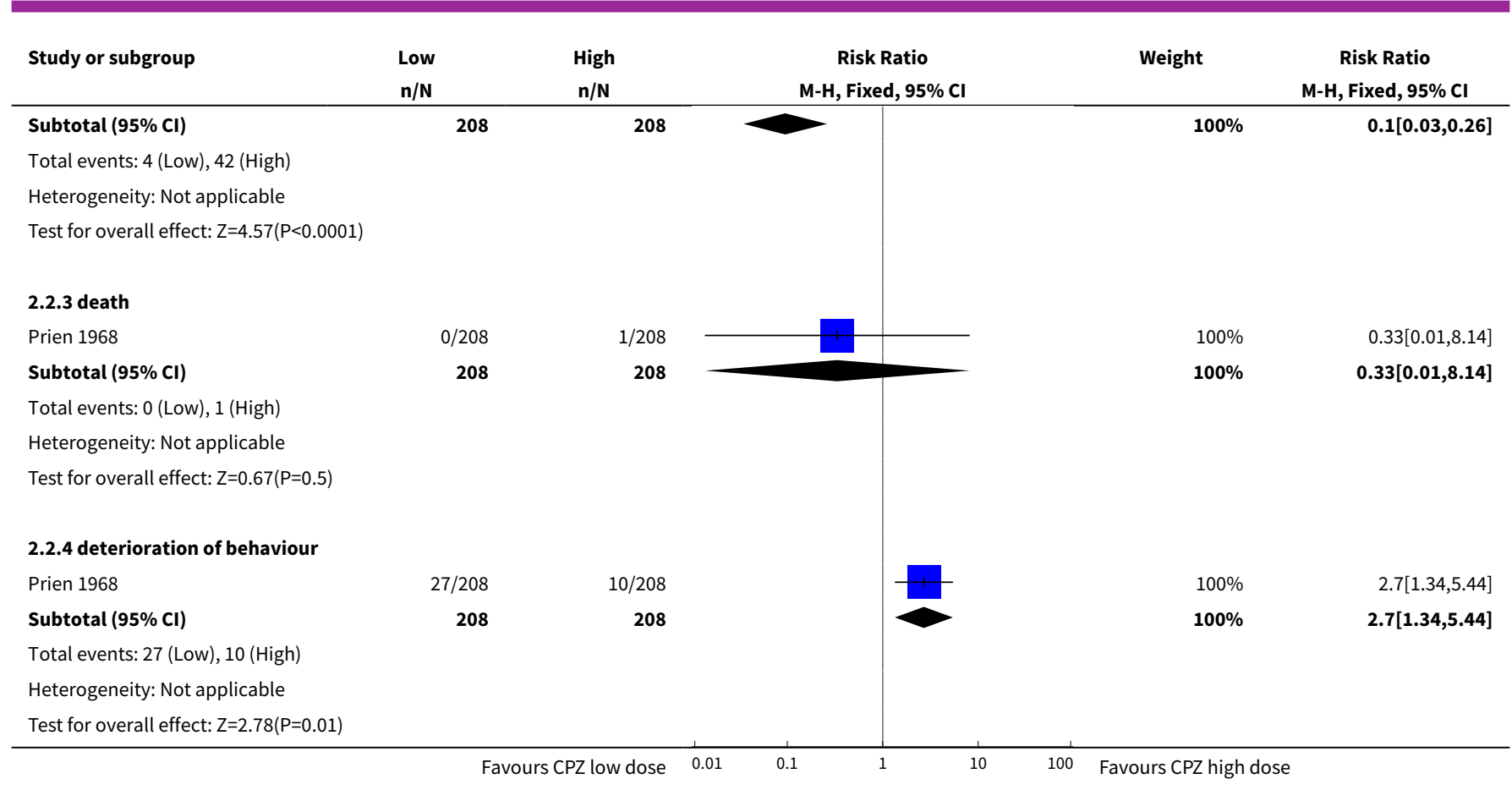

Analysis 2.3. Comparison 2 CHLORPROMAZINE LOW DOSE ( $\leq 400 \mathrm{mg} / \mathrm{day})$ vs HIGH DOSE ( $>800 \mathrm{mg} / \mathrm{day}$ - all medium term), Outcome 3 Adverse effects: 1. Central nervous system - extrapyramidal symptoms.

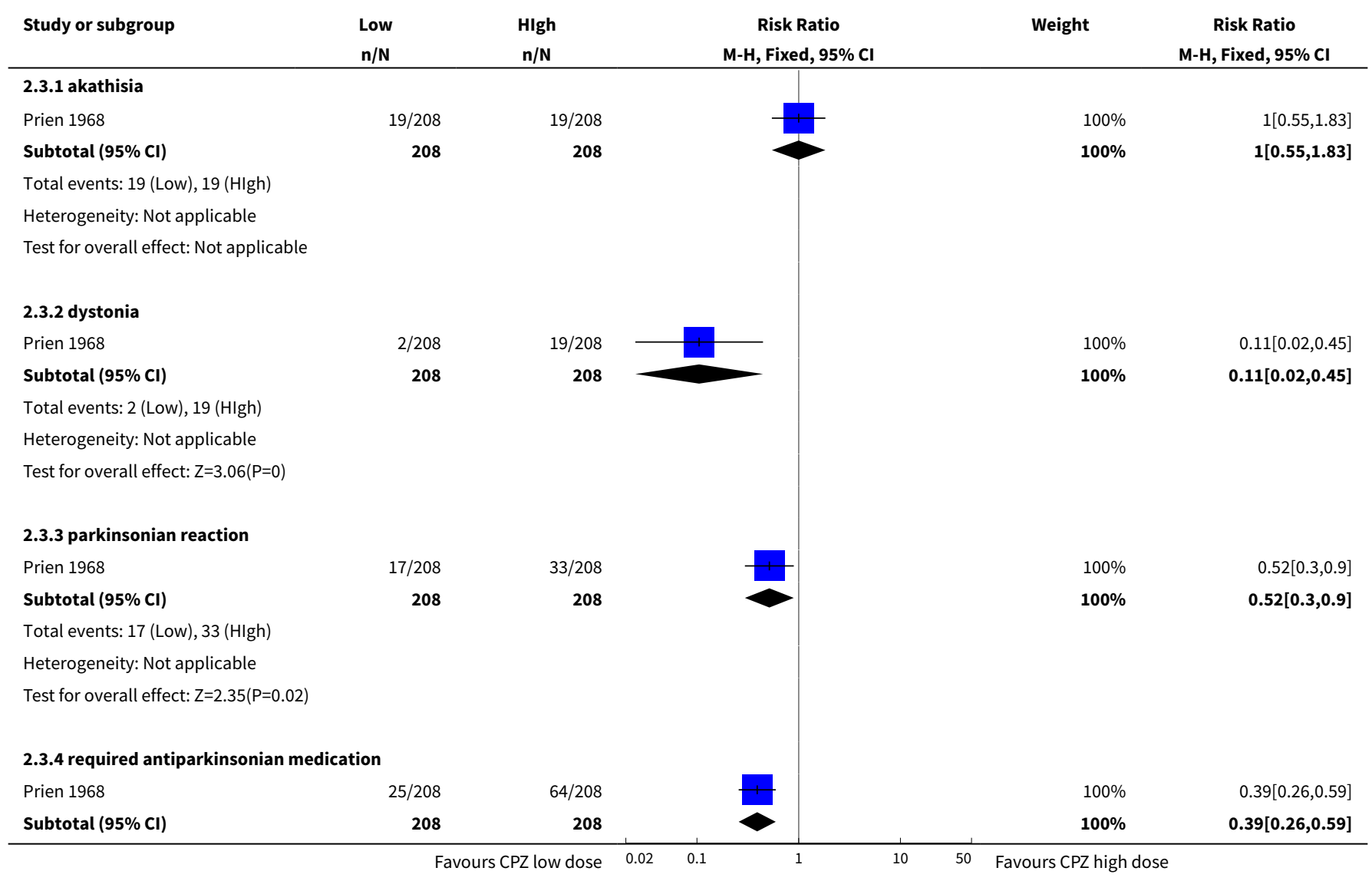




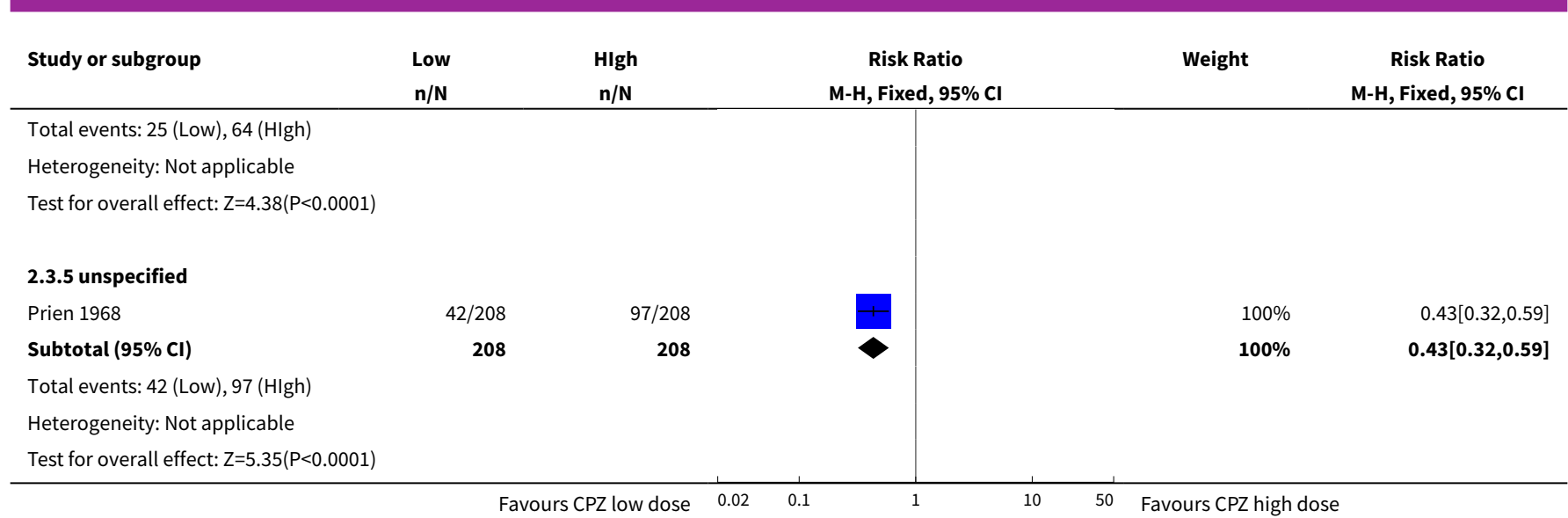

Analysis 2.4. Comparison 2 CHLORPROMAZINE LOW DOSE ( $\leq 400 \mathrm{mg} /$ day) vs HIGH DOSE ( $>800 \mathrm{mg} /$ day - all medium term), Outcome 4 Adverse effects: 2 . Anticholinergic symptoms.

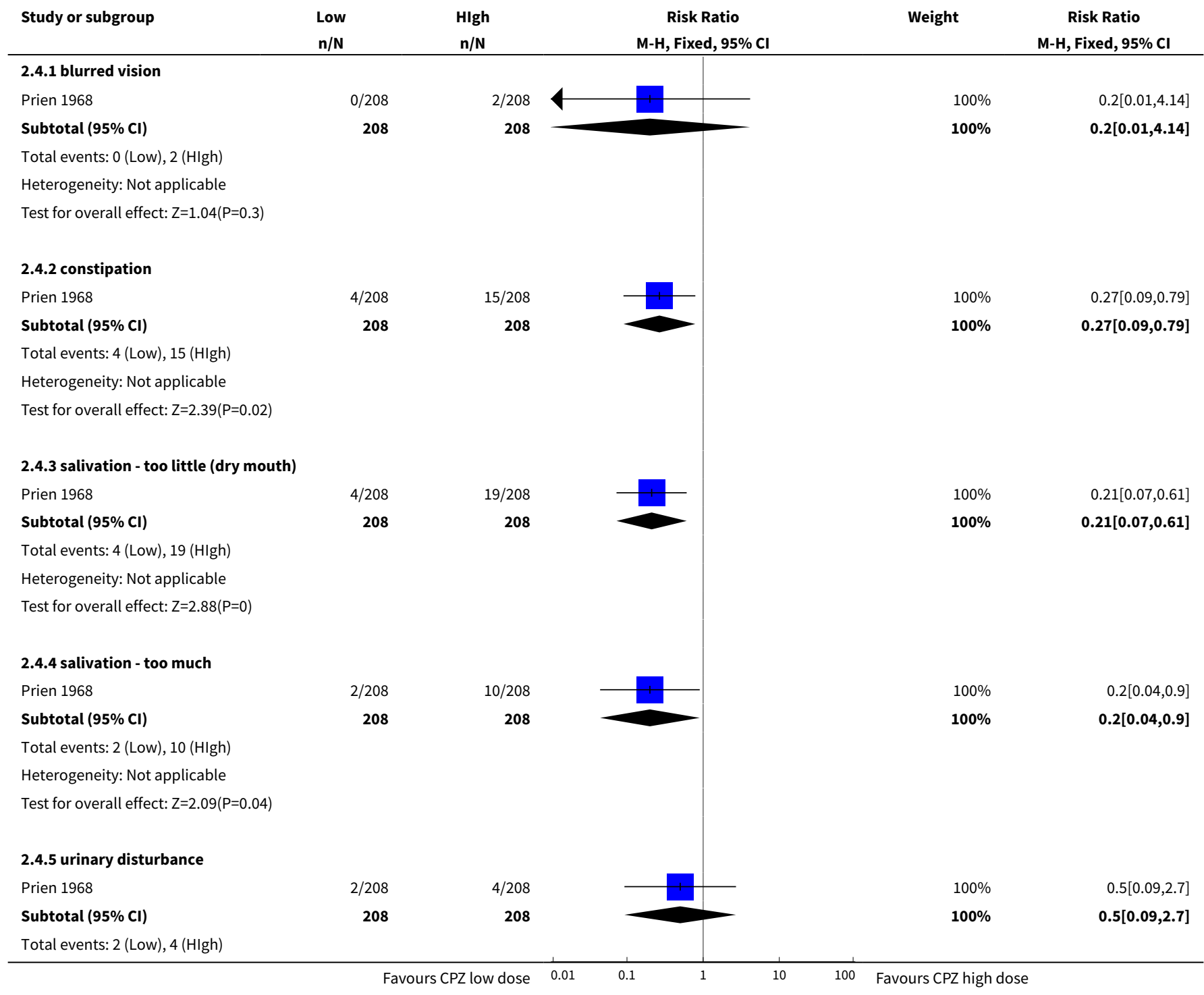




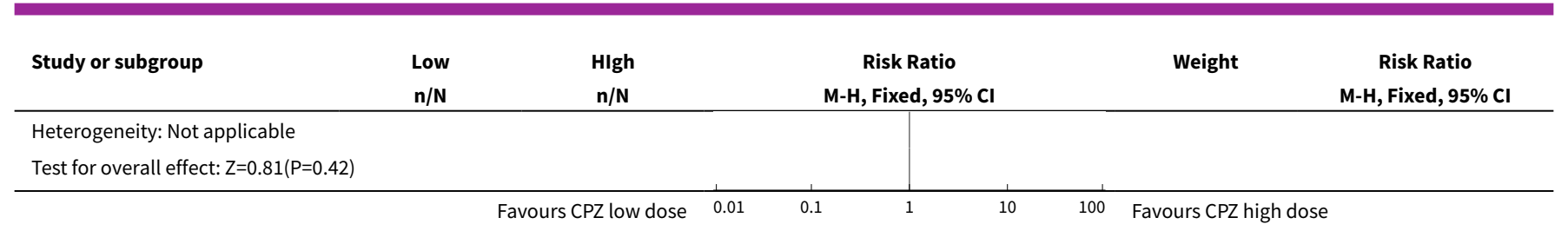

Analysis 2.5. Comparison 2 CHLORPROMAZINE LOW DOSE ( $\leq 400 \mathrm{mg} /$ day) vs HIGH DOSE ( $>800 \mathrm{mg} / \mathrm{day}$ - all medium term), Outcome 5 Adverse effects: 3 . Central nervous system - other than extrapyramidal symptoms.

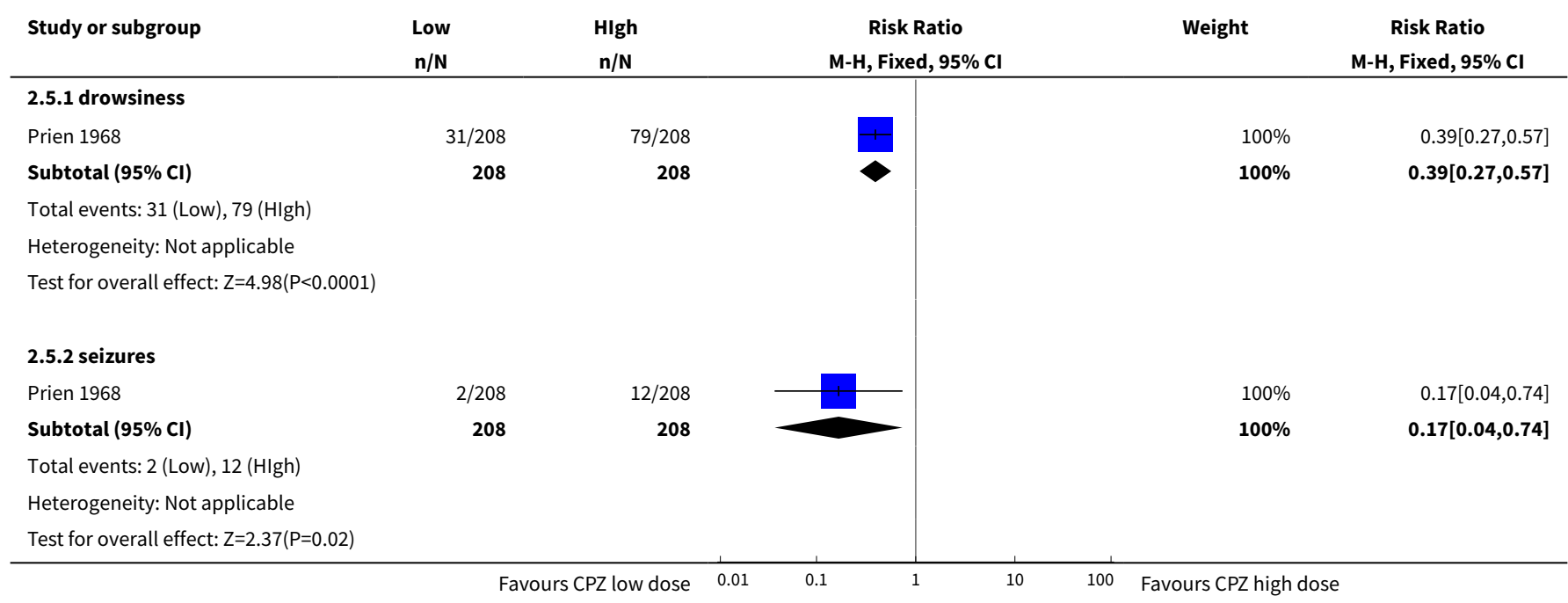

Analysis 2.6. Comparison 2 CHLORPROMAZINE LOW DOSE ( $\leq 400 \mathrm{mg} /$ day) vs HIGH DOSE (>800 mg/day - all medium term), Outcome 6 Adverse effects: 4 . Cardiovascular.

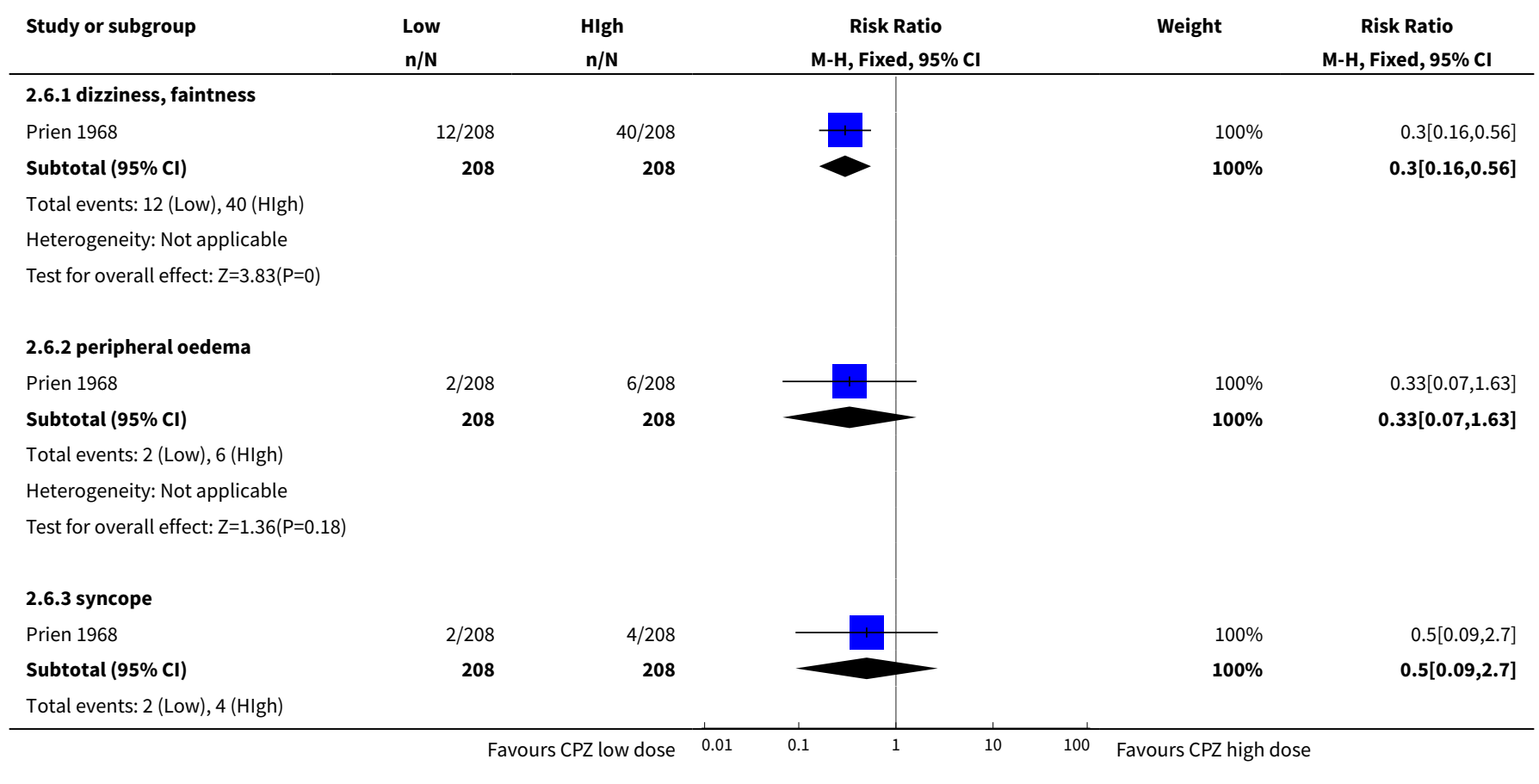




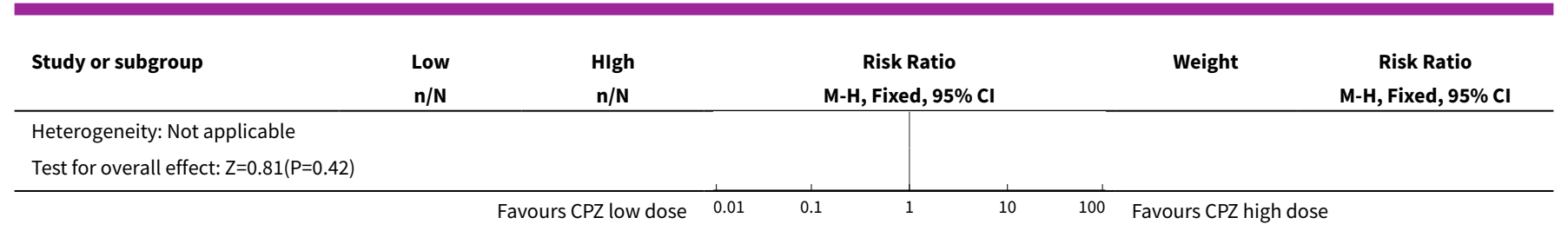

Analysis 2.7. Comparison 2 CHLORPROMAZINE LOW DOSE ( $\leq 400 \mathrm{mg} /$ day) vs HIGH DOSE (>800 mg/day - all medium term), Outcome 7 Adverse effects: 5. Dermatological.

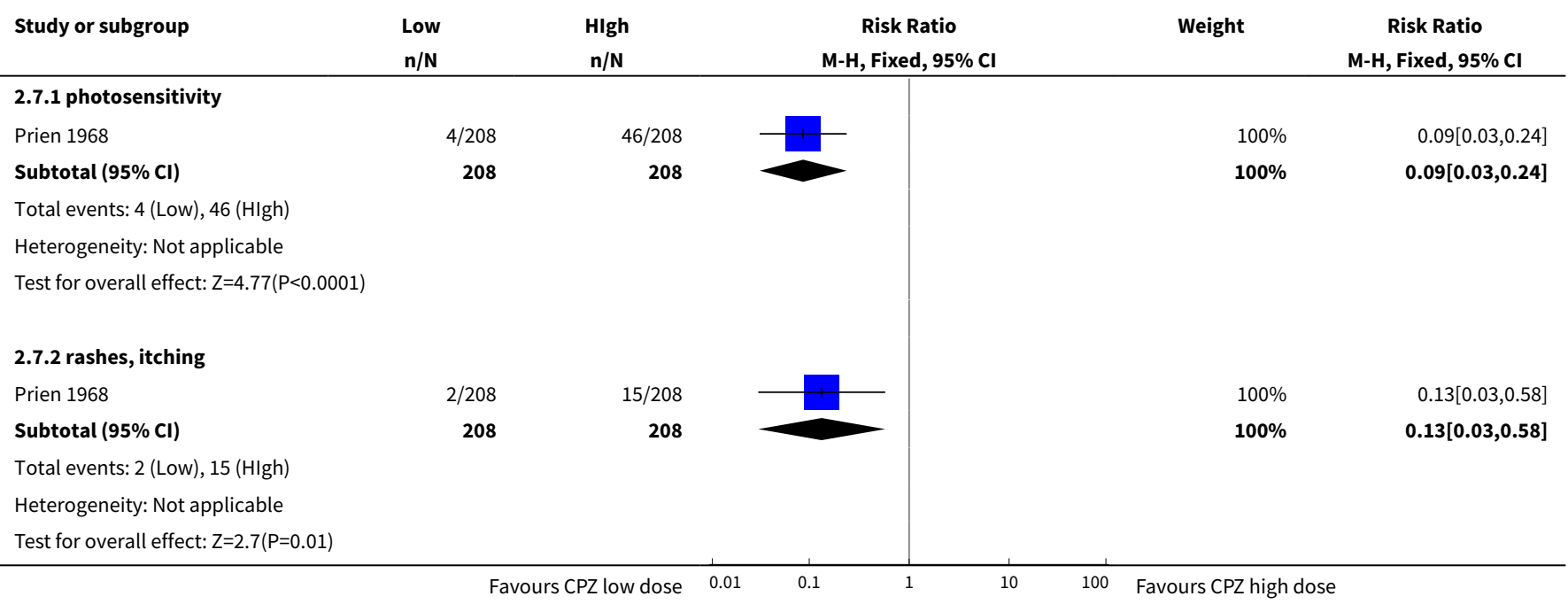

Analysis 2.8. Comparison 2 CHLORPROMAZINE LOW DOSE ( $\leq 400 \mathrm{mg} /$ day) vs HIGH DOSE (>800 mg/day - all medium term), Outcome 8 Adverse effects: 6 . Gastrointestinal.

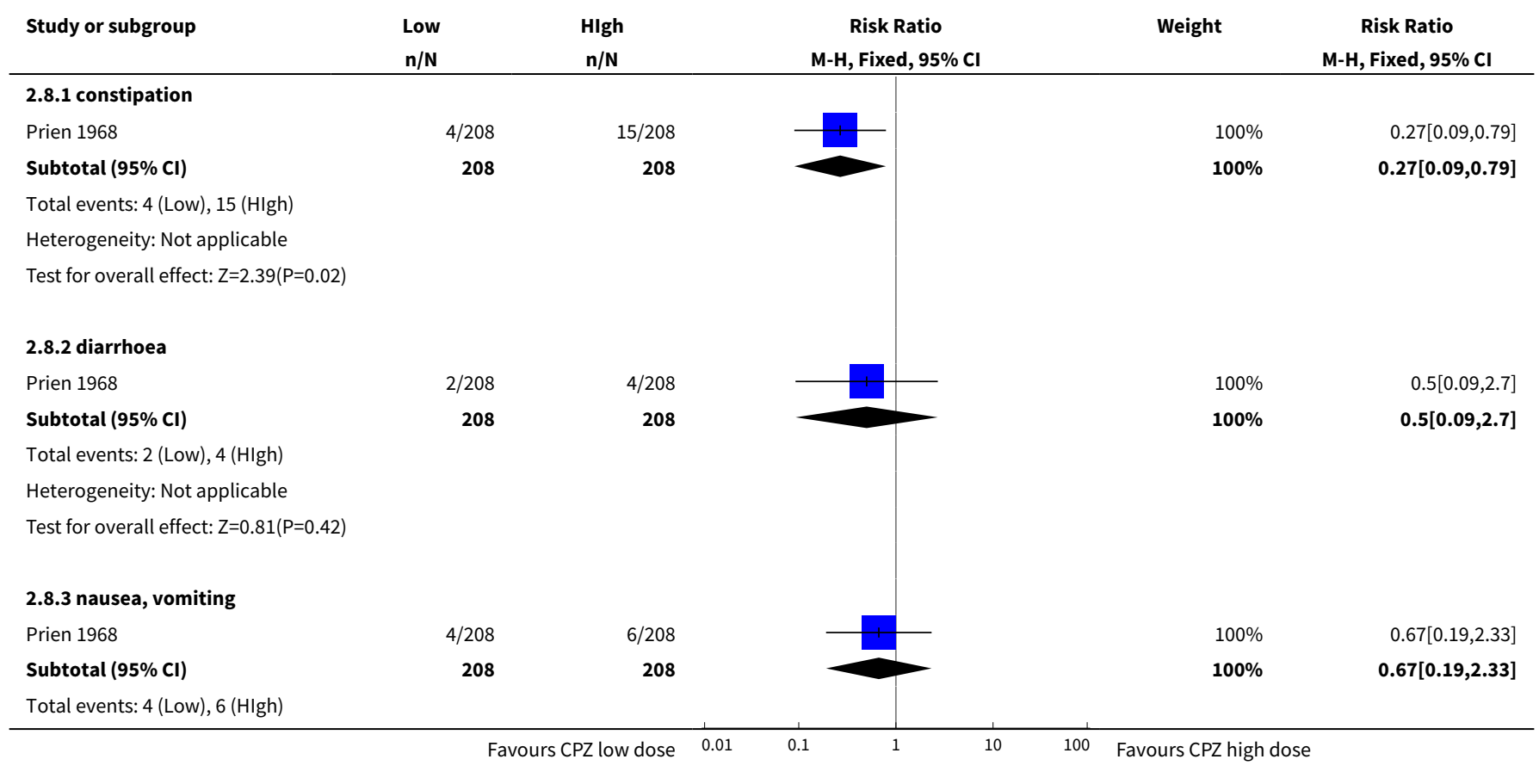




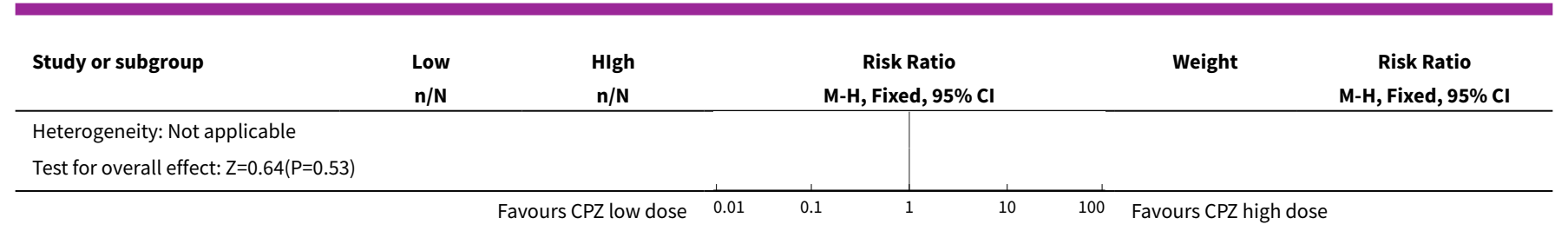

Analysis 2.9. Comparison 2 CHLORPROMAZINE LOW DOSE ( $\leq 400 \mathrm{mg} /$ day) vs HIGH DOSE ( $>800 \mathrm{mg} /$ day - all medium term), Outcome 9 Adverse effects: 7 . Genitourinary.

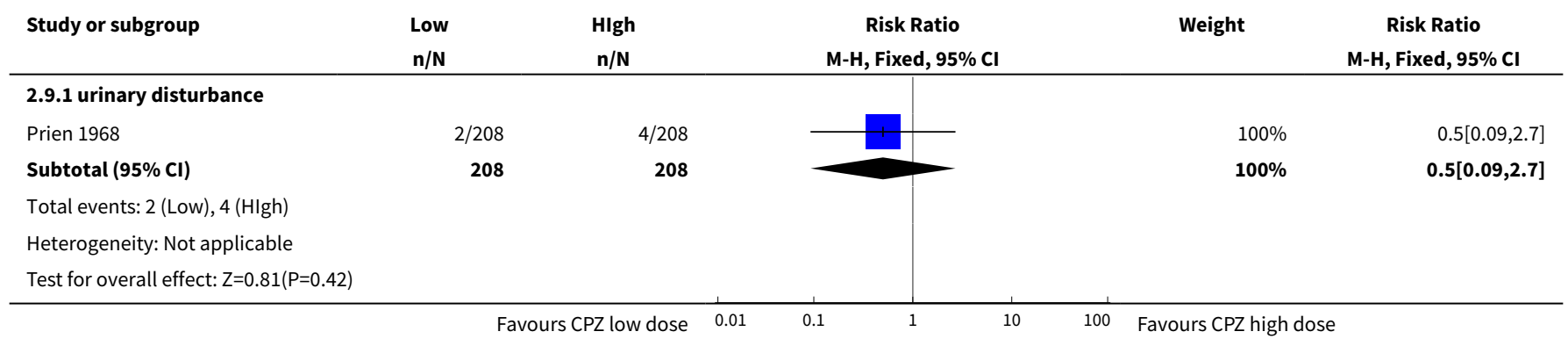

Analysis 2.10. Comparison 2 CHLORPROMAZINE LOW DOSE ( $\leq 400 \mathrm{mg} /$ day) vs HIGH DOSE (>800 mg/day - all medium term), Outcome 10 Adverse effects: 8. Others.

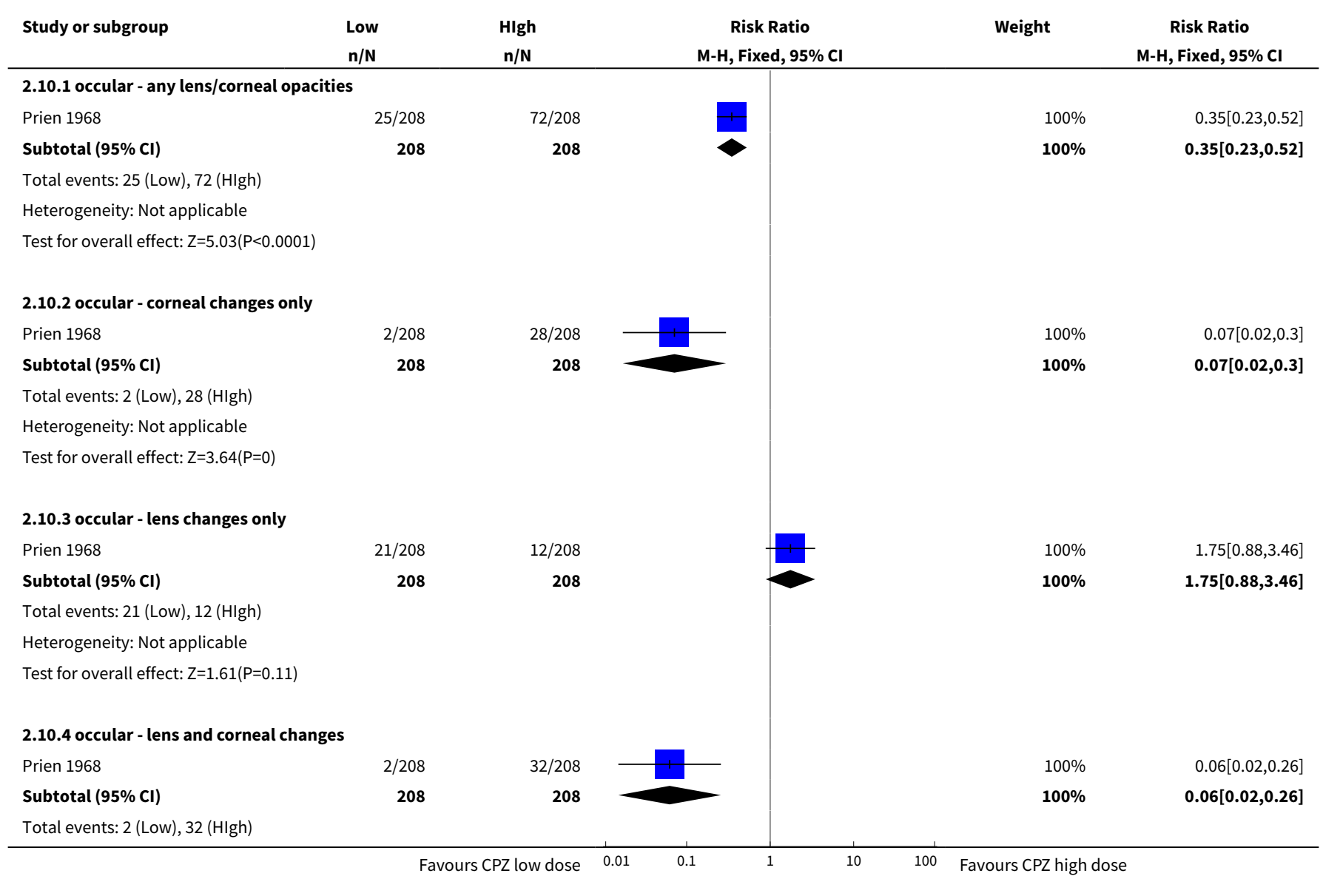




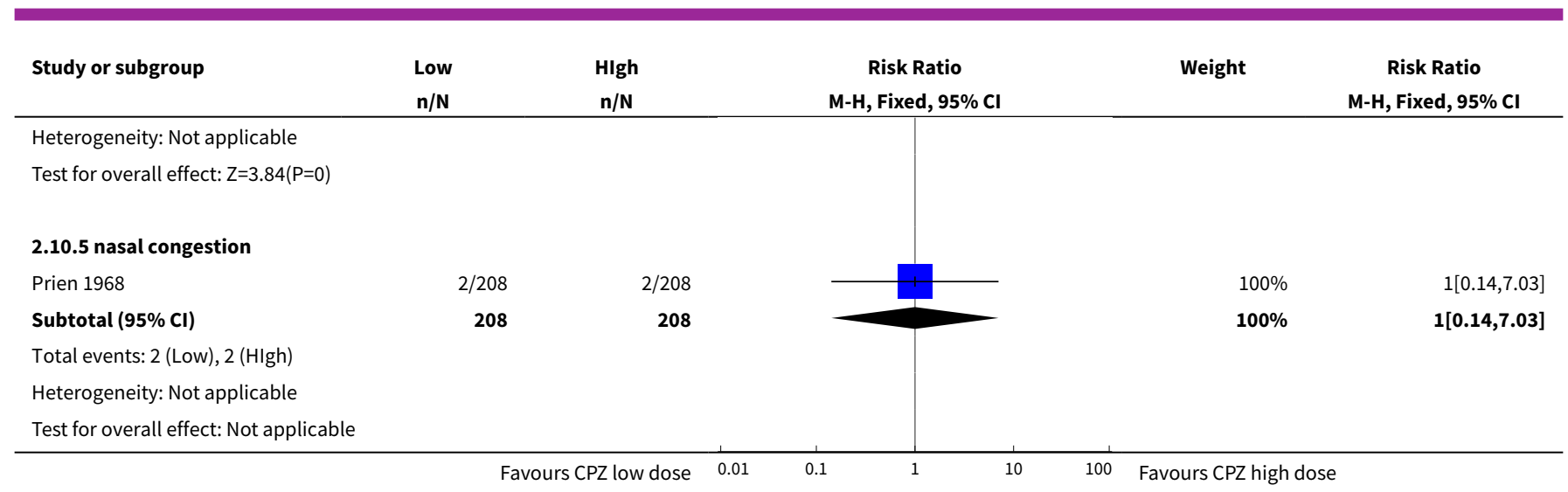

\section{ADDITIONAL TABLES}

Table 1. Reviews suggested by excluded studies

\begin{tabular}{|c|c|c|c|c|c|}
\hline \multicolumn{2}{|l|}{ Medication } & Comparison & $\begin{array}{l}\text { For people } \\
\text { with }\end{array}$ & $\begin{array}{l}\text { Relevant exclud- } \\
\text { ed study }\end{array}$ & $\begin{array}{l}\text { Relevant exist- } \\
\text { ing Cochrane } \\
\text { review }\end{array}$ \\
\hline \multicolumn{2}{|c|}{$\begin{array}{l}\text { Antiparkinsonian drug - unspec- } \\
\text { ified }\end{array}$} & $\begin{array}{l}\text { Antiparkinsonian treatment versus } \\
\text { placebo }\end{array}$ & $\begin{array}{l}\text { Movement } \\
\text { disorders }\end{array}$ & Caffey 1975 & - \\
\hline \multirow[t]{3}{*}{$\begin{array}{l}\text { Antipsychot- } \\
\text { ic drugs - un- } \\
\text { specified }\end{array}$} & \multirow[t]{2}{*}{ Doses } & $\begin{array}{l}\text { Any antipsychotic at high chlorpro- } \\
\text { mazine equivalent dosages vs lower } \\
\text { chlorpromazine equivalent dosages }\end{array}$ & \multirow[t]{3}{*}{ Schizophrenia } & Lehmann 1983 & - \\
\hline & & $\begin{array}{l}\text { Dose reduction of multiple antipsy- } \\
\text { chotics versus control group }\end{array}$ & & $\begin{array}{l}\text { Sukegawa 2008; } \\
\text { Sukegawa } 2014\end{array}$ & - \\
\hline & $\begin{array}{l}\text { Timing of } \\
\text { treatment }\end{array}$ & $\begin{array}{l}\text { Treatment days per week of antipsy- } \\
\text { chotics }\end{array}$ & & Caffey 1975 & - \\
\hline \multirow{7}{*}{$\begin{array}{l}\text { Chlorpro- } \\
\text { mazine }\end{array}$} & \multirow{7}{*}{$\begin{array}{l}\text { Mostly versus } \\
\text { other antipsy- } \\
\text { chotic drug }\end{array}$} & Chlorpromazine brand comparisons & & Ota 1974 & - \\
\hline & & Chlorpromazine versus clopenthixol & & Clark 1970b & Kumar 2005 \\
\hline & & Chlorpromazine versus clozapine & & Chen 2002 & $\begin{array}{l}\text { Essali 2009; Sa- } \\
\text { ha } 2016\end{array}$ \\
\hline & & Chlorpromazine versus haloperidol & & Eitan 1992 & $\begin{array}{l}\text { Leucht 2008; } \\
\text { Tardy } 2014\end{array}$ \\
\hline & & Chlorpromazine versus placebo & & $\begin{array}{l}\text { Borison 1991; } \\
\text { Clark 1967; Clark } \\
\text { 1970a; Clark } \\
\text { 1970b; Eitan } 1992\end{array}$ & Adams 2014 \\
\hline & & Chlorpromazine versus rimcazole & & Borison 1991 & - \\
\hline & & Chlorpromazine versus risperidone & & Chen 2002 & $\begin{array}{l}\text { Hunter 2003; } \\
\text { Saha } 2016\end{array}$ \\
\hline
\end{tabular}


Table 1. Reviews suggested by excluded studies (Continued)

Chlorpromazine versus thioridazine

Chlorpromazine versus trifluoperazine

Doses Ultra-low doses of chlorpromazine

\begin{tabular}{ll}
\cline { 2 - 2 } & Ultra-low doses of thioridazine \\
\hline $\begin{array}{l}\text { Timing of } \\
\text { treatment }\end{array}$ & $\begin{array}{l}\text { Night doses versus daytime doses of } \\
\text { chlorpromazine }\end{array}$
\end{tabular}

Single doses versus divided doses of chlorpromazine

Q.I.D versus O.D of chlorpromazine

\begin{tabular}{ll}
\hline Clopenthixol & Clopenthixol versus placebo \\
\hline Clozapine & Clozapine versus risperidone
\end{tabular}

\begin{tabular}{ll}
\hline Dextroamphetamine & $\begin{array}{l}\text { Dextroamphetamine versus } \\
\text { imipramine }\end{array}$
\end{tabular}

Dextroamphetamine versus isocarboxazid

Dextroamphetamine versus placebo

Dextroamphetamine versus trifluoperazine

\begin{tabular}{ll}
\hline Haloperidol & Haloperidol versus placebo \\
\cline { 2 - 2 } & Haloperidol versus trifluoperazine \\
\cline { 2 - 2 } & Haloperidol versus thioridazine \\
\hline Imipramine & - \\
\hline Isocarboxazid & Isocarboxazid versus placebo \\
\cline { 2 - 2 } & Isocarboxazid versus trifluoperazine
\end{tabular}

Altman 1973; Ei- $\quad$ Fenton 2007 $\tan 1992$

\begin{tabular}{ll}
\hline Eitan 1992 & $\begin{array}{l}\text { de Oliveira Mar- } \\
\text { ques 2004; } \\
\text { Tardy 2014a }\end{array}$ \\
\hline Altman 1973; An- & - \\
drews 1976; Gibbs & \\
1956; Yuan-Guang & \\
1994 & \\
\hline
\end{tabular}

\begin{tabular}{ll}
\hline Altman 1973 & - \\
\hline Altman 1973; & - \\
Kalyanasundaram & \\
1981
\end{tabular}

Altman 1973;
Kalyanasundaram
1981

Jeste $1977 \quad-$

\begin{tabular}{|c|c|}
\hline Clark 1970b & Kumar 2005 \\
\hline Chen 2002 & $\begin{array}{l}\text { Komossa 2011; } \\
\text { Tuunainen } \\
2000\end{array}$ \\
\hline \multirow[t]{4}{*}{ Casey 1961} & $\begin{array}{l}\text { Rummel-Kluge } \\
2006\end{array}$ \\
\hline & $\begin{array}{l}\text { Rummel-Kluge } \\
2006\end{array}$ \\
\hline & - \\
\hline & - \\
\hline \multirow[t]{3}{*}{ Eitan 1992} & Adams 2013 \\
\hline & $\begin{array}{l}\text { de Oliveira Mar- } \\
\text { ques 2004; Dold } \\
2015\end{array}$ \\
\hline & $\begin{array}{l}\text { Fenton 2007; } \\
\text { Tardy } 2014\end{array}$ \\
\hline Casey 1961 & - \\
\hline \multirow[t]{2}{*}{ Casey 1961} & $\begin{array}{l}\text { Rummel-Kluge } \\
2006\end{array}$ \\
\hline & $\begin{array}{l}\text { Rummel-Kluge } \\
2006\end{array}$ \\
\hline
\end{tabular}

Chlorpromazine dose for people with schizophrenia (Review) 
Table 1. Reviews suggested by excluded studies (Continued)

\begin{tabular}{|c|c|c|c|c|c|}
\hline \multirow[t]{2}{*}{ Rimcazole } & \multicolumn{2}{|r|}{ Rimcazole versus placebo } & & \multirow[t]{2}{*}{ Borison 1991} & \multirow[b]{2}{*}{-} \\
\hline & Doses & Rimcazole dose & & & \\
\hline Risperidone & & - & & Chen 2002 & - \\
\hline \multirow[t]{3}{*}{ Thioridazine } & & Thioridazine versus placebo & & Eitan 1992 & Fenton 2007 \\
\hline & $\begin{array}{l}\text { Timing of } \\
\text { treatment }\end{array}$ & $\begin{array}{l}\text { Night doses versus daytime doses of } \\
\text { thioridazine }\end{array}$ & & Altman 1973 & - \\
\hline & $\begin{array}{l}\text { Timing of } \\
\text { treatment }\end{array}$ & $\begin{array}{l}\text { Thioridazine - single doses versus di- } \\
\text { vided doses }\end{array}$ & & & - \\
\hline \multirow[t]{2}{*}{ Trifluoperazine } & & Trifluoperazine versus placebo & & $\begin{array}{l}\text { Casey 1961; Eitan } \\
1992\end{array}$ & Koch 2014 \\
\hline & & Trifluoperazine versus thioridazine & & Eitan 1992 & $\begin{array}{l}\text { de Oliveira Mar- } \\
\text { ques 2004; Fen- } \\
\text { ton 2007; Tardy } \\
\text { 2014a }\end{array}$ \\
\hline \multicolumn{2}{|l|}{ Trihexyphenidyl } & Trihexyphenidyl versus placebo & $\begin{array}{l}\text { Movement } \\
\text { disorders }\end{array}$ & Yuan-Guang 1994 & - \\
\hline \multicolumn{2}{|c|}{ Vitamin preparation } & Vitamin preparation versus placebo & Schizophrenia & Joshi 1982 & Magalhaes 2016 \\
\hline
\end{tabular}

Table 2. Suggested design for trial

\begin{tabular}{|c|c|}
\hline \multirow[t]{3}{*}{ Methods } & Allocation: clearly randomised, well-described concealment. \\
\hline & $\begin{array}{l}\text { Blindness: triple-blinding clearly described including information on method administration, vol- } \\
\text { ume and concentration of chlorpromazine. }\end{array}$ \\
\hline & Duration: 28 weeks ( 2 weeks of no antipsychotic medication). \\
\hline
\end{tabular}

Participants Diagnosis: people with schizophrenia - diagnosed by any criteria.

Age: any.

Sex: both.

$\mathrm{N}=450 .^{*}$

History: acute or long-term illness.

Excluded: borderline cases, mental deficiency (IQ < 70), bad physical health with complicating organic illness or known brain damage, medical conditions constraining use of high doses, alcoholism or drug use, showing severe suicidal or aggressive impulses.

$\begin{array}{ll}\text { Interventions } & \text { 1. Chlorpromazine: dose } 300 \mathrm{mg} / \text { day. } N=150 . \\ \text { 2. Chlorpromazine: dose } 600 \mathrm{mg} / \text { day. } N=150 . \\ \text { 3. Chlorpromazine: dose } 900 \mathrm{mg} / \text { day. } N=150 .\end{array}$

\section{Outcomes}

Leaving the study early (reasons, timing, gender and treatment group provided).

Deaths. 
Table 2. Suggested design for trial (Continued)

Adverse effects (clinically important and specific).

Needing additional medication (information about doses, timings and reasons for drug administration provided).

Effectiveness:

1. Total number improved/not improved global state.

2. Total number improved/not improved mental state.

3. Total number improved/not improved behavioural state.

4. Total number with improved quality of life.

5. Total number satisfied with treatment.

6. Total number with improved social skills.

7. Total number with improved life skills

* 150 in each group allows for good statistical power.

\section{AP PEN DICES}

\section{Appendix 1. Previous searches}

\section{Search in 2008}

\section{Electronic searches}

\section{Cochrane Schizophrenia Group Trials Register}

We searched the register (December 2008) using the following phrases:

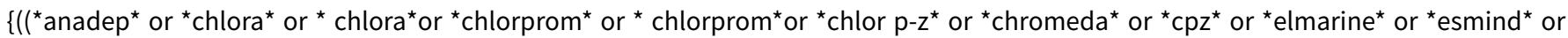
${ }^{\star}$ fenactil ${ }^{\star}$ or ${ }^{\star}$ hibanil ${ }^{\star}$ or ${ }^{\star}$ hibernal ${ }^{\star}$ or ${ }^{\star}$ klorazin ${ }^{\star}$ or ${ }^{\star}$ klorpro* or ${ }^{*}$ largactil ${ }^{\star}$ or ${ }^{*}$ megaphen ${ }^{\star}$ or ${ }^{\star}$ neurazin ${ }^{\star}$ or ${ }^{\star}$ plegomaz $^{\star}$ or ${ }^{\star}$ procalm $^{\star}$ or

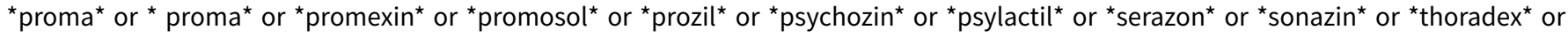

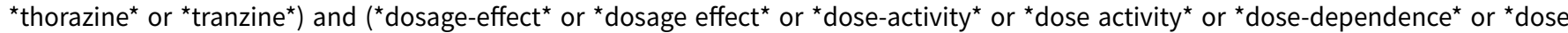

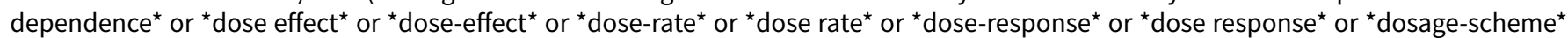
or *dosage scheme* or *drug-response* or *drug response ${ }^{\star}$ or *effective-dose* or *effective dose* or *dose-finding* or *dose finding ${ }^{\star}$ or

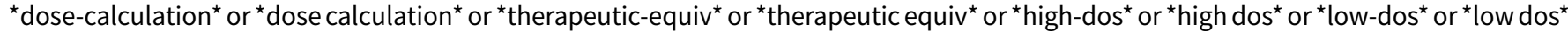

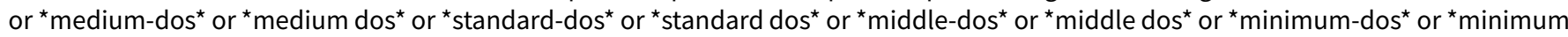

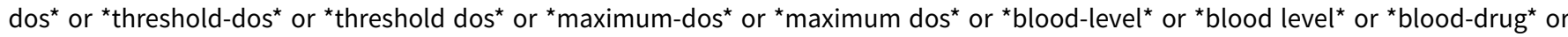

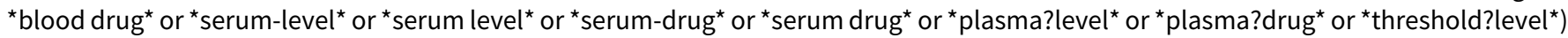
in title, abstract, index terms of REFERENCE) and ((chlorpromazine* and dosage $\left.{ }^{\star}\right)$ in interventions of STUDY))\}

\section{Search in 2014}

\section{Electronic searches}

\section{Cochrane Schizophrenia Group's Trials Register}

On October 2, 2014, the Trials Search Coordinator (TSC) searched the register using the following search strategy:

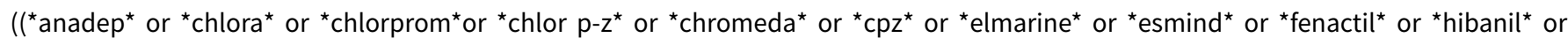

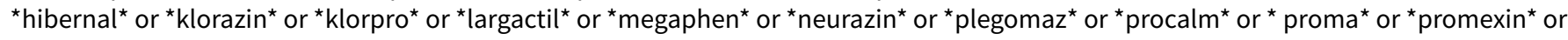

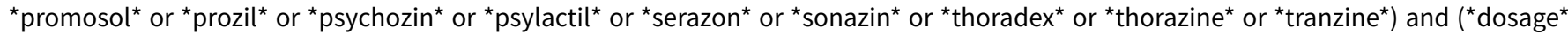
or *dose or *doses or *dosing or *drug-response* or *drug response* or *therapeutic-equiv* or "*therapeutic equiv*" or *blood-level* or "*blood level " or *blood-drug* or "*blood drug*" or *serum-level* or "*serum level ${ }^{\star *}$ or *serum-drug* or "*serum drug*" or "*plasma level*" or *plasma-level* or "*plasma drug" or *plasma-drug* or "*threshold level*" or *threshold-level*)) in Title and Abstract of REFERENCE or (chlorpromazine* and dosage ${ }^{\star}$ ) in Intervention of STUDY

The Cochrane Schizophrenia Group's Registry of Trials is compiled by systematic searches of major resources (including AMED, BIOSIS, CINAHL, Embase, MEDLINE, PsycINFO, PubMed, and registries of clinical trials) and their monthly updates, hand-searches, grey literature, and conference proceedings (see Group Module). There is no language, date, document type, or publication status limitations for inclusion of records into the register. 


\section{Searching other resources}

\section{Reference lists}

We searched all references of articles selected for inclusion for further relevant trials.

\section{Personal contact}

If required, we contacted the first author of each included study for information regarding unpublished trials and noted response or nonresponse in Characteristics of included studies.

\section{Appendix 2. Previous methods}

\section{Selection of studies}

Authors XL and SH independently inspected citations found to identify potentially relevant reports. Full papers were ordered for reassessment if the study was potentially relevant or not clearly irrelevant. This process was repeated for the full papers. If it was impossible to resolve disagreements the authors of the papers were contacted for clarification.

\section{Data extraction and management}

\section{Extraction}

Authors XL and SH independently extracted data from the included studies. Again, all disagreements were discussed, decisions were documented and, if necessary, authors of studies were contacted for clarification.

\section{Management}

Data were extracted onto standard, simple forms.

\section{Scale-derived data}

A wide range of instruments are available to measure outcomes in mental health studies with great variety in quality. Unpublished scales are known to be subject to bias in trials of treatments for schizophrenia (Marshall 2000). Therefore data from rating scales were included only if the measuring instrument had been described in a peer-reviewed journal. In addition, the following minimum standards for instruments were set: the instrument should either be (a) a self-report or (b) completed by an independent rater or relative (not the therapist) and (c) the instrument should be a global assessment of an area of functioning.

\section{Assessment of risk of bias in included studies}

Again working independently, XL and SH assessed risk of bias in accordance with the Cochrane Collaboration's tools for assessing quality and risk of bias (Higgins 2008). This tool encourages consideration of how the sequence was generated, how allocation was concealed, the integrity of blinding, the completeness of outcome data, selective reporting and other biases.

The risk of bias in each domain and overall were assessed and categorised into:

A. Low risk of bias: plausible bias unlikely to seriously alter the results (categorised as 'No' in Risk of Bias table)

B. High risk of bias: plausible bias that seriously weakens confidence in the results (categorised as 'Yes' in Risk of Bias table)

C. Unclear risk of bias: plausible bias that raises some doubt about the results. (categorised as 'Unclear' in Risk of Bias table)

Trials with high risk of bias ( $3 / 5$ domains being at high risk) were not included in the meta-analysis. If the raters disagreed, the final rating was made by consensus with the involvement of a member of the Cochrane Schizophrenia Group's Editorial Base team. Where inadequate details of randomisation and other characteristics of trials are provided, authors of the studies were contacted in order to obtain further information. Non-concurrence in quality assessment was reported.

\section{Measures of treatment effect}

1. Binary data

For binary outcomes we calculated a standard estimation of the fixed-effect risk ratio (RR) and its $95 \%$ confidence interval (CI). It has been shown that RR is more intuitive (Boissel 1999) than odds ratios and that odds ratios tend to be interpreted as RR by clinicians (Deeks 2000). This misinterpretation then leads to an overestimate of the impression of the effect.

2. Continuous data

2.1 Summary statistic

For continuous outcomes we estimated a fixed-effect weighted mean difference (WMD) between groups. We did not calculate effect size measures.

\subsection{Endpoint versus change data}

We preferred to use scale endpoint data, which typically cannot have negative values and is easier to interpret from a clinical point of view. Change data are often not ordinal and are very problematic to interpret. If endpoint data were unavailable, we used change data. 


\subsection{Skewed data}

Continuous data on clinical and social outcomes are often not normally distributed. To avoid the pitfall of applying parametric tests to nonparametric data, we aimed to apply the following standards to all data before inclusion: (a) standard deviations and means are reported in the paper or obtainable from the authors; (b) when a scale starts from the finite number zero, the standard deviation, when multiplied by two, is less than the mean (as otherwise the mean is unlikely to be an appropriate measure of the centre of the distribution, (Altman 1996); (c) if a scale starts from a positive value (such as PANSS which can have values from 30 to 210) the calculation described above will be modified to take the scale starting point into account. In these cases skew is present if 2SD>(S-S min), where $\mathrm{S}$ is the mean score and S min is the minimum score. Endpoint scores on scales often have a finite start and end point and these rules can be applied. When continuous data are presented on a scale which includes a possibility of negative values (such as change data), it is difficult to tell whether data are skewed or not. Skewed data from studies of less than 200 participants were entered in additional tables rather than into an analysis. Skewed data pose less of a problem when looking at means if the sample size is large and were entered into syntheses.

\section{Unit of analysis issues}

\section{Cluster trials}

Studies increasingly employ 'cluster randomisation' (such as randomisation by clinician or practice) but analysis and pooling of clustered data poses problems. Firstly, authors often fail to account for intra-class correlation in clustered studies, leading to a 'unit of analysis' error (Divine 1992) whereby $P$ values are spuriously low, confidence intervals unduly narrow and statistical significance overestimated. This causes type I errors (Bland 1997, Gulliford 1999).

Where clustering is not accounted for in primary studies, we presented data in a table, with a $\left(^{\star}\right)$ symbol to indicate the presence of a probable unit of analysis error. In subsequent versions of this review we will seek to contact first authors of studies to obtain intraclass correlation coefficient of their clustered data and to adjust for this by using accepted methods (Gulliford 1999). Where clustering had been incorporated into the analysis of primary studies, we present these data as if from a non-cluster randomised study, but adjusted for the clustering effect. For this we divided binary data as presented in the report by a 'design effect'. This is calculated using the mean number of participants per cluster $(\mathrm{m})$ and the intraclass correlation coefficient (ICC) [Design effect $=1+(\mathrm{m}-1)^{\star} \mathrm{ICC}$ ] (Donner 2002). If the ICC was not reported it was assumed to be 0.1 (Ukoumunne 1999).

If cluster studies had been appropriately analysed taking into account the intraclass correlation coefficient and relevant data documented in the report, synthesis with other studies would have been possible using the generic inverse variance technique.

\section{Cross-over trials}

A major concern of cross-over trials is the carry-over effect. It occurs if an effect (e.g. pharmacological, physiological or psychological) of the treatment in the first phase is carried over to the second phase. As a consequence on entry to the second phase the participants can differ systematically from their initial state despite a wash-out phase. For the same reason cross-over trials are not appropriate if the condition of interest is unstable (Elbourne 2002). As both effects are very likely in schizophrenia, we will only use data of the first phase of cross-over studies.

3. Studies with multiple treatment groups

Where a study involved more than two treatment arms, if relevant, the additional treatment arms were presented in comparisons. Where the additional treatment arms were not relevant, these data were not reproduced.

\section{Dealing with missing data}

1. Overall loss of credibility At some degree, loss of follow-up data will impair the credibility of the study (Xia 2007). At 12, 26 and 52 weeks we assessed the provided data. We reproduced the numerical data from outcomes with less than $40 \%$ attrition. If the loss to follow-up was greater than this these outcomes were only reported in the 'Characteristics of included studies' table 'Outcomes' section as 'unable to use'.

\section{Binary}

In the case where attrition for a binary outcome is between 0 and $40 \%$ and outcomes of these people are described, we included these data as reported. Where these data were not clearly described, we assumed no clinically important change in global state, and rates of adverse effects (especially extrapyramidal) similar to those who continued to have their data recorded.

\section{Continuous}

In the case where attrition for a continuous outcome is between 0 and $40 \%$ and completer-only data were reported, we have reproduced these.

\section{Assessment of heterogeneity}

1. Clinical heterogeneity

We considered all included studies initially, without seeing comparison data, to judge clinical heterogeneity.

\section{Statistical}

2.1 Visual inspection 
We visually inspected graphs to investigate the possibility of statistical heterogeneity.

2.2 Employing the I-squared statistic

This provided an estimate of the percentage of inconsistency thought to be due to chance. I-squared estimate greater than or equal to $50 \%$ accompanied by a statistically significant Chi-square statistic, was interpreted as evidence of substantial levels of heterogeneity (Higgins 2003).

\section{Assessment of reporting biases}

Reporting biases arise when the dissemination of research findings is influenced by the nature and direction of results. These are described in section 10.1 of the Cochrane Handbook (Higgins 2008). We are aware that funnel plots may be useful in investigating reporting biases but are of limited power to detect small-study effects (Egger 1997). We did not use funnel plots for outcomes where there were ten or fewer studies, or where all studies were of similar sizes. In other cases, where funnel plots were possible, we sought statistical advice in their interpretation.

\section{Data synthesis}

Where possible we employed a fixed-effect model for analyses. We understand that there is no closed argument for preference for use of fixed or random-effects models. The random-effects method incorporates an assumption that the different studies are estimating different, yet related, intervention effects. This does seem true to us, however, random-effects does put added weight onto the smaller of the studies - those trials that are most vulnerable to bias. For this reason we favour using a fixed-effect model employing random-effects only when investigating heterogeneity.

\section{Subgroup analysis and investigation of heterogeneity}

If data are clearly heterogeneous we checked that data are correctly extracted and entered and no unit of analysis errors are made. If the high levels of heterogeneity remained we did not undertake a meta-analysis at this point. It may be misleading to quote an average value for the intervention effect if considerable variation in results, and particularly inconsistency in the direction of effect, exists. We pre-specify no characteristics of studies that may be associated with heterogeneity except quality of trial method. If no clear association could be shown by sorting studies by quality of methods a random-effects meta-analysis was performed. Should other characteristics of the studies be highlighted by the investigation of heterogeneity, perhaps some clinical heterogeneity not hitherto predicted but plausible causes of heterogeneity, these post-hoc reasons were discussed and the data analysed and presented. However, should the heterogeneity be substantially unaffected by use of random-effects meta-analysis and no other reasons for the heterogeneity be clear, the final data were presented without a meta-analysis.

\section{Sensitivity analysis}

We analysed the effect of our assumptions regarding those lost to follow-up in a sensitivity analysis for the primary outcome, but reported our data, assumptions included, in the final analysis. If necessary, we analysed the effect of including studies with high attrition rates in a sensitivity analysis. We aimed to include trials in a sensitivity analysis if they are described as double-blind but only implied randomisation. If we found no substantial differences within primary outcome when these high attrition and implied randomisation studies were added to the overall results, we included them in the final analysis. However, if there was a substantial difference we only used clearly randomised trials and those with attrition lower than $40 \%$.

\section{Appendix 3. Previous PLS}

\section{Chlorpromazine dose for people with schizophrenia}

There are 24 million people in the world with schizophrenia according to the World Health Organisation (WHO), of which 90 per cent live in the developing world and are not using pharmaceutical treatments. Schizophrenia is a long-term mental illness that causes people to have false perceptions of the senses (hallucinations), see the world in a different way from the majority (delusions), or to withdraw socially and psychologically ('negative' symptoms). This illness can separate people from their peers in a profound way. Antipsychotic medication can reduce these symptoms in most people and improve their functioning. Chlorpromazine is the oldest of these medications and the most readily available, especially in the developing world. This review looks at trials that try to find the optimum dose of chlorpromazine for people with schizophrenia. Four trials were identified, which included a total of 1012 people. All of them were carried out before 1980 , the participants were all in hospital, and no trial was longer than 26 weeks - indeed two were only 12 weeks. Three trials compared low doses of chlorpromazine to medium doses (174 people) and one trial compared low doses to very high doses (838 people). When comparing a low dose to a medium dose, the low dose was significantly better in stopping people from withdrawing socially (withdrawal/retardation). It also was less likely to cause people to adopt strange postures (dystonia) and to allow people to have a better general state of life in the medium term (up to 26 weeks). However these trials contained a relatively small number of people. When low doses were compared to what today would be a very high dose, those in the high dose group had significantly more adverse effects but showed a small but significant improvement in general functioning. Chlorpromazine has been available since the 1950s and is one of the three antipsychotic drugs on the WHO essential drug list. It is still extensively used to treat many people with schizophrenia, especially in the developing world. Therefore it is surprising to find that so few studies have been done to determine the optimal dose. Over time the maximum recommended dose has been reduced considerably, presumably in response to observation from clinicians and the personal experience of those taking 
it. Therefore, a good randomised controlled trial of low and medium doses of chlorpromazine for people in the community (concentrating on adverse effects and long-term acceptability) would benefit those with schizophrenia who take this medication.

(Plain language summary prepared for this review by Janey Antoniou of RETHINK, UK www.rethink.org).

WHAT'S NEW

\begin{tabular}{lll}
\hline Date & Event & Description \\
\hline 8 March 2017 & $\begin{array}{l}\text { New citation required but conclusions } \\
\text { have not changed }\end{array}$ & $\begin{array}{l}\text { Results from 2014 and 2016 searches fully incorporated into the } \\
\text { review. Overall conclusions of the review are unchanged. }\end{array}$ \\
\hline 20 December 2016 & New search has been performed & $\begin{array}{l}\text { Further search undertaken December 2016. Four new citations to } \\
\text { Prien 1968 added with important additional data for outcomes } \\
2.1 \text { (Global state) and 2.10 (Adverse effects). }\end{array}$ \\
& $\begin{array}{l}\text { Two additional excluded studies with one trial (Gibbs 1956) illus- } \\
\text { trating how old studies can generate important questions for to- } \\
\text { day's practice. }\end{array}$ \\
\hline 14 January 2015 & $\begin{array}{l}\text { Amended } \\
\text { excluded studies, past trials re-inspected, data extracted, risk of } \\
\text { bias added, 'Summary of findings' tables included, text re-writ- } \\
\text { ten. }\end{array}$ \\
\hline
\end{tabular}

\section{H I S T O R Y}

Review first published: Issue 2, 2009

\begin{tabular}{lll}
\hline Date & Event & Description \\
\hline 2 October 2014 & Amended & $\begin{array}{l}\text { Search was updated and 22 new studies added to 'Classification } \\
\text { pending references' section of the review. }\end{array}$ \\
\hline 11 November 2009 & Amended & Contact details updated. \\
\hline 3 August 2009 & Amended & Consumer-written Plain language summary added. \\
\hline
\end{tabular}

\section{CONTRIBUTIONS OF AUTHORS}

Katharine Dudley - data re-extraction, 'Risk of bias' tables, 'Summary of findings' tables, analyses, re-writing the report (2014, 2016 searches).

Saskia de Haan - development of the protocol, data extraction, analyses, writing the report (2009 search).

Xiaomeng Liu - development of the protocol, data extraction, analyses, writing the report (2009 search).

\section{DECLARATIONS OF INTEREST}

None known.

\section{SOURCES OF SUPPORT}

\section{Internal sources}

- University of Nottingham, UK.

- Utrecht University, Netherlands. 


\section{External sources}

- No sources of support supplied

\section{DIFFERENCES BETWEEN PROTOCOLANDREVIEW}

For the 2014 update, we included data from Wode-Helgodt 1978 for extrapyramidal adverse effects that had been reported using a modification of a previously published scale (Simpson 1970). We realise that this is not entirely in keeping with our previous methods where we stated that we should not use any modified scales - citing Marshall 2000. However, we felt these outcomes to be important although they must carry high risk of bias.

We have moved the outcome of leaving the study early to below global and mental state, moved 'death' to adverse effects.

\section{NDEX TERMS}

\section{Medical Subject Headings (MeSH)}

Antipsychotic Agents [*administration \& dosage] [adverse effects]; Barbiturates [administration \& dosage]; Chloral Hydrate [administration \& dosage]; Chlorpromazine [ ${ }^{*}$ administration \& dosage] [adverse effects]; Drug Administration Schedule; Hypnotics and Sedatives [administration \& dosage]; Patient Dropouts [statistics \& numerical data]; Randomized Controlled Trials as Topic; Schizophrenia [ ${ }^{\star}$ drug therapy]

\section{MeSH check words}

Humans 